Florida International University FIU Digital Commons

\title{
Design of a Low Power - High Temperature Heated Ceramic Sensor to Detect Halogen Gases
}

Mary Cristina Ruales

Florida International University,mruales@suagm.edu

DOI: $10.25148 /$ etd.FI08081543

Follow this and additional works at: https://digitalcommons.fiu.edu/etd

\section{Recommended Citation}

Ruales, Mary Cristina, "Design of a Low Power - High Temperature Heated Ceramic Sensor to Detect Halogen Gases" (2007). FIU Electronic Theses and Dissertations. 33.

https://digitalcommons.fiu.edu/etd/33 


\title{
FLORIDA INTERNATIONAL UNIVERSITY \\ Miami, Florida
}

\section{DESIGN OF A LOW POWER - HIGH TEMPERATURE HEATED CERAMIC SENSOR TO DETECT HALOGEN GASES}

\author{
A dissertation submitted in partial fulfillment of the \\ requirements for the degree of \\ DOCTOR OF PHILOSOPHY \\ in \\ MECHANICAL ENGINEERING \\ by \\ Mary Cristina Ruales Ortega
}


To: Interim Dean Amir Mirmiran

College of Engineering and Computing

This dissertation, written by Mary Cristina Ruales Ortega, and entitled Design of a Low Power-High Temperature Heated Ceramic Sensor to Detect Halogen Gases, having been approved in respect to style and intellectual content, is referred to you for judgment.

We have read this dissertation and recommended that it be approved.

Wonbong Choi

Surendra K. Saxena

W. Kinzy Jones, Major Professor

Date of Defense: November 20, 2007

The dissertation of Mary Cristina Ruales Ortega is approved.

Interim Dean Amir Mirmiran

College of Engineering and Computing

Dean George Walker

University Graduate School

Florida International University, 2007 


\section{DEDICATION}

I dedicate this dissertation to my family, friends and especially to my guardian angel. 


\section{ACKNOWLEDGMENTS}

I want to thank Dr. Kinzy Jones for his invaluable help as adviser and professor. I want to thank my committee members and all people that made this work possible. From Florida International University, I want to thank Richard Castillo, Neal Ricks, Milagros Chavez, Dr. Liu, Jane Wang and Pierre Schmidth. From University of Turabo to Jose Deliz, Juan Carlos Morales, and Daisy Roman. From CPS Products to Jose Sacerio, and from Heraeuous Company to Andy London. I really appreciate all help and support you gave me through this stage of my life. 


\title{
ABSTRACT OF THE DISSERTATION \\ DESIGN OF A LOW POWER-HIGH TEMPERATURE HEATED CERAMIC SENSOR TO DETECT HALOGEN GASES
}

\author{
by \\ Mary Cristina Ruales Ortega \\ Florida International University, 2007 \\ Miami, Florida \\ Professor W. Kinzy Jones, Major Professor
}

The design, construction and optimization of a low power-high temperature heated ceramic sensor to detect leaking of halogen gases in refrigeration systems are presented. The manufacturing process was done with microelectronic assembly and the Low Temperature Cofire Ceramic (LTCC) technique. Four basic sensor materials were fabricated and tested: $\mathrm{Li}_{2} \mathrm{SiO}_{3}, \mathrm{Na}_{2} \mathrm{SiO}_{3}, \mathrm{~K}_{2} \mathrm{SiO}_{3}$, and $\mathrm{CaSiO}_{3}$. The evaluation of the sensor material, sensor size, operating temperature, bias voltage, electrodes size, firing temperature, gas flow, and sensor life was done. All sensors responded to the gas showing stability and reproducibility. Before exposing the sensor to the gas, the sensor was modeled like a resistor in series and the calculations obtained were in agreement with the experimental values. The sensor response to the gas was divided in surface diffusion and bulk diffusion; both were analyzed showing agreement between the calculations and the experimental values. The sensor with $51.5 \% \mathrm{CaSiO}_{3}+48.5 \% \mathrm{Li}_{2} \mathrm{SiO}_{3}$ shows the best results, including a stable current and response to the gas. 


\section{TABLE OF CONTENTS}

\section{CHAPTER}

PAGE

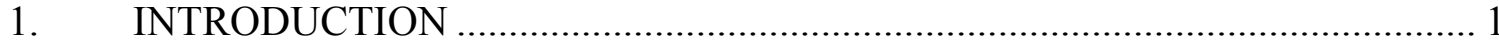

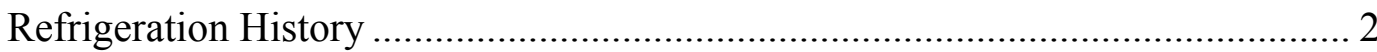

CFCs, HCFCs, and HFCs ........................................................................... 2

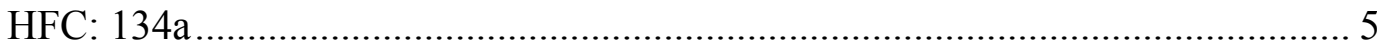

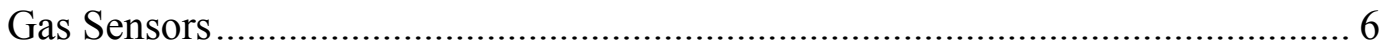

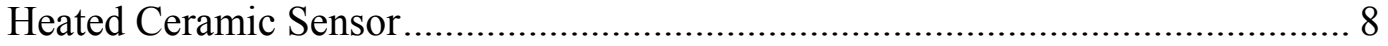

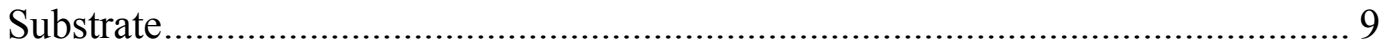

Micro Heater ......................................................................................... 10

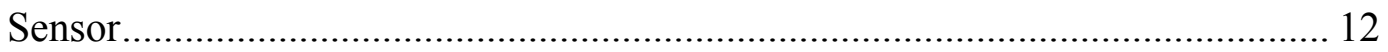

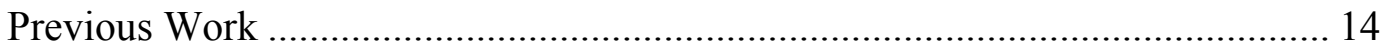

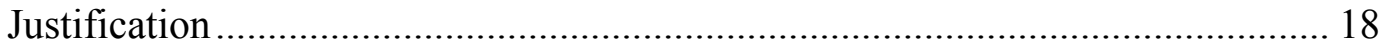

2. FABRICATION AND EXPERIMENTAL PROCESSES ............................... 21

Thick Film Technology........................................................................... 21

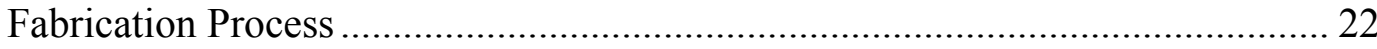

Substrate Preparation ............................................................................... 23

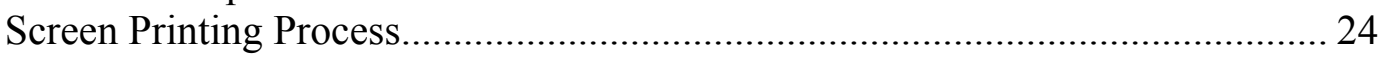

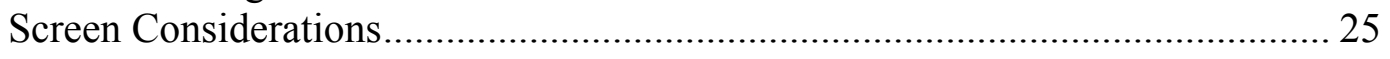

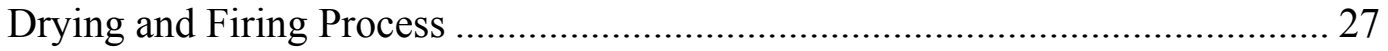

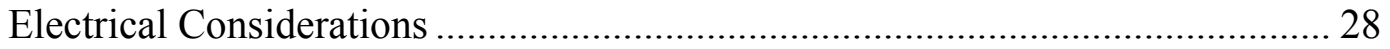

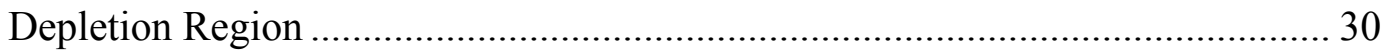

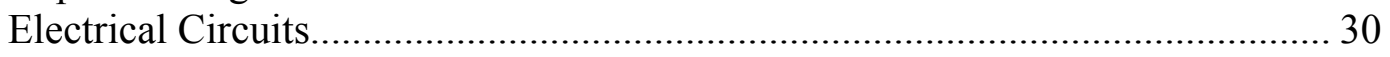

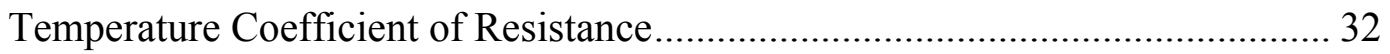

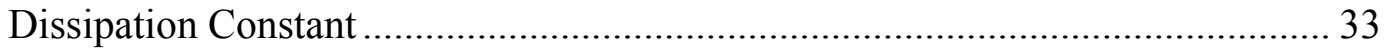

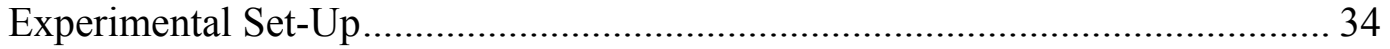

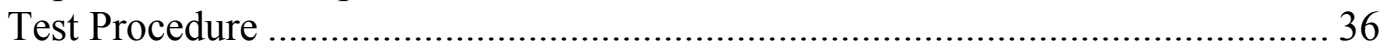

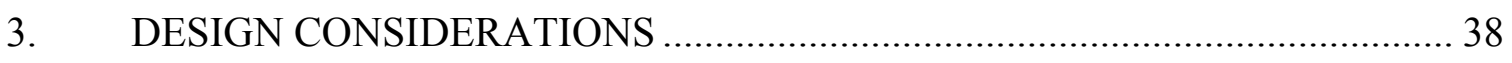

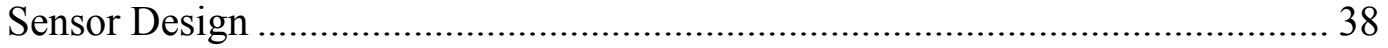

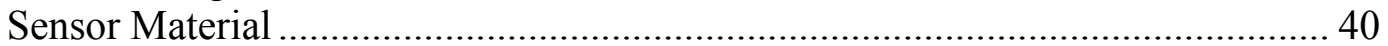

Sensor Ink Fabrication .............................................................................. 41

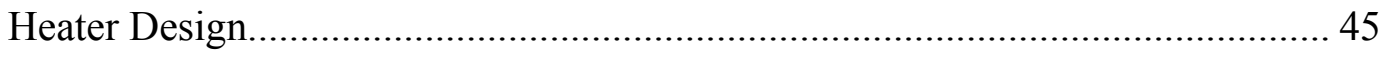

4. EXPERIMENTAL RESULTS AND ANALYSIS ............................................ 50

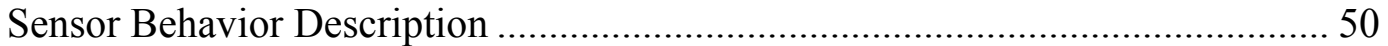

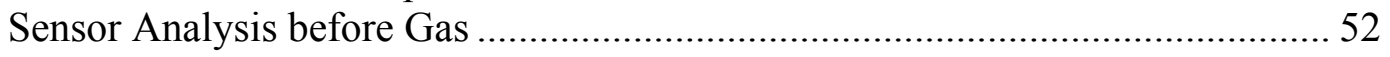

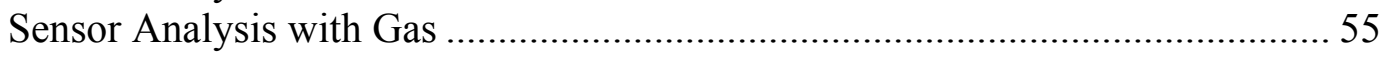

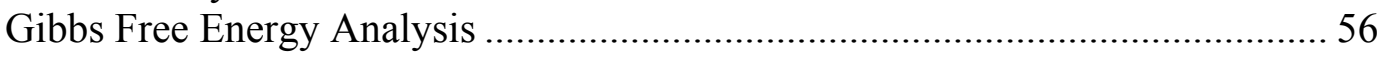

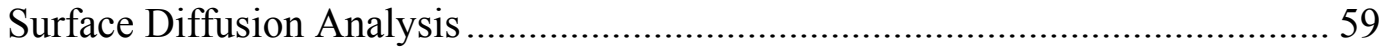

Bulk Diffusion Analysis ............................................................................. 61 


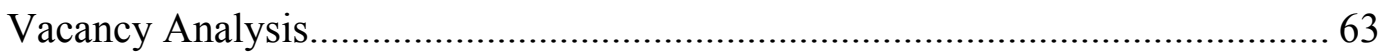

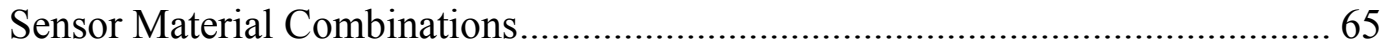

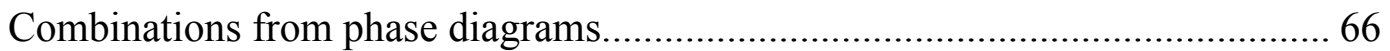

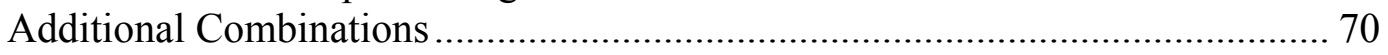

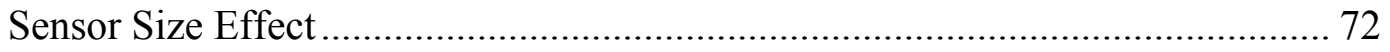

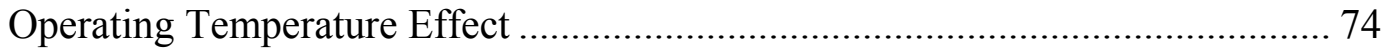

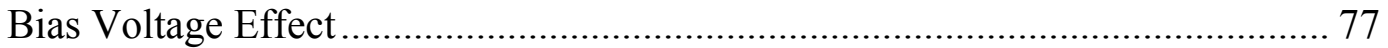

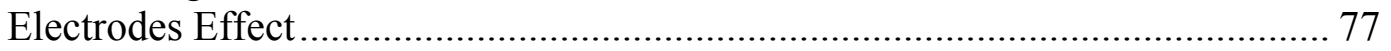

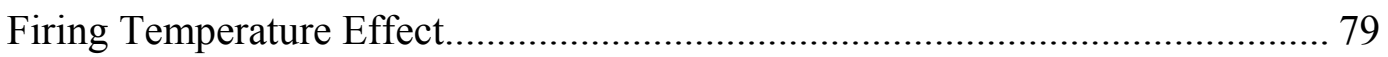

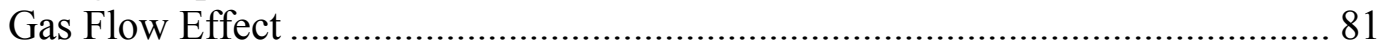

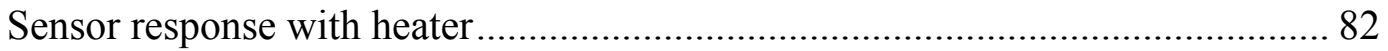

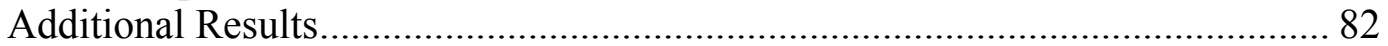

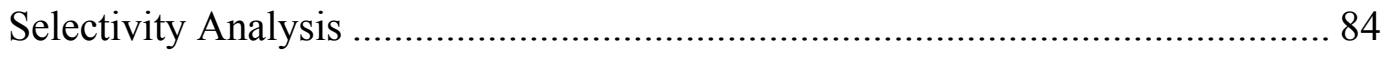

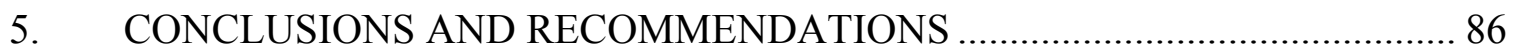

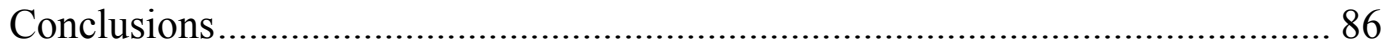

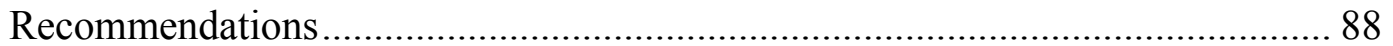

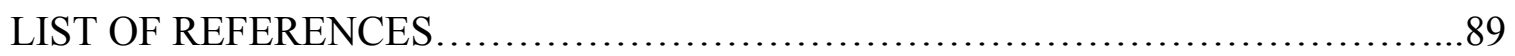

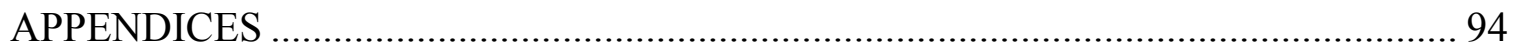

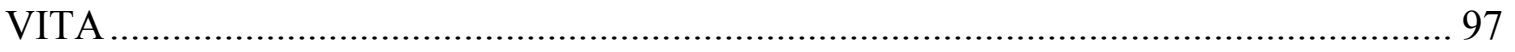




\section{LIST OF TABLES}

TABLE

PAGE

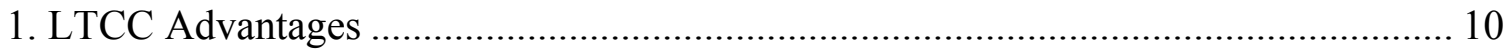

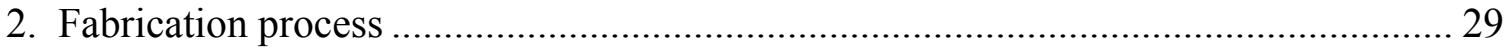

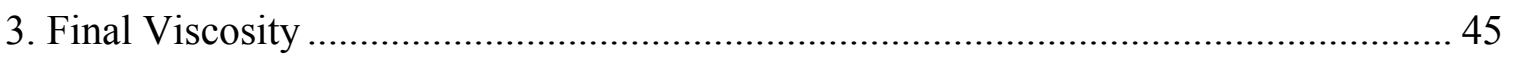

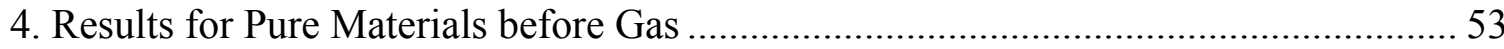

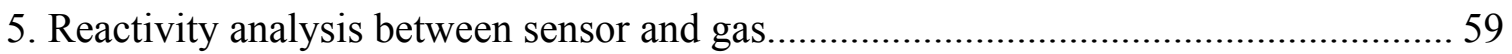

6. Sensor Response to Gas - Surface Diffusion ................................................................. 60

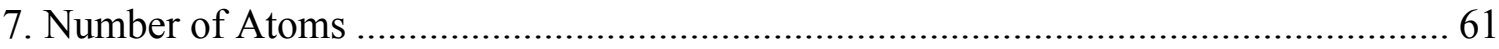

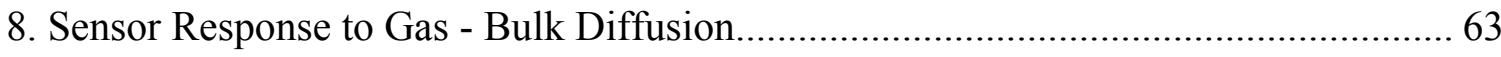

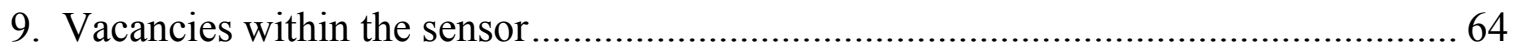

10. Results for Combinations from Phase Diagram......................................................... 68

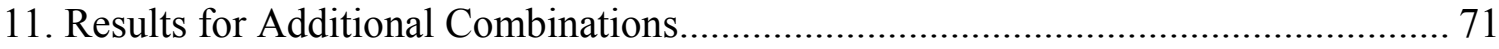

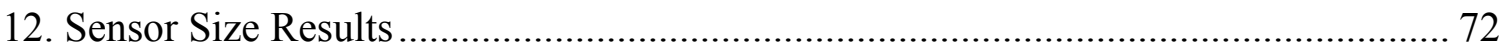

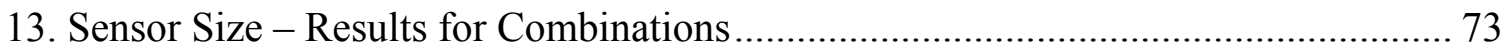

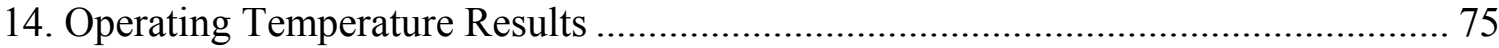

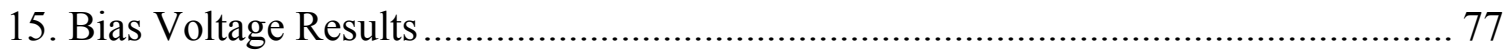

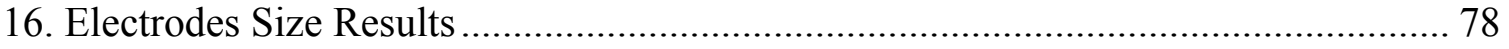

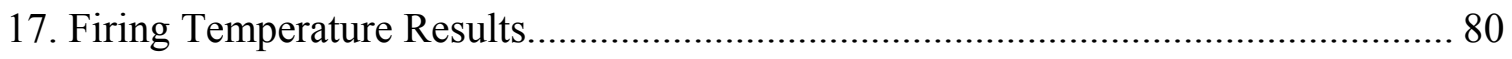

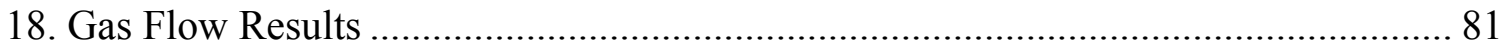

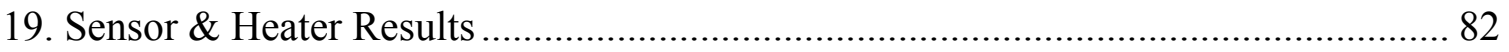

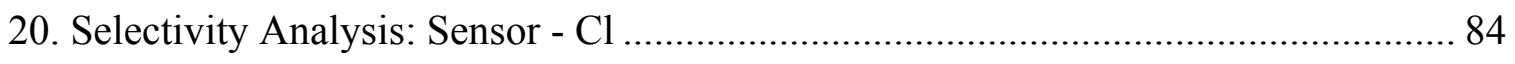

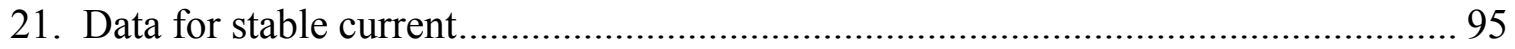


22. Data for reactivity analysis between sensor and gas (fluorine)

23. Data for number of atoms 95

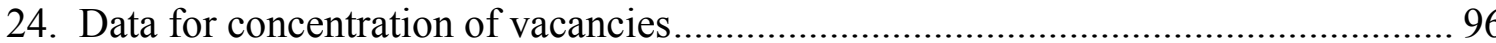

25. Data for reactivity analysis between sensor and gas (chlorine) 96 


\section{LIST OF FIGURES}

FIGURE

PAGE

1. Vapor Compression Refrigeration Cycle ............................................................ 1

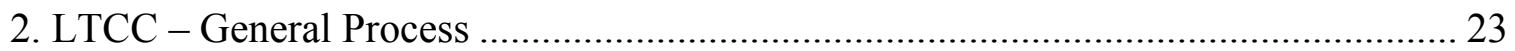

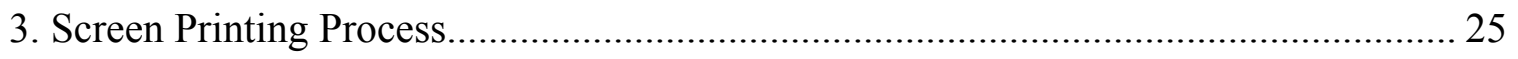

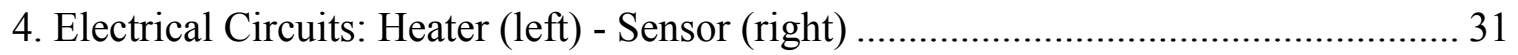

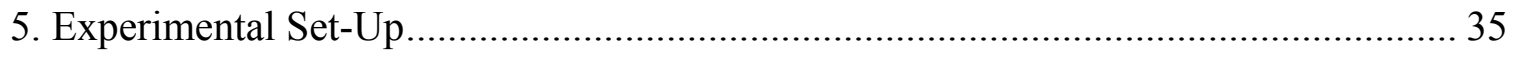

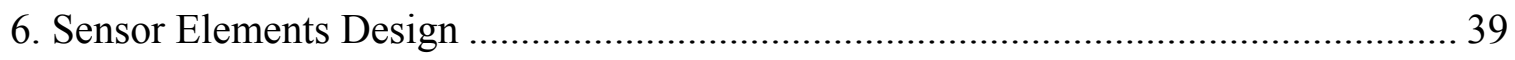

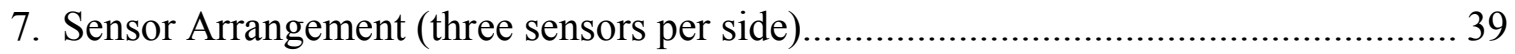

8. Particle Size Distribution - Powder Silicates ....................................................... 44

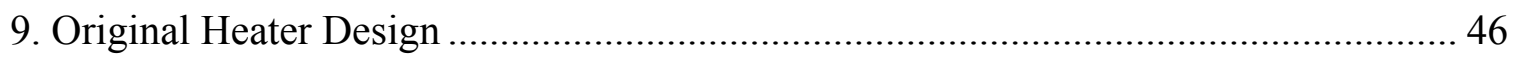

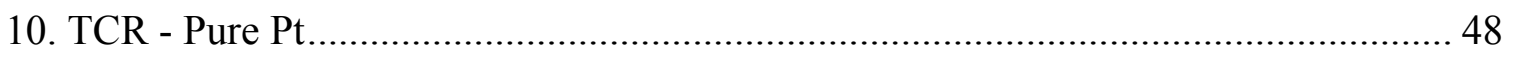

11. Heater Fired Structure: Single Printing (left) - Double Printing (right) ................... 49

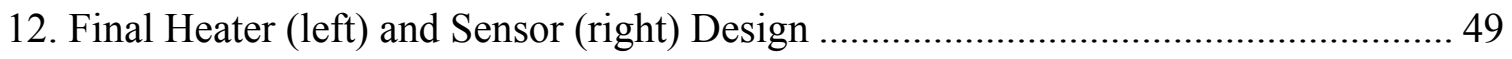

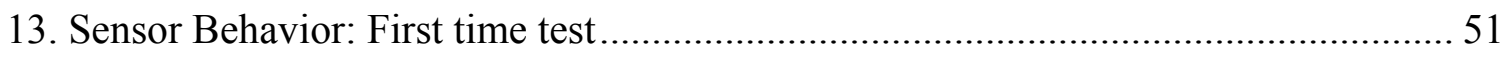

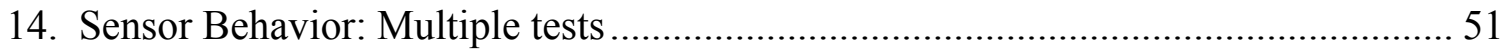

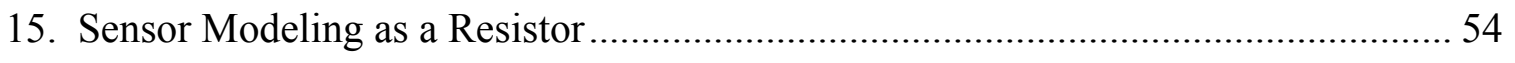

16. Experimental and Calculated Stable Current .................................................. 55

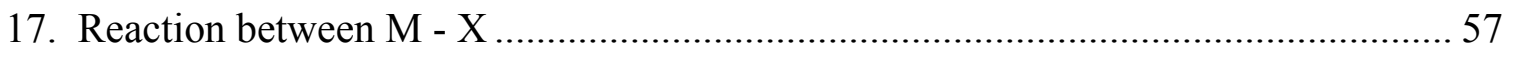

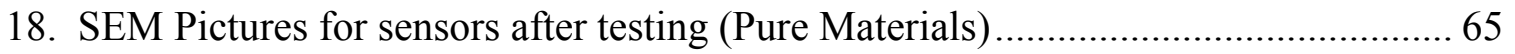

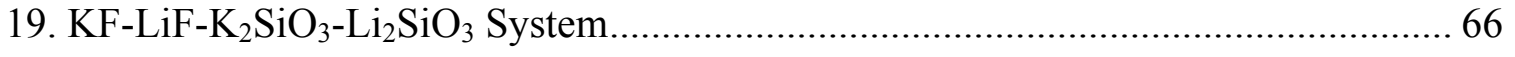

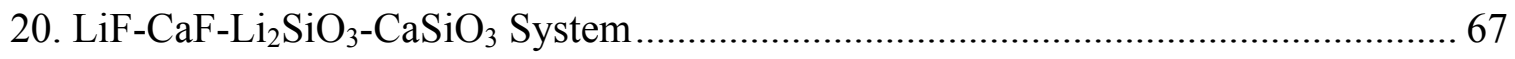

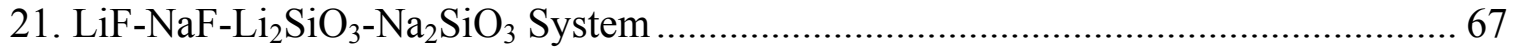


22. SEM Pictures for sensors after testing (Phase Diagram Combinations)................... 69

23. SEM Pictures for sensors after testing (Additional Combinations)......................... 71

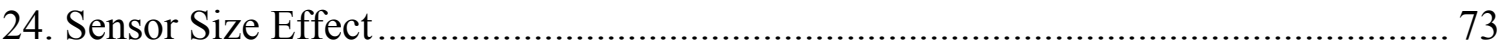

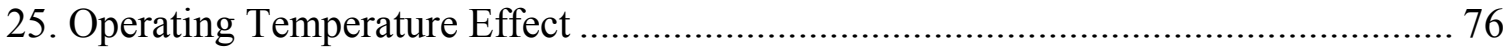

26. SEM Pictures - Operating Temperature Effect .................................................... 76

27. Electrodes (Up) - Sensor \& Electrodes (Bottom) ............................................... 78

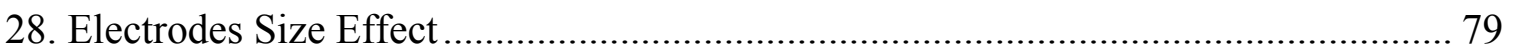

29. Sensor Response to Gas for 2 minuttes............................................................ 83

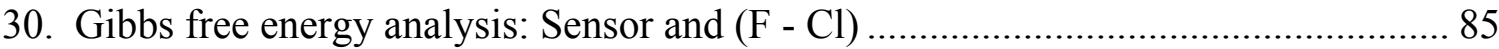

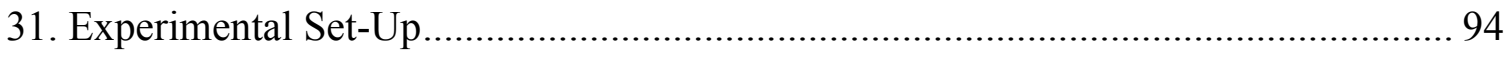




\section{LIST OF FIGURES}

FIGURE

PAGE

1. Vapor Compression Refrigeration Cycle ............................................................ 1

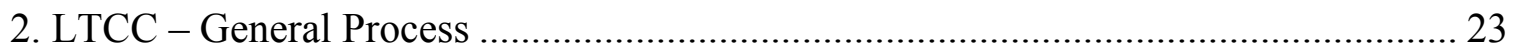

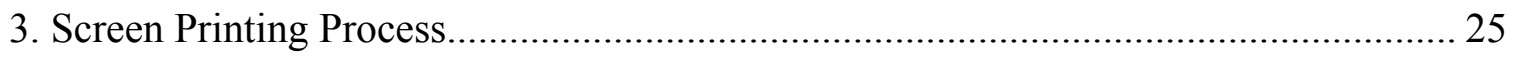

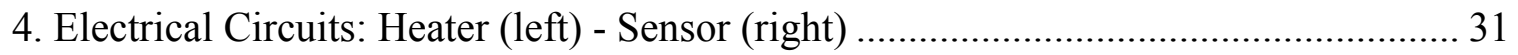

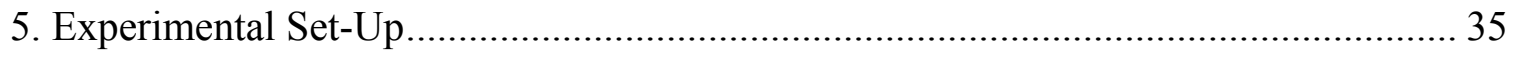

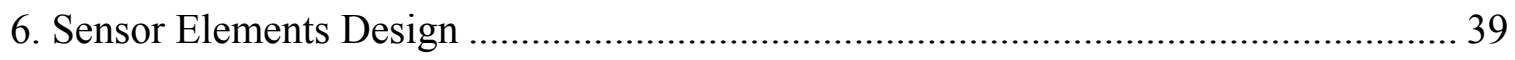

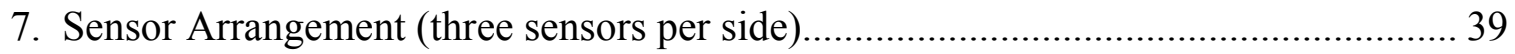

8. Particle Size Distribution - Powder Silicates ....................................................... 44

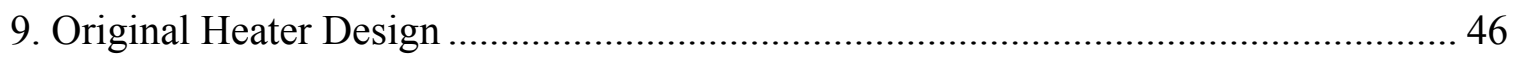

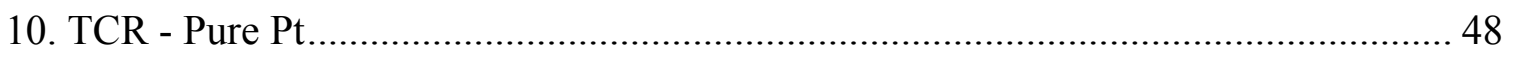

11. Heater Fired Structure: Single Printing (left) - Double Printing (right) ................... 49

12. Final Heater (left) and Sensor (right) Design ................................................. 49

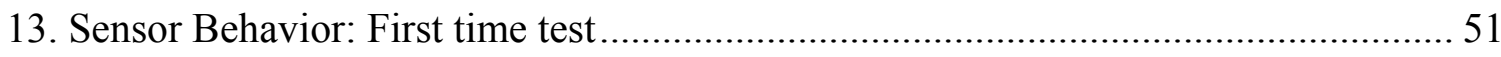

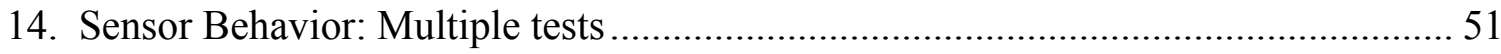

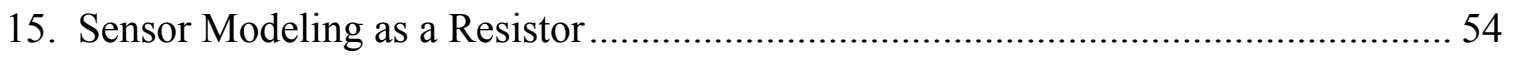

16. Experimental and Calculated Stable Current .................................................. 55

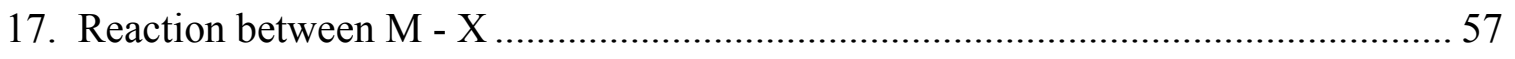

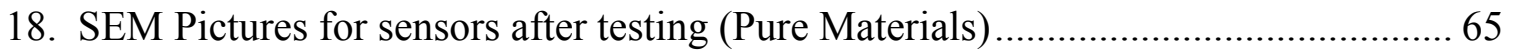

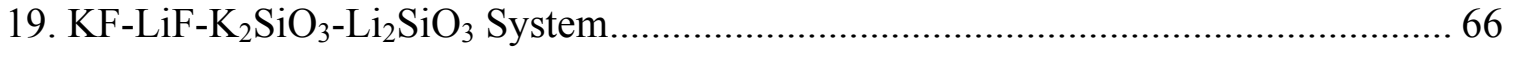

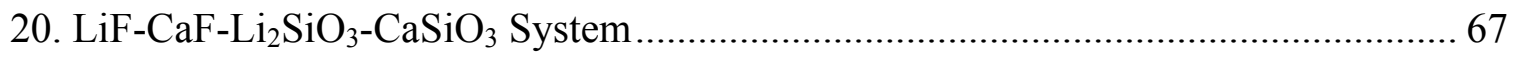

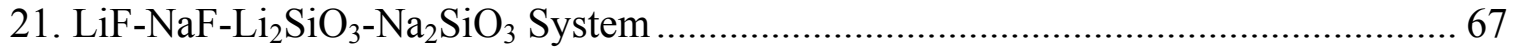


22. SEM Pictures for sensors after testing (Phase Diagram Combinations)................... 69

23. SEM Pictures for sensors after testing (Additional Combinations)......................... 71

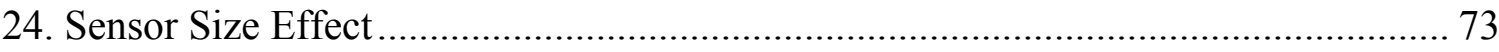

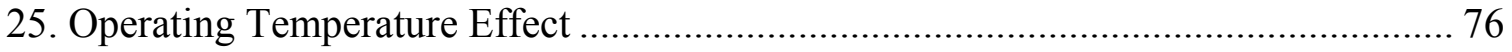

26. SEM Pictures - Operating Temperature Effect .................................................... 76

27. Electrodes (Up) - Sensor \& Electrodes (Bottom) ............................................... 78

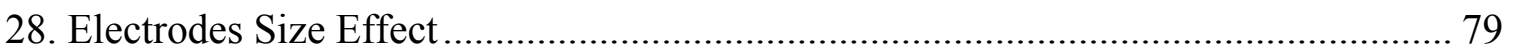

29. Sensor Response to Gas for 2 minuttes............................................................ 83

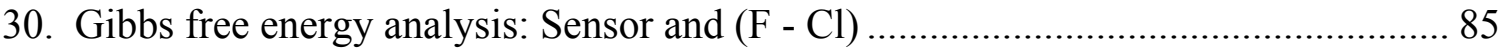

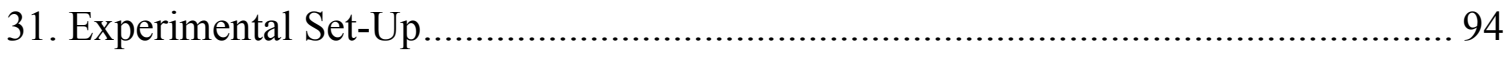




\section{CHAPTER 1 - INTRODUCTION}

Refrigeration has been around, in some form or another, since humans habited the earth. Refrigeration is the withdrawal of heat from a substance or space so that temperature lower than that of the natural surroundings is achieved. Refrigeration may be produced by thermoelectric means, vapor compression systems, expansion of compressed gases, throttling or unrestrained expansion of gases. Vapor compression systems are employed in most refrigeration systems. Here, cooling is accomplished by evaporation of a liquid refrigerant under reduced pressure and temperature (see Figure 1). The fluid enters the compressors at state 1 where the temperature is elevated by mechanical compression (state 2). The vapor condenses at this pressure, and the resultant heat is dissipated to the surrounding. The high pressure liquid (state 3 ) then passes through an expansion valve through which the fluid pressure is lowered. The low-pressure fluid enters the evaporator at state 4 where it evaporates by absorbing heat from the refrigerated space, and reenters the compressor. The whole cycle is repeated.

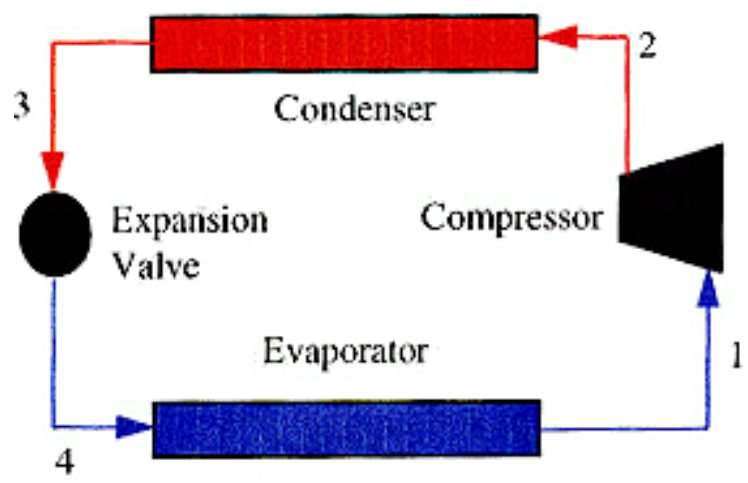

Figure 1. Vapor Compression Refrigeration Cycle 


\section{1 - Refrigeration History}

The first practical refrigerating machine was built by Jacob Perkins in 1834; it used ether in a vapor-compression cycle. The first absorption machine was first developed by Edmond Carr, in 1850, using water and sulfuric acid. His brother, Ferdinand Carr, demonstrated an ammonia/water refrigeration machine in 1859 [1]. A mixture called chemogene, consisting of petrol ether and naphtha, was patented as a refrigerant for vapor-compression systems in 1866. Carbon dioxide was introduced as a refrigerant in the same year. Ammonia was first used in vapor-compression systems in 1873, sulfur dioxide and methyl ether in 1875, and methyl chloride in 1878. Dichloroethene (dilene) was used in Willis Carrier's first centrifugal compressors, and was replaced with methylene chloride in 1926 [2]. Nearly all of the early refrigerants were flammable, toxic, or both, and some also were highly reactive. After a series of fatal accidents when methyl chloride leaked out of refrigerators, a search for a less toxic replacement began as a collaborative effort of three American corporations- Frigidaire, General Motors, and Du Pont.

\subsection{1 - CFCs, HCFCs, and HFCs}

Chlorofluorocarbons (CFCs) were first synthesized in 1928 by Thomas Midgley, Jr. of General Motors, as safer chemicals for refrigerators used in large commercial applications [1]. CFCs are classified as halocarbons, a class of compounds that contain carbon and halogen atoms. General Motors and Du Pont formed the Kinetic Chemical Company to produce Freon (a $\mathrm{Du}$ Pont tradename for CFCs) in large quantities. Commercial CFC production began with R-12 in early 1931. In 1932 the Carrier Engineering Corporation used Freon-11 (CFC-11) in the world's first self-contained 
home air-conditioning unit, called the "Atmospheric Cabinet". Because of the CFCs safety record for nontoxicity, Freon became the preferred coolant in large airconditioning systems. Public health codes in many American cities were revised to designate Freon as the only coolant that could be used in public buildings. After World War II, CFCs were used as propellants for bug sprays, paints, air conditioners, and other health care products. During the late 1950s and early 1960s the CFCs made possible an inexpensive solution to the desire for air conditioning in many automobiles, homes, and office buildings.

These chlorofluorochemicals were viewed as nearly nontoxic, nonflammable, and highly stable in addition to offering good thermodynamic properties and materials compatibility at low cost. Close to half a century passed between the introduction of CFCs and recognition of their harm to the environment when released. Specific concerns relate to their depletion of stratospheric ozone and to possible global warming by actions as greenhouse gases. Ironically, the high stability of CFCs enables them to deliver ozonedepleting $\mathrm{Cl}$ to the stratosphere. The same stability prolongs their atmospheric lifetimes, and thus their persistence as greenhouse gases [3].

In 1974, two University of California chemists, Professor F. Sherwood Rowland and Dr. Mario Molina, showed that the CFCs could be a major source of inorganic Chlorine $(\mathrm{Cl})$ in the stratosphere following their photolytic decomposition by UV radiation. In addition, some of the released $\mathrm{Cl}$ would become active in destroying ozone in the stratosphere [2]. Ozone is a trace gas located primarily in the stratosphere. Ozone absorbs harmful ultraviolet radiation in the wavelengths between 280 and $320 \mathrm{~nm}$ of the UV-B band which can cause biological damage in plants and animals. A loss of stratospheric ozone 
results in more harmful UV-B radiation reaching the Earth's surface. $\mathrm{Cl}$ released from CFCs destroys ozone in catalytic reactions where 100,000 molecules of ozone can be destroyed per $\mathrm{Cl}$ atom.

The demand for the CFCs was accommodated by recycling, and reuse of existing stocks of CFCs and by the use of substitutes. Industry developed two classes of halocarbon substitutes- the hydrochlorofluorocarbons (HCFCs) which have a significantly reduced ozone depletion potential and the hydrofluorocarbons (HFCs) which have no ozone depletion potential. The HCFCs include hydrogen $(\mathrm{H})$ atoms in addition to $\mathrm{Cl}$, Fluorine (F), and Carbon (C) atoms. The advantage of using HCFCs is that $\mathrm{H}$ reacts with tropospheric hydroxyl $(\mathrm{OH})$, resulting in a shorter atmospheric lifetime. HCFC-22 $\left(\mathrm{CHClF}_{2}\right)$ has an atmospheric lifetime of about 13 years and has been used in lowdemand home air-conditioning and some refrigeration applications since 1975. However, HCFCs still contain $\mathrm{Cl}$ which makes it possible for them to destroy ozone. The Copenhagen amendment calls for their production to be eliminated by the year 2030 [4]. Examples of CFCs, HCFCs, and HFCs are:

- CFCs: R-11, R-12, R-13, R-13b1, R-114, R-500, R-502, R-503

- HCFCs: R-22, R-123, R-124, R-401A, R-401B, R-402A, R-402B,

R-403B, R-406A, R-408A, R-409A

- HFCs: R-23, R-134a, R-236fa, R-404A, R-407A, R-407B, R-407C, R-410A R-507, R-508 


\subsubsection{1 - HFC: 134a}

The HFCs are considered one of the best substitutes for reducing stratospheric ozone loss because of their short lifetime and lack of Cl. In the United States, HFC-134a is used in all new domestic automobile air conditioners. For example, HFC-134a is growing rapidly in 1995 at a growth rate of about $100 \%$ per year with an atmospheric lifetime of about 12 years [5]. HFC-134a replace CFC-12 in mobile air conditioning and in residential, commercial and industrial refrigeration systems. It is also used as a blowing agent in rigid foam insulation, and an important component of blends such as R404a, R407c, etc. HFC134a corresponds to the gas used during the experimentation process. HFC-134a properties are as follows:

- Synonyms: Norflurane; Norfluran; 1,1,1,2-Tetrafluoroethane; R-134a; R134a; 1,2,2,2-Tetrafluoroethane; $\mathrm{CF}_{3} \mathrm{CH}_{2} \mathrm{~F}$

- Appearance: A colorless gas with a slight ethereal odor

- Composition: 1,1,1,2-Tetrafluoroethane 100\%

- Molecular weight: $102.03 \mathrm{~g} / \mathrm{mol}$

- $\quad$ Melting Point: $101^{\circ} \mathrm{C}$

- Flash Point: $79^{\circ} \mathrm{C}$

- Boiling Point: $26.2{ }^{\circ} \mathrm{C}$

- Specific Gravity: 1.2076 g/ $\mathrm{cm}^{3}$

- Molecular formula: $\mathrm{F}_{3} \mathrm{CCH}_{2} \mathrm{~F}$ 


\section{2 - Gas Sensors}

A sensor is a device that detects a change in a physical stimulus and turns it into a signal which can be measured or recorded. Requirements for leak detection applications include small, highly portable leak detection equipment as well as adequate chemical and thermal stability, rapid interaction with gas and dramatic change in conductivity with small change in gas concentration. Ideally the leak detector should be a light weight, battery powered device [6].

The prior art of sensors for detecting gases or vapors in an atmosphere has utilized a number of different detection principles [7]. These include: Measuring changes in the rate of heat loss from a circuit component resulting from changes in thermal conductivity of the atmosphere being sampled. Electron capture methods which measure ions formed by the gas of interest when it is exposed to low energy electrons. Positive ion emission methods in which the gas of interest facilitates emission of positive ions from a metal surface in the presence of a strong electric field. Thermal conductivity detectors are not specific to a given gas and thus are likely to give false responses. They also do not have as high sensitivity as other types of detectors. Electron capture detectors use a radioactive source which requires special handling and in most cases must be licensed by governmental authorities. Other methods include chemical to solid state, electrochemical, infrared, and ion mobility detectors. Solid state sensors use a heated semiconductor that changes internal resistance when a refrigerant gas is present. Electrochemical sensors use electrodes immersed in an electrolyte under a permeable membrane and measure voltage change when a gas permeates the membrane [8]. 
For oxide gas sensors two sensor types can be distinguished: surface layer controlled gas and bulk conduction based sensors [9]. If the interaction between the adsorbed molecules and the semiconductor is refined to the boundary between the two phases, and if the conductivity of the space-charge region near the interface is sensitive to the sample gas, the sensor is called a boundary conductivity sensor. These sensors utilize the change in the concentration of conduction electrons as a result of chemical reactions at the surface. These reactions: chemisorption and/or catalytic reactions modify the defect states of the oxide's surface layer to a depth of a few micron or less [10]. The main advantage of this sensor is the flexibility to be operated at low temperatures, where bulk diffusion process is prohibited. On the other hand, if the surface absorbents can further interact and exchange electrons with the interior of the semiconductor so that the conductivity of the bulk material is controlled by the sample gas, the sensor is then called a bulk conductivity sensor. The bulk conduction based sensors involve gas-solid reactions in series with a change in the stoichiometry of the bulk (grains) of the sensor material. These sensors are often operated at elevated temperatures, where bulk diffusion of lattice defects such as vacancies or metal interstitials is sufficiently fast for the system to reach equilibrium with the environment.

Prior art positive ion emission and surface depletion layer detectors have very low sensitivity to HFCs. One way to increase their sensitivity to HFCs is to increase the sensor operating temperature. However, this has the adverse effect of significantly shortening the life of the sensor, increase the power consumption, and greatly increasing its sensitivity to other gases, particularly to chlorinated and/or brominated gases [6]. This extreme sensitivity to minor impurities in the background atmosphere makes existing 
sensors unsuitable for detecting HFCs. Portable refrigeration leak detectors in the prior art operate on the principle of suppression of a corona discharge. These devices are in wide use, but are not as sensitive as heated element type sensors. Focus on this research is on a heated ceramic sensor.

\subsection{1 - Heated Ceramic Sensor}

The heated ceramic sensor is based on a heating element and a sensor element that increases in surface conductivity when exposed to a decomposed halogen gas at high temperatures. When a halogen based gas comes into contact with the hot surface of the heating element, the halogen atoms are separated from the molecules and ionized. The ions react with the cations increasing the electrical current flow within the sensor, which can be measured to determine the presence of the gas. The sensor consists of a diode sensor that is fabricated on one side of the substrate and a heater on the opposite side. After the material is heated up, an equilibrium concentration of both anion and cation vacancies will occur. Since the number of vacancies (and therefore reaction of sites), is a function of temperature, the higher the temperature, the greater the number of vacancies. Upon reaction of the sensor ink with the halogen species (because of a higher thermodynamic free energy of reaction) an oxygen vacancy must be annihilated to maintain electrical charge partial neutrality of the remaining ceramic silicate, resulting in

a change of current flow. Three elements are critical in a heated ceramic sensor: the substrate, heater and sensor material. 


\subsubsection{1 - Substrate}

The substrate corresponds to the surface on which all elements are attached, i.e. heater, sensor, leads, and electrodes. For high reliability electronic circuitry, ceramics historically have been the choice for both semiconductor packages and substrates [11]. The standard for thick-film substrates is Alumina $\left(\mathrm{Al}_{2} \mathrm{O}_{3}\right)$ which has been used widely in the fabrication of hybrid microelectronic circuits. This is due in large part to their technical qualities. In general, all formulations contain an alkaline-earth/aluminosilicateglass phase that bonds the $\alpha-\mathrm{Al}_{2} \mathrm{O}_{3}$ crystals together, the glass phase also provides a bonding mechanism for adherence of the thick film with both conductor and resistor material. Thick film gas sensors have been known for a long time and they were also based on ceramic materials like $\mathrm{Al}_{2} \mathrm{O}_{3}$, they are found in a wide range of applications due to their stability at high temperature (typically they operate in the range from $400^{\circ} \mathrm{C}-$ $700^{\circ} \mathrm{C}$ ), outstanding thermal corrosion and their ability to be hermetic. Another advantage is the high thermal conductivity. However, this also causes high power consumption due to the heat distribution along the whole substrate and not only in the area of the gas sensing [12].

$\mathrm{Al}_{2} \mathrm{O}_{3}$ substrates have been replaced by Low Temperature Co-fired Ceramic (LTCC) that has a thermal conductivity about $3 \mathrm{~W} / \mathrm{mK}$, this allows reducing power consumption up to $70 \%$ only by changing the substrate material and considering the same dimensions and work temperature above $250^{\circ} \mathrm{C}[13,14$, and 15]. LTCC is a ceramic sintered with a glass, Calcium (Ca), Aluminium (Al), Silicon ( $\mathrm{Si}$ ), and Oxygen (O) mixture. LTCC can be defined as a multilayer circuit fabricated by laminating single green-sheets (term for 
unfired tapes; Green Tape, DuPont) with printed conductor lines on the surface on top of each other and firing them all together in one step. This process is similar to that of High Temperature Co-fired Ceramic (HTCC), but the big advantage of the LTCC system is the possibility to use low resistivity conductors like silver, gold, copper and alloys with Palladium (Pd) and Platinum (Pt) instead of Tungsten (W) and Molybdenum (Mo). The separation between these two technologies is defined with the firing temperature: in excess of $6000^{\circ} \mathrm{C}$ for $\mathrm{HTCC}$ and $850^{\circ} \mathrm{C}-875^{\circ} \mathrm{C}$ for LTCC. Applications for LTCC include: chip packaging; integrated circuits; antenna arrays; waveguides; "Bluetooth" microwave devices, Ceramic Micro Sensors, Micro actuators, and Ceramic Micro Electronic and Mechanical Systems (C-MEMS) [16, and 17]. Table 1 shows some of the LTCC advantages.

Table 1. LTCC Advantages

\begin{tabular}{|c|l|}
\hline Area & \multicolumn{1}{|c|}{ Advantages } \\
\hline \hline Process & $\begin{array}{l}\text { Parallel processing (High Yield/Quality) } \\
\text { Single sintering step for all materials (Co-fire) } \\
\text { Inexpensive }\end{array}$ \\
\hline Electrical & $\begin{array}{l}\text { Integrated passive components (R, L, C) } \\
\text { High circuit density (3D Structure) }\end{array}$ \\
\hline Thermal & $\begin{array}{l}\text { High ambiente temperature resistance } \\
\text { Better thermal conductivity than PCB's }\end{array}$ \\
\hline Mechanical & $\begin{array}{l}\text { Machineable (Drill, Cut, Punch) in green state } \\
\text { High mechanical strenght with multi-layer structure } \\
\text { Hermetically sealed package }\end{array}$ \\
\hline
\end{tabular}

\subsubsection{2 - Micro Heater}

The microheater corresponds to the element that increases in temperature under the voltage application. The heater can be deposited on the substrate using thin film technology or thick film technology $[18,19,20,21$, and 22]. Thin film technology in the 
packaging world is generally accepted as materials, processes, and structures used to form a coating layer of thickness in the range from a few $(2-3)$ atomic layers to about 5 $\mu \mathrm{m}$ as compared with $100 \mu \mathrm{m}$ typically achieved with thick film technologies. The important feature distinguishing thin films from thick films is not so much the difference in thickness as the method of deposition which takes place by a variety of technologies such as sputtering, evaporation, and chemical vapor deposition (CVD) for thin film technology and screen printing process for thick film technology. Thick film technology is an additive process for the conductors, resistors and dielectrics resulting in high and precise line resolution $(10-200 \mu \mathrm{m})$. After the thick ink is deposited on the substrate by a screen printing process, the dry and fire process take place at high temperature to fuse into its final form. Typical conductor materials used are those that can be fired below $1000^{\circ} \mathrm{C}$ with good electrical conductivity. Thick film technology includes applications such as automotive electronics, microelectronics packaging, resistive heaters, and passive circuits. During this research thick film technology was used during the fabrication process.

Integrated Micro Heaters offer a unique role in the development of micro gas sensors and micro sensor arrays, especially since the heater can be integrated into C-MEMS structure containing interconnected, embedded passives and other MEMS type devices [23, and 24]. Stability, low-power and high temperature heating characteristics are critical in determining the sensitivity, selectivity and response time of a micro gas sensor. Therefore, thick film technology offers a unique possibility to realize integrated micro heater modules. High line resolution allows fabrication of precision heating elements and 
integrated resistance-temperature detector (RTD) and a sensor electrode structure. The manufacturing is compatible with the standard LTCC manufacturing process.

\subsubsection{3 - Sensor}

The sensor corresponds to a material that increases in surface conductivity when exposed to a decomposed halogen gas at high temperatures. Using LTCC and thick film technology it is possible to make an array of sensors for gas analysis [25, and 26]. The requirements regarding performance of the sensor depends on the application [27, and 28]. In general, the performance is typically evaluated in terms of:

- Selectivity

- Sensitivity

- Range of operation

- Reproducibility and stability

- Speed of response

- Durability and lifetime

Selectivity is the ability of a sensor to respond selectively to a specific species while inactive to other species in the sample gas. It is the selectivity which makes a sensor specific to a chemical species of interest.

Sensitivity is usually defined as the slope of sensor response versus concentration of the chemical species to be detected. Thus, sensitivity is a measure of the ability of a sensor to respond to small amount of change in concentration. Sensitivity is largely determined by the principle of operation and materials properties, but it also is influenced strongly by sensor design and operating conditions. 
Range of operation is typically defined as the concentration range within which sensitivity is greater than zero and the sensor response is linearly related to the concentration of the species to be analyzed. The range of operation of a sensor is preferably within or overlapped with the linear dynamic range, although it is possible to extend to the concentration range over which the sensor response obeys a theoretical or empirical equation. Range of operation depends on the principle of operation, the materials employed, sensor design, as well as operating conditions.

Reproducibility is the dispersion of the sensor output signal and typically characterized by standard deviation. Stability is the percent of change of the offset and/or sensitivity in time. Reproducible and stable sensor response is necessary for reliable monitoring and control. Reproducibility and stability are vital characteristics for a sensor. These parameters depend critically on the stability of materials and reproducibility of the chemical, physical, or electrochemical phenomena on which the sensor operation is based as well as environmental contamination.

Speed of response refers to the kinetics to reach equilibrium. Fast response is crucially important when the sensor is used to initiate a control or function. The kinetics of sensor response varies with the principle of operation and sensor configuration. Especially on the dynamics of the gas transport, the kinetics of the interaction between surface absorbent and lattice defects, and the diffusion of charge carriers such as vacancies and electron in the sensor material

Durability and Lifetime is an engineering or economic parameter. The factor influencing the durability and lifetime of a sensor include: thermodynamic and kinetic stability of 
sensor materials, thermal stability or thermal-shock resistance of the device to thermal cycle or temperature gradient, fabrication processes, as well as operating conditions.

\section{3 - Previous Work}

A summary of previous works related to gas sensors is presented starting with research related with the heaters. A first work includes a heater with operating temperature of $500^{\circ} \mathrm{C}$ which was fabricated with glass and Ruthenium Oxide $\left(\mathrm{RuO}_{2}\right)$ on $\mathrm{Al}_{2} \mathrm{O}_{3}$ substrate [29]. Since this work a concern with the heater was the low power consumption operating at different temperatures. To meet heating requirements for sensors and other applications another heater previously developed presented the following characteristics:

- Surface area: $0.025 \mathrm{in}^{2}$

- Operating temperature: $600^{\circ} \mathrm{C}$

- Power: $1.5 \mathrm{~W}$

- Substrate: $\mathrm{Al}_{2} \mathrm{O}_{3}(35 \times 45 \times 10$ mils $)$

- Heater material: Pt serpentine thick film with a total of 3 layers (0.6 mils/layer). The first layer was printed with Pt and glass, and the second and third layer just with Pt.

The problems for this heater to become a commercial product were the construction $\left(\mathrm{Al}_{2} \mathrm{O}_{3}\right.$ substrate with $\mathrm{Pt}$ wires) and excessive power loss due to radiation [29]. To overcome these problems a third heater was developed. For this heater, the thermal impedance and therefore the power consumption of the sensor assembly was optimized to allow for high temperature heater operation with the lowest power consumption. To minimize power, the overall thermal impedance from the heater to ambient was maximized including each component of thermal impedance (conduction, convection and 
radiation). The conduction impedance was maximized suspending the heater on narrow arms. The convective losses were minimized reducing the sensor area while still maintaining sensitivity and manufacturability of the heater [25]. Because of radiation was the dominant factor for power loss for the micro heater radiation shields were incorporated into the sensor to minimize this loss. After including all the modifications, the result was a heater fabricated on LTCC substrate with a cover with space for radiation control, and slots to increase conduction heat transfer [30]. Additional characteristics include:

- Surface area: $2.06 \mathrm{~mm}^{2}$

- Operating temperature: $800^{\circ} \mathrm{C}$

- Power: $0.8 \mathrm{~W}$

- Substrate: LTCC (200x200x10 mils)

- Heater material: Pt serpentine thick film with a total of 2 layers (5 mils/layer) green thickness, 3.33 mils/layer after firing. Shrinkage $32 \%$ in z axes.

This resistor structure was tested with a 1000 cycle max on-off cycles and 48 hours operational life without failure. Conduction impedance was increased to $2500{ }^{\circ} \mathrm{C} / \mathrm{W}$ by suspending the heater on narrow arms. Radiation shielding proved to be and efficient way of reducing the radiation losses by approximately $90 \%$ the original losses with the incorporation of 3 shields [30].

While low temperature sensors have been commercially successful, their higher temperature counterparts have been less so. This is mainly due to problems associated with sensitivity, selectivity, stability and reproducibility at higher temperatures [28, and 31]. The base materials most widely used for ceramic gas sensors are transition metal 
oxides. A change in their electrical conductivity is typically exploited in the sensing measurements. Oxides such as Zinc Oxide $(\mathrm{ZnO})$, Titanium Dioxide $\left(\mathrm{TiO}_{2}\right)$, and Tin Dioxide $\left(\mathrm{SnO}_{2}\right)$ are the most widely investigated. They not only have been adopted as model systems for fundamental studies, but also as base materials for the development of various sensors for the detection of gases such as Hydrogen $\left(\mathrm{H}_{2}\right)$, Oxygen $\left(\mathrm{O}_{2}\right)$, Carbon Oxide (CO), Nitrogen Oxide $\left(\mathrm{NO}_{\mathrm{X}}\right)$, Carbon Dioxide $\left(\mathrm{CO}_{2}\right)$, Methane $\left(\mathrm{CH}_{4}\right)$, and other hydrocarbons [9, 32 and 33].

Previous works related with sensors also include investigations on DC emission currents from heated surfaces at ambient pressures for the purpose of gas sensing. Since applied gases alter the work function (WF) of a material, the emitted electron current changes and becomes gas sensitive. Gas sensitive effects were identified as being dependent upon the emission material used. In contrast with vacuum conditions, additional effects arise from interactions among electrons, ions and atoms. Consequently, the electrical behavior at atmospheric pressure is completely different. This work was done on classical $\mathrm{Al}_{2} \mathrm{O}_{3}$ substrates and materials such as barium nitrate and scandium oxide. On $\mathrm{Al}_{2} \mathrm{O}_{3}$ substrate the electrical heater structure is a thin film Pt electrode. The gases evaluated were CO, $\mathrm{CH}_{4}, \mathrm{H}_{2}$, propane and ethanol [34, and 35].

It has been showed that LTCC technology can be successfully applied in manufacture of gas sensors [13, 25, 36, and 37]. An example includes sensors for $\mathrm{CO}$ and $\mathrm{CH}_{4}$ made by LTCC technique with a Pt heater buried inside the multilayer structure and $\mathrm{SnO}_{2}$ or $\mathrm{SnO}_{2}$ doped with Pd as catalyst thick film that were used as gas sensitive materials in which the Pd catalyst improved sensitivity for $\mathrm{CH}_{4}$ [36]. Optmization of $\mathrm{SnO}_{2}$ gas sensor integrating silicon oxynitride membranes and electrothermal simulations with finite 
element methods using SESES software showed excellent correlation between measured and simulated results allowed to adjust a model using suitable coefficients [38, and 39]. In another work a gas sensor was presented combining the advantages of micro machined silicon gas sensors and ceramic gas sensors. The sensor devices are shaped like already known hot-plate low-power micron machined silicon gas sensors. Compared to classical ceramic gas sensors the low thermal conductivity $(3 \mathrm{~W} / \mathrm{mK})$ leads to a low power consumption $\left(480 \mathrm{~mW}\right.$ at $\left.330^{\circ} \mathrm{C}\right)$. Thermal properties like power consumption and temperature distributions were measured and compared to FEM simulations. First measurements using a propane sensitive $\mathrm{Cr}_{2} \mathrm{O}_{3}$ layer show the principal operativeness of the concept using LTCC meso hot-plates for gas sensors [25].

In relation with the hot plates LTCC gas sensors combine advantages of silicon structures like low power consumption with the stability and reliability typical of ceramics gas sensors [40]. Such elements can be integrated in MEMS packages as well as in ceramic sensor arrays. Moreover, they can be produced in small series with relatively low cost. One important key in hot plate design are properly formed beams. This work presented possibilities and problems related to laser forming of LTCC ceramics for hot-plate gas sensors and a discussion of the influence of beam width on power consumption and temperature distribution. Possibilities to achieve beam width as narrow as possible are practically tested by laser cutting. Only by changing the substrate material from $\mathrm{Al}_{2} \mathrm{O}_{3}$ substrate to LTCC, the power consumption was reduced by $70 \%$. FEM analysis based on measured data showed that decreasing beam cross-section causes reduction of heater's power about $15-20 \%$ without significant temperature distribution changes in hot plate 
area. LTCC tapes were structured successfully with UV laser. The minimal beam width obtained was about 200 or $300 \mu \mathrm{m}$ (after firing) [12, 25, 41, and 42].

LTCC also enables the development and testing of critical elements on microsystem boards as well as non-microelectronic meso scale applications [16, 17, 37, 43, and 44]. A description of silicon-based MEMS packaging and LTCC meso scale applications was presented using a variant of the sacrificial volume materials (SVM) it has been possible to create channels, suspended thick films, cavities, and techniques for pressure and flow sensing, as well as radio frequency (RF) components with improved performance such as inductors, and antennae [45].

Typical operating temperature for sensors that detect CFCs and $\mathrm{HCFCs}$ is about $600^{\circ} \mathrm{C}$, while for $\mathrm{HFCs}$ is about $750^{\circ} \mathrm{C}$. For 134 a the temperature range is $750^{\circ} \mathrm{C}-950^{\circ} \mathrm{C}[6]$. A previous work for this particular sensor shows a preferred ceramic composition for the sensor material was as a mixture of potassium silicate and either one of silicon dioxide or aluminum oxide [46]. The sensor was developed based on this formulation using 3-4 layers of $80 \%\left[\mathrm{Li}_{2} \mathrm{SiO}_{3}(10 \%)+\mathrm{K}_{2} \mathrm{SiO}_{3}(90 \%)\right]+20 \%\left[\mathrm{Al}_{2} \mathrm{O}_{3}\right.$ powder]. It was determined that the response of the sensor depends on the concentration of the gas presented, the amount of sensor material, the applied bias voltage, and a crucial factor was the operating temperature of the sensor. The final sensor presented different problems as power consumption and life expectancy [29].

\section{4 - Justification}

There are many instances where it is necessary to detect the presence of a specific gas because the gas may be harmful to human health and thus it may be desirable to monitor a work environment to insure that the concentration of the gas or vapor does not exceed 
some threshold level. Refrigeration and air conditioning industries are a major part of US production capacity. Since the discovered harmful environmental impacts of CFCs these have been replaced with less harmful gases: HCFCs and the most common HFCs that are considered one of the best substitutes for reducing stratospheric ozone loss because of their short lifetime and lack of $\mathrm{Cl}$. Originally focus on halogen gas sensors was on CFCs, but these sensors do not work with HFCs gases because most prior art sensors have low sensitivity to gases which do not contain $\mathrm{Cl}$ or $\mathrm{Br}$ atoms.

There is a continuing need for the development of rugged and reliable sensors capable of making measurements in harsh environments where many test atmospheres contain more than one constituent that can react with the sensing element and, as a result, unwanted interference signal are sometimes generated making difficult to discern the presence of the gas of immediate interest [9]. Cleaning solvents such as trichloroethylene containing Hydrocarbons and $\mathrm{Cl}$ have proven to be troublesome background gases commonly found in industrial environments.

It is also desirable to test pressurized equipment for leaks which could indicate a malfunction. Therefore to maintain the proper operation of cooling systems it is necessary that the system be free of leaks or for all those systems the leakage must be minimized using compact sensors that detect small amounts of refrigerant gases and have long life expectancy [26, and 29].

The main facets of the research problem can be classified in two: the science and the engineering aspect. The science part involves the sensor and the engineering part corresponds to the heater. For the heater the main goal is the low power consumption and for the sensor the selectivity and sensitivity. Through the theoretical and experimental 
analysis of different sensor materials, as well as different combinations between them, new phases and materials are going to be developed in order to find the most reactive for a particular halogen gas. It is crucial a detailed understanding of the science and engineering part of this research including the sensing mechanisms and microstructureproperty correlation in order to exploit the full potential of existing materials or to find new systems with improved performance to control the stability of fabricated devices increasing the energy efficiency and the general quality.

LTCC technology offers a lot of advantages which can be utilized in the production of gas sensors. The main advantage of LTCC is the possibility of forming three dimensional multilayer structures which form one multichip module (MCM) package. It consists of a very high density of electrical connections which allow it to be built inside and on the top of one substrate both the sensor and microelectronic circuits for data analysis. Another advantage of developing an LTCC sensor is the ease of manufacture and mass production of sensors in a short period of time. This reduces the production costs of the sensors and increases the profit of manufacturers. 


\section{CHAPTER 2 - FABRICATION AND EXPERIMENTAL PROCESSES}

The fabrication process used during this research corresponds to thick film technology. This has been used for many years in the hybrid microelectronics industry. For the LTCC green tape, green sheet or unfired sheet the processing is very similar to that of HTCC without the complex firing conditions, flattening fires, and plating steps. After the fabrication process is complete it is necessary to test the sensor isolating it from the ambient environment and placing it in a controlled atmosphere. Therefore, an experimental set-up was designed and constructed based on different parameters and electrical considerations to obtain an accurate measurement of different inputs as temperature, flow gas, current, and voltage. It was also necessary to guarantee the repeatability of the conditions during the experimentation process and a test procedure was established for that purpose. In this chapter a description of the fabrication process, the experimental set-up, the electrical considerations and the testing procedure is presented.

\section{1 - Thick Film Technology}

The thick film technology process is used to provide conductive traces for electrical interconnection between active and passive elements as well as for resistive and dielectric components in electronic devices. It is an additive process where a thixotropic ink is patterned by screen printing onto a ceramic substrate. Depending on the circuit complexity, the processing for the substrate may stars with the preconditioning of the green tape based on oven drying of the green sheets at a predefine temperature and time or allowing the tape to stand for 24 hours in a nitrogen dry box. On the green tape or after its preconditioning vias for electrical connection, tooling holes for registration and 
automatic vision system alignment are created via formation using mechanical punching or laser drilling. The next process can be lamination using either uniaxial lamination in a hydraulic press with heated platens or using isostatic lamination with heated water for special designs without requiring rotation. After lamination, via fill can be performed using a conventional thick film screen printer or extrusion via filler. The conductor printing is performed using conventional thick film screen printing. This is follow by a drying process which is accomplished in a box oven at predefined time and temperature. The last process is firing that can be cofiring or postfiring. Cofire occurs when tape and the elements printed are fired in a single step all together. The postfiring process is used for some applications where elements are incorporated after the substrate firing [47]. Actions as cut of the tape can also be done as a post fire operation using ultrasonic or laser cutting, both producing tight outside dimensional tolerances as well as high quality edges. The LTCC general process is presented in Figure 2.

\subsection{1 - Fabrication Process}

The fabrication process used during this research includes the following steps:

1. Substrate preparation:
a. Cutting and stacking
b. Lamination
c. Routing and drilling

2. Screen printing

3. Drying and firing 


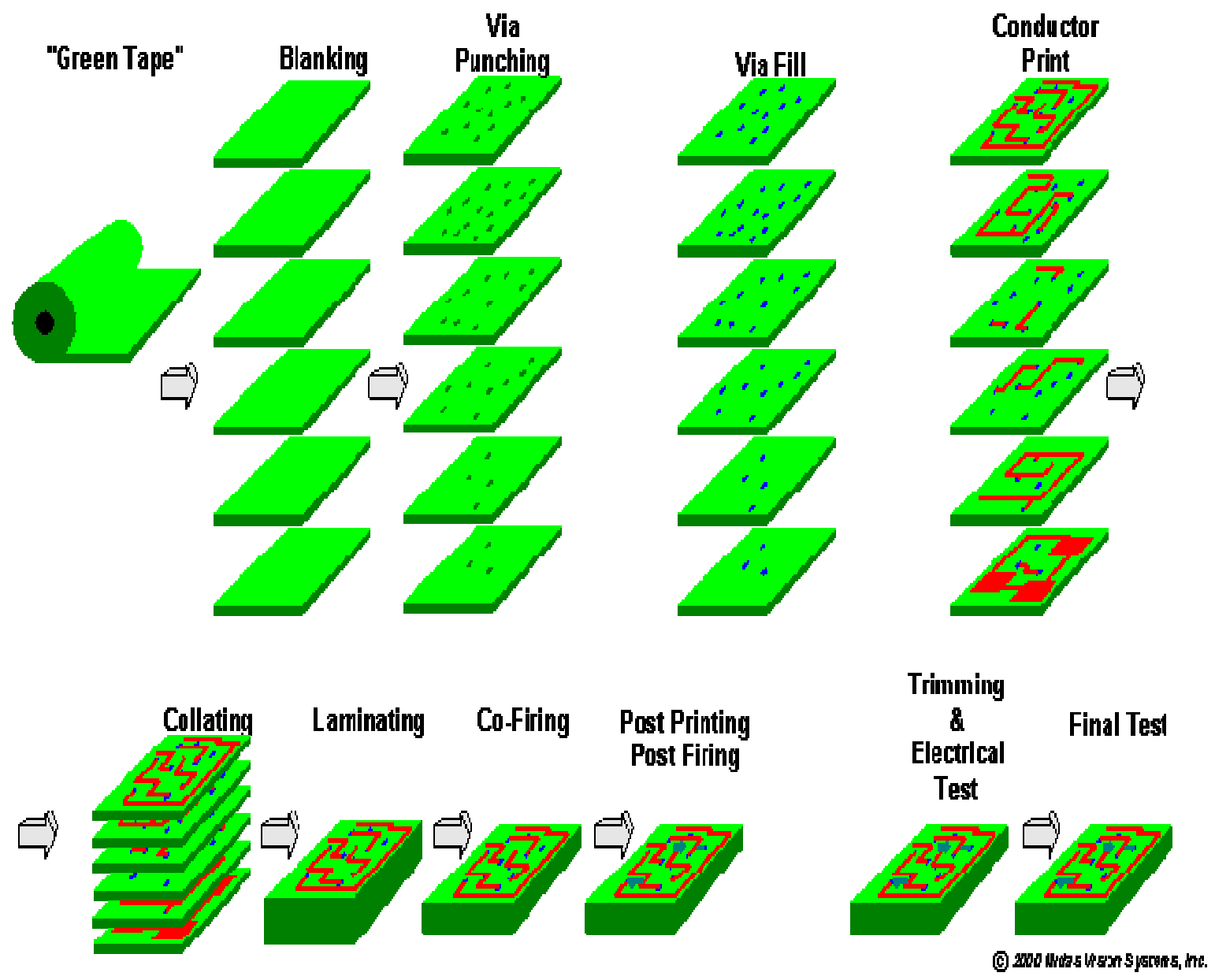

Figure 2. LTCC - General Process

\subsubsection{1 - Substrate Preparation}

The substrate preparation includes the cutting and stacking, the lamination and the machining. The cutting of each layer is a rough cut from a roll of green tape. The layers are cut into squares in order to obtain a uniform lamination. Three layers of green tape are collated and stacked in the lamination jig where the lamination process is done in order to bond the layers together and create a single structure. A Uniaxial Hydraulic Laminator is used for this process. The stack is pressed for 15 minutes at $75^{\circ} \mathrm{C}$ and a 
pressure of 3,000 psi times the area of the layers. Green tape layers have a shine and a dull side, during the lamination process is important to join the shine and the dull sides because of the solvents are more on the shine side. After the lamination process the machining using routing and drilling is done to transfer a previously designed pattern on the laminated structure by removing material from it. AutoCAD software was used to create the design patterns. The 2D patterns are converted to drill/route patterns using InstantCAM software. The model is drilled on the substrate that is held in the machine with vacuum through a porous stone. Patterns are machined on the laminated structure using OZO diversified micro-machining system.

\subsubsection{2 -Screen Printing Process}

The screen printing process is used to transfer a screen design to the substrate passing ink or paste through the screen mesh with a squeegee. The screen printing process was done with a MPM semi-automatic screen printer that is a flexible thick film printing machine. Single printing was used for elements as heater leads, sensor leads, and electrodes meanwhile double printing for elements as heater and sensor. Vision alignment, mechanical registration and vacuum through a porous stone were used to hold the substrate in place. A schematic representation of the screen printing process is presented in Figure 3.

Three elements are essential for the screen printing process: the substrate, the ink and the screen. The substrate corresponds to the laminated and drilled structure where the ink is going to be deposited. The inks used are thick film inks. For the elements as heater, electrodes and leads commercial inks are available. This was not the case for the sensor 
inks, and it was necessary to fabricate them. Details on the fabrication can be found on section 3.2.2 Sensor Inks Fabrication. In relation with the screen there are different factors to consider before its selection which are discussed in the next section.
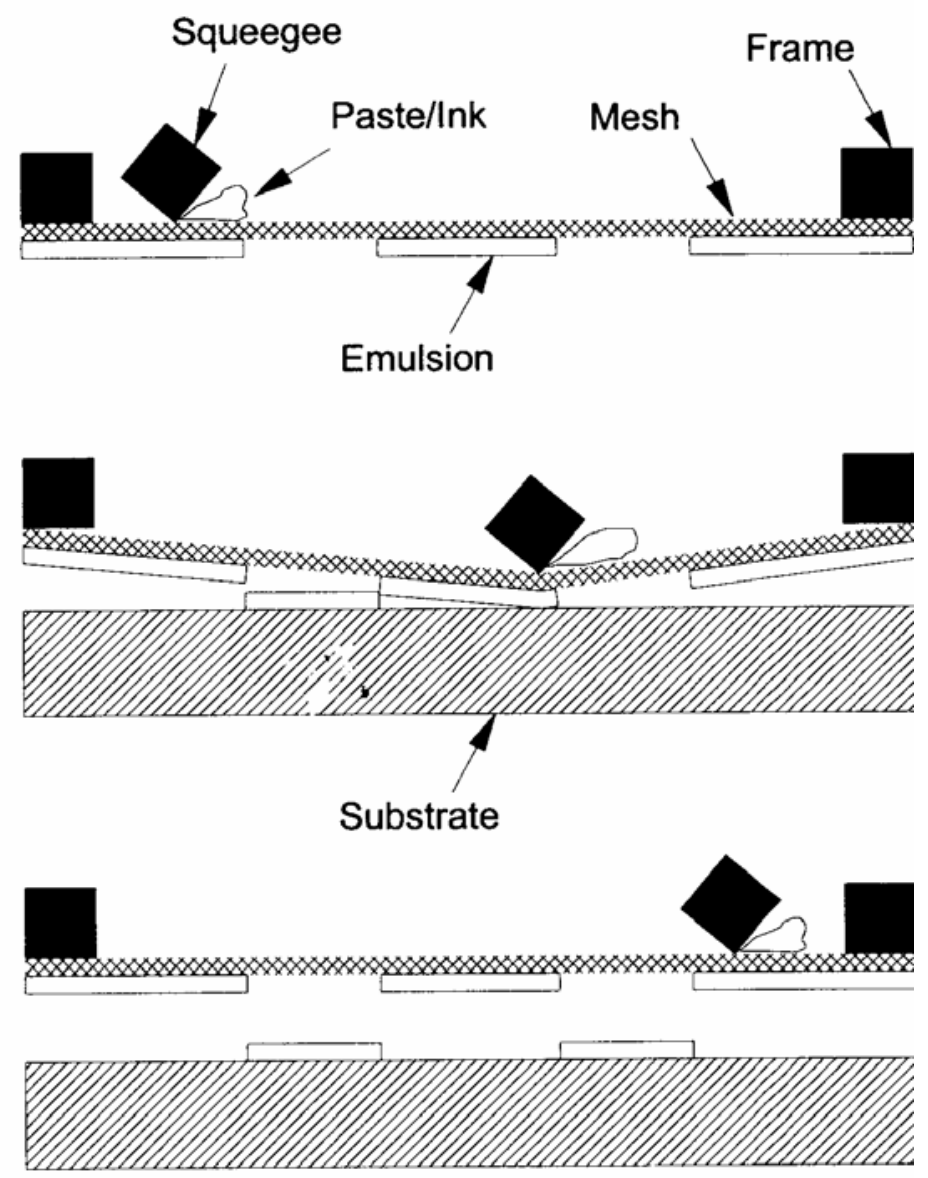

Figure 3. Screen Printing Process

\subsubsection{1 -Screen Considerations}

Some of the factors to consider for the screen selection include: frame size, mesh, mesh angle, emulsion type and emulsion thickness. The screen mesh is defined as the number of openings per inch. The wire diameter contributes to the wet print thickness. The mesh is selected based on the feature size to be printed, the wet print thickness desired, and the 
type of paste to be printed. Finer features require finer wire diameters. A coarse mesh is generally more difficult to image because of its thickness and because of the number of wires available to support the image. Finer wire diameters will produce thinner prints and this may be necessary to allow better image resolution in fine line patterns. Paste solids content and viscosity are decisive for the mesh choice.

The mesh is mounted to the frame and it is necessary to select the mesh angle that refers to the wires position, if they are perpendicular to the sides of the frame, it is specified as 90 degrees. Other angle selections, 45 and 22.5 degrees are standard recommendations for better tension distribution and longer screen life. Angling the mesh also helps to eliminate wire and pattern interference during printing.

The final factor to consider is the emulsion or stencil that is used to coat the mesh with an ultraviolet negative photosensitive organic emulsion that is subsequently photopatterned. It is important to define the emulsion type and the emulsion thickness that is the amount of emulsion build-up applied to the mesh. The final printed wet thickness is a combination of the material deposited by the mesh and the material deposited by the emulsion. Emulsion thickness can be varied to adjust wet print thickness.

The screens used during the fabrication process are standard emulsion type thick film screens. They are developed by transferring the pattern from 2D artwork using UV light box. The artwork was created using AutoCAD software and printed on clear transparency sheets using a laser printer. The sheets are attached to the screen and the artwork is transfer from the transparency to the screen using a UV light box for four minutes due to the emulsion works with light sensitive material and it hardens when exposed to ultraviolet light. During the photodefinition, ultraviolet light is exposed through a 
positive photomask of the desired pattern. The emulsion that is exposed hardens, while the unexposed emulsion remains soluble to water. After the artwork is transferred to the screen, this is flushed with pressurized water and all the areas of the emulsion that were not exposed to ultraviolet light are dissolved, leaving an open pattern of screen identical to the original artwork. It is important to keep a regulated water pressure to avoid ruining the screen.

An inspection of the screen is necessary to detect any visible defect before it is dry and cured by exposing it to ambient room light for a period of 24 hours. During the fabrication process one screen per each element (heater, heater leads, sensor, sensor leads, and electrodes) was fabricated. The screens used are precoat, stainless steel material, 325 mesh, $45^{\circ}$ mesh angle, 0.6 emulsion thickness and E11 emulsion type.

\subsubsection{3 -Drying and Firing Process}

After the screen printing process the ink needs to be dry. Therefore, the drying process has to be done separately for every element. The substrate is dried for $10 \mathrm{~min}$ at $125^{\circ} \mathrm{C}$ in a Single Wall Transite Oven and then the next element or a second layer of the same element is printed and dried. The alignment of a second layer or a new layer is a time consuming process and it is crucial for an optimum Isotemp Programable Force-Draft Furnace. The firing process activates the adhesion mechanism between the ink and the substrate and allows the organics burn out from the tape. For every substrate and ink there is a particular firing profile cycle. The cycle for the substrate used in this research is as follows: 
1. Increase temperature from room temperature to $400^{\circ} \mathrm{C}$ at a rate of $1{ }^{\circ} \mathrm{C} / \mathrm{min}$.

2. When the temperature of $400^{\circ} \mathrm{C}$ is reached maintain it for $30 \mathrm{~min}$.

3. Increase temperature to $875^{\circ} \mathrm{C}$ at a rate of $10^{\circ} \mathrm{C} / \mathrm{min}$.

4. When the temperature of $875^{\circ} \mathrm{C}$ is reached maintain it for $30 \mathrm{~min}$.

5. Reduce temperature to $100^{\circ} \mathrm{C}$ at a rate of $10^{\circ} \mathrm{C} / \mathrm{min}$.

6. The substrate is removed from the oven after room temperature is reached.

It is important to keep all the equipment and instruments used during the fabrication process thoroughly cleaned, and during every step an inspection with the aid of a suitable light source or a visual inspection on the substrate and the elements has to be done to verify alignment, no visible defects, and accordance with the parameters established. Microscope and Scanning Electron Microscope (SEM) are also used to analyze the behavior and performance of each material including the substrates and the inks used for the heater, leads, electrodes and the sensor material. Once the device has been completed the electrical connections are hand attached using copper wires and regular solder. The device is ready to be tested after its complete final inspection. The fabrication process for one sensor is summarized in Table 2 .

\section{2 - Electrical Considerations}

Before the experimental set-up design it was necessary to consider different electrical characteristics [48, and 49]. The first one is the resistance. The sheet resisitivity is commonly expressed in terms of ohms per square $(\Omega / \square)$ units. It is defined as the bulk resisitivity divided by the thickness of the resistor. Thickness is typically a constant in thick film technology. 
Table 2. Fabrication process

\begin{tabular}{|l|c|}
\hline \multicolumn{1}{|c|}{ Process } & Time (hr) \\
\hline \hline Cutting and Stacking & 0.5 \\
\hline Lamination & 1 \\
\hline Machining & 1 \\
\hline Screen printing - Heater (Double) & 1 \\
\hline Dry - Heater (Double) & 0.5 \\
\hline Screen printing - Heater leads & 0.5 \\
\hline Dry - Heater Heater leads & 0.25 \\
\hline Screen printing - Electrodes & 0.5 \\
\hline Dry - Electrodes & 0.25 \\
\hline Screen printing - Sensor leads & 0.5 \\
\hline Dry - Sensor leads & 0.25 \\
\hline Screen printing - Sensor (Double) & 1 \\
\hline Dry - Sensor (Double) & 0.5 \\
\hline Fire & 15 \\
\hline Electrical Connections & 1 \\
\hline Total Time (including dead time) & $\mathbf{3 0}$ \\
\hline
\end{tabular}

For thick film resistors the electrical resistance is expressed as Equation 1.

$$
R=R_{S} n
$$

Where:

\section{Equation 1. Electrical Resistance}

$R: \quad$ Resistance

$R_{S}: \quad$ Sheet resistivity

$n: \quad$ number of squares

The number of squares is a dimensionless quantity defined as resistors length (L) divided between resistors width (W). Considering that the length is equal to the width, one square is $\mathrm{L} / \mathrm{W}$, two squares $2(\mathrm{~L} / \mathrm{W})$, and so on. It can be seen that the value of the resistance is independent of the size of the element (for a specific thickness) and it depends only on the number of squares. 


\subsection{1 - Depletion Region}

The depletion region is the area of a semiconductor where all of the mobile carriers have been swept out by an electric field. The depletion region in the sensor is known as vacancy formation. A vacancy is the absence of an atom in the position it should occupy in the periodic array called crystal. To form the depletion region is necessary to assure high temperature and the application of a constant bias voltage at the two sensor electrodes. The temperature defines the number of vacancies formed and high temperature is necessary to assure that the maximum number of vacancies is formed within the material. The recommended temperature is $90 \%$ of the sensor material melting temperature. Once the desired temperature is achieve the bias voltage is apply and the current flow within the sensor material is measured.

To know when the depletion region is formed in the sensor it is necessary to plot current vs. time. At the beginning the current increases to a very large number and immediately decrease exponentially until it reaches stabilization after some time. Once the current value is presenting a minimum change or not change it means that the depletion region is stable and the maximum number of vacancies has been created. After the depletion region stabilization the sensor is ready to measure the gas presence.

\subsection{2 - Electrical Circuits}

A four leaded sensor circuit was designed with two independent electrical circuits: one for the heater and one for the sensor. It was necessary that the sensor element and the heater element were not electrically coupled in order to obtain a direct determination of the sensor response to the gas presence due to the sensor element alone without 
interferences from the heater part. Figure 4 shows a schematic representation of the electrical circuits.
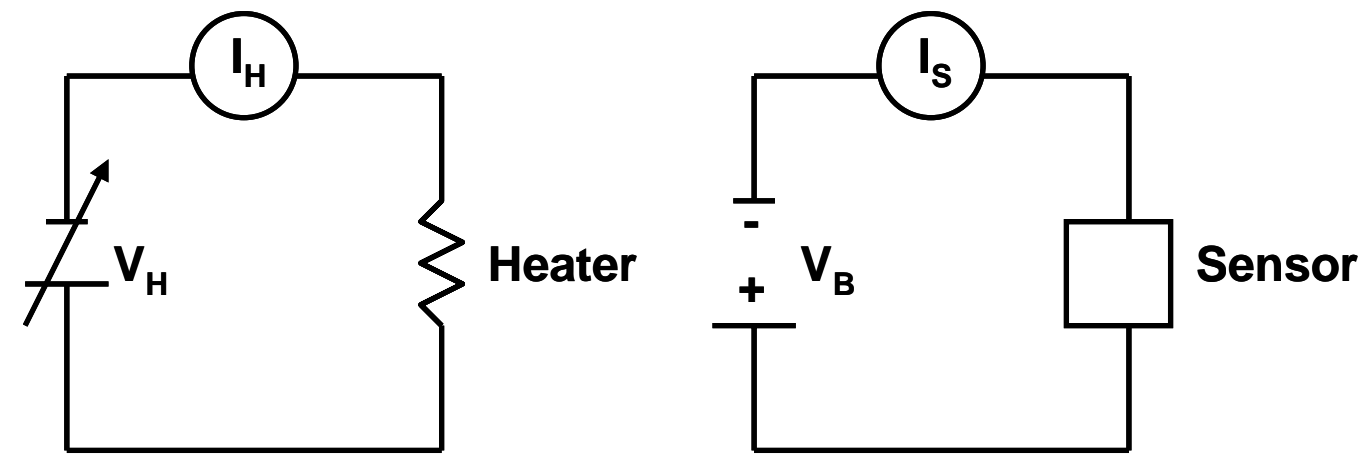

Figure 4. Electrical Circuits: Heater (left) - Sensor (right)

For the heater it is necessary to apply a variable voltage $\left(\mathrm{V}_{\mathrm{H}}\right)$ using a power supply to increase its temperature to the required value and the heater current $\left(\mathrm{I}_{\mathrm{H}}\right)$ is measured. For the sensor a bias voltage $\left(\mathrm{V}_{\mathrm{B}}\right)$ is applied between the two sensor element electrodes and the current value $\left(\mathrm{I}_{\mathrm{S}}\right)$ is measured. After assure the depletion region stabilization, the voltage in the heater is set to reach the operating temperature desired.

The first experimental set-up used to determine the electrical parameters for the heater and sensor at different temperature values consisted of two regulated DC power supplies that were manually operated, and digital multimeters to measure resistance and current. Once the ranges for voltage, current, and resistance values for the heater and the sensor were defined a programming using LabView software and hardware was done in order to set the data acquisition system.

It was difficult to obtain an accurate measurement for the heater temperature because of the lack of an independent way to measure it. This was due mainly to the high temperature range used and the small heater area. The use of thermocouples did not give an accurate value of the temperature because the thermocouple wires draw heat from the 
heater given a false measurement. An infrared pyrometer (IR) has its focal point bigger than the heater size resulting again in a false response, in addition the temperature range goes only to $500^{\circ} \mathrm{C}$ and higher temperatures are required. The method of measuring the heater resistance and its temperature in an oven was also inaccurately. A good estimation for the heater temperature was done using two electrical characteristics: the temperature coefficient of resistance and the dissipation constant, both are explain in the following sections.

\subsection{3 - Temperature Coefficient of Resistance}

The temperature Coefficient of Resistance (TCR) is usually expressed in parts per million per degree Centigrade $\left(\mathrm{ppm} /{ }^{\circ} \mathrm{C}\right)$ units. It is a measure of how much the resistance value changes as its temperature changes. TCR can be calculated using Equation 2.

$$
T C R=\left(\frac{R-R_{O}}{R_{O}}\right)\left(\frac{1}{T-T_{O}}\right) 10^{6}
$$

Where:

\section{Equation 2. Temperature Coefficient of Resistance}

\section{TCR: Temperature Coefficient of Resistance}

$R: \quad$ Resistance at $\mathrm{T}$

$R_{O}: \quad$ Resistance at $\mathrm{T}_{\mathrm{O}}$

T: $\quad$ Test temperature

$T_{O}: \quad$ Base temperature (standard value: $25^{\circ} \mathrm{C}$ )

The TCR value can be experimentally determined and knowing the TCR the resistance at a specific temperature can be calculated using Equation 2. However TCR alone is not enough to determine the voltage required to reach that temperature unless the design 
includes a second heater used as a temperature sensor. This is unnecessary and it complicates the sensor fabrication. In order to calculate the voltage at which the heater needs to be operated to reach a certain temperature it is necessary to know an additional property known as dissipation constant $(\delta)$.

\subsection{4 - Dissipation Constant}

The dissipation constant $(\delta)$ is expressed in terms of degree Celsius per watts $\left({ }^{\circ} \mathrm{C} / \mathrm{W}\right)$ units. It is the ratio at a specified ambient temperature of a change in power dissipation to the resultant body temperature change. The dissipation constant can be calculated using Equation 3.

$$
\delta=\frac{T-T_{O}}{P}
$$

Where:

\section{Equation 3. Dissipation Constant}

\section{$\delta: \quad$ Dissipation constant \\ T: $\quad$ Test temperature \\ $T_{O}: \quad$ Base temperature \\ P: $\quad$ Power}

The $\delta$ value can be experimentally determined and knowing $\delta$ the power can be calculated using Equation 3.

In order to operate the heater it is necessary to know the voltage required to increase the temperature until the desired value. Knowing the resistance and power at the test temperature (equations 2 and 3 respectively) the voltage can be calculated by Equation 4 . 


$$
V=\sqrt{R P}
$$

Where:

\section{Equation 4. Voltage at Test Temperature}

\section{$V: \quad$ Voltage}

$R: \quad$ Resistance at test temperature

P: $\quad$ Power at test temperature

\section{3 - Experimental Set-Up}

After the sensor fabrication, its ability to detect halogen based gases as well as the evaluation of different factors as electrodes size, firing temperature, working temperature, different sensor material combinations, power consumption, and gas concentrations have to be measure. It is necessary to test the sensor in a controlled environment where the sensor is subjected to known quantities of the specific gas. Another concern is the high temperature required for the sensor work, and the guarantee that disturbances in the air will not affect the sensor behavior. Therefore, the experimental set-up includes a tube furnace to generate the working temperature required. After the sensor behavior has been defined a heater was placed in the opposite side of the sensor and using the same set-up the sensor was tested keeping the furnace off during the experiments.

A critical element during the design of the experimental set-up was the chamber where the sensor is going to be placed. The tube furnace contains a ceramic tube that was used for this purpose. Two covers were designed and constructed in aluminum for each end of the ceramic tube: one had one port to allow the gas entrance and the other cover had two ports: one for the gas run off and the other to place the sensor inside the chamber. The sensor is hold by a connector that is attached to a PCB (Printed Circuit Board) to easily 
connect the sensor to a data acquisition system. Up to 6 different sensors can be accommodated with its own parameters. The board was fabricated by CPS Products, Hialeah. The experimental set-up also includes the gas tank (R-134a 10000 ppm), air tank, pipes, data acquisition system and computer. A schematic representation is presented in Figure 5.

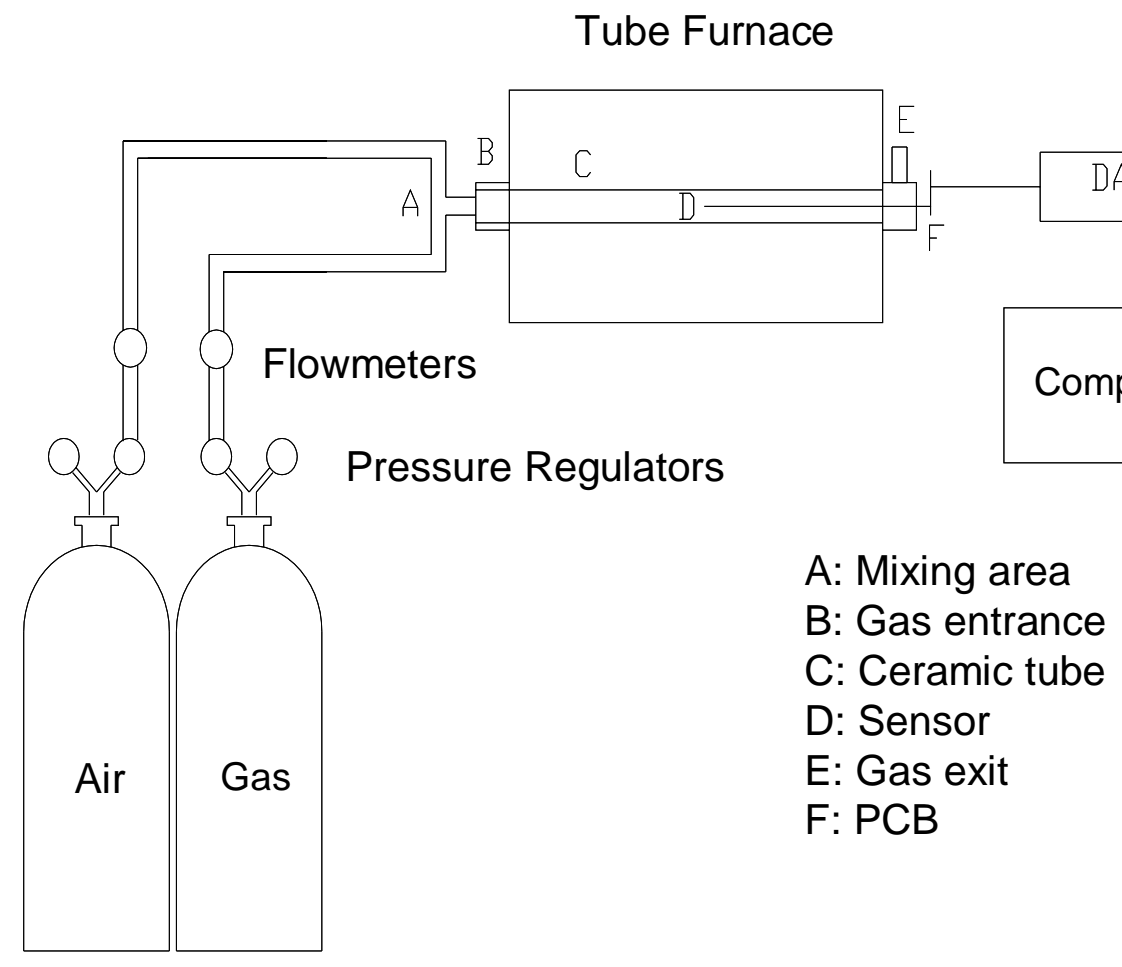

Figure 5. Experimental Set-Up

The gas and air tank are connected to the pressure regulator and flowmeters. The gas and air travel through separate pipes until both fluids are combined in the mixing area that is connected to the port in the ceramic tube cover. The board in which the sensor is plugged is connected to a data acquisition system (LabView software and hardware) which is connected to a computer. Air is used to clean and purge the system and also to combine 
with the R-134a to produce different gas concentrations. Pictures of the experimental setup are presented in appendix 1.

\section{4 - Test Procedure}

The procedure to test the sensor using the tube furnace as the heat source is as follows:

- Clean the chamber with air to avoid any residues of the gas.

- Turn on the furnace until the desired operating temperature is reached.

- Verify the connections from the wires to the data acquisition system.

- Turn on the data acquisition system to set the electrical parameters.

- Place the sensor in the chamber hold.

- Apply the bias voltage to the sensor until the depletion region is stable.

- Introduce gas into the chamber.

- Save the registered results.

The procedure to test the sensor using the heater is as follows:

- Clean the chamber with air to avoid any residues of the gas.

- Place the sensor in the chamber hold.

- Verify the connections from the wires to the data acquisition system.

- Turn on the data acquisition system to set the electrical parameters.

- Apply voltage to the heater until the temperature for the depletion region is reached.

- Apply the bias voltage to the sensor until the depletion region is stable.

- Change the heater voltage to reach operating temperature.

- Introduce gas into the chamber. 
- Measure sensor current.

- Save the registered results. 


\section{CHAPTER 3 - DESIGN CONSIDERATIONS}

Design of modern electronic devices requires consideration of four important properties. They must be small, fast, low cost and low power devices. These requirements are valid for gas sensor design as well. The sensor design joins two developments: the development of a heated ceramic sensor and a micro heater. The original heater design was a modification of a previous work done at FIU. The final heater and sensor design was an iterative process where several modifications where added in order to obtain the minimum operating temperature that represents minimum power for the heater, and an accurate response from the sensor to the gas presence.

\section{1 - Sensor Design}

The sensor operation requires high temperature values for two processes: to decompose the halogen gas and to achieve the depletion region within the sensor. For the sensor design three elements were required: sensor, electrodes, and leads. The final sensor was designed as a square element, and the final electrodes and leads were designed as two parallel lines. The leads are used to apply the bias voltage required to form the depletion region as well as to measure the current flow when the sensor detects the gas presence. The design of the artwork for each sensor element can be seen in Figure 6.

As it was explained in section 2.3 Experimental Set-Up, the sensor was evaluated first using a tube furnace. This is the reason why the design includes long leads in order to place the sensor element in the center of the tube. Additionally, three sensors were printed in each side of the substrate in order to evaluate six independent sensors simultaneously. One sensor side arrangement can be observed in Figure 7. 


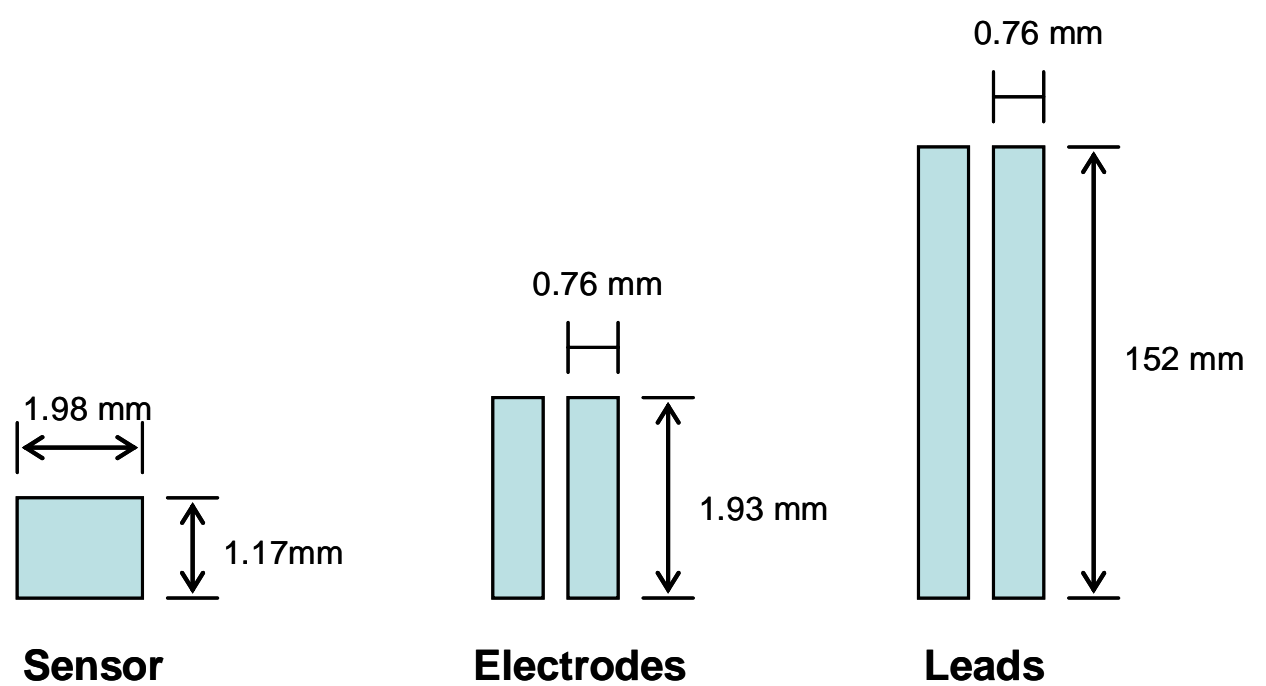

Figure 6. Sensor Elements Design

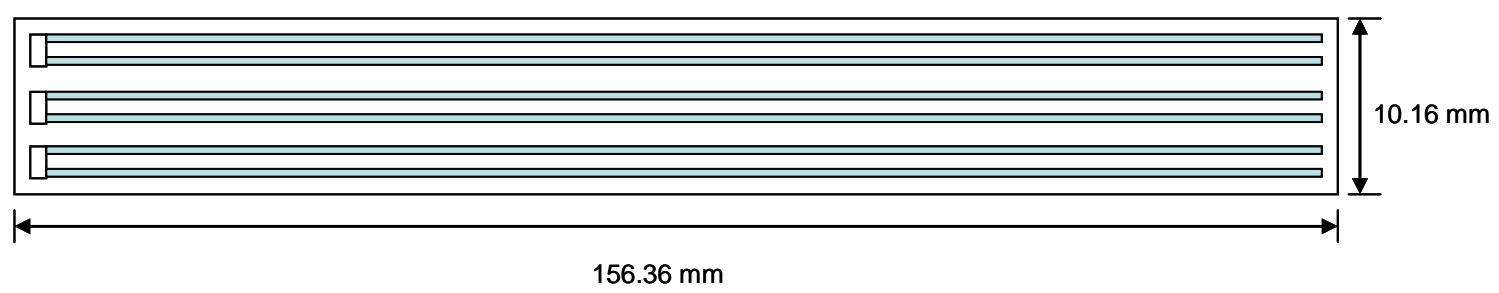

Figure 7. Sensor Arrangement (three sensors per side)

After the sensor elements design was completed it was necessary to select the substrate material as well as the thick film ink for each element. This was an iterative process in which different LTCC materials were tested with different inks for each element. Five LTCC tapes from different companies were considered. The tapes are named: DuPont 951, Ferro A6, Heraeus CT 2000, Heraeus CL91-8242, and Heraeus Heralock. Different inks including pure $\mathrm{Pt}, \mathrm{Pt}+$ glass, $\mathrm{Pt}+\mathrm{Pd}, \mathrm{Pt}+\mathrm{Ag}, \mathrm{Pt}+\mathrm{Pd}+\mathrm{Ag}$, and $\mathrm{Au}$ were tested for the electrodes and leads where good conductivity and stability at high temperature was required. 
The substrate was finally fabricated out of three layers of Heraeus CL91-8242 that shows minimum shrinkage on firing and was compatible with the ink for the leads, electrodes and sensor. The total thickness for the substrate after the lamination and firing processes is approximately $270 \mu \mathrm{m}$. The electrodes were printed with Heraeus CL11-5100, which is

pure Pt. The leads were printed with Heraeus C4740 which contains Ag and 1\% Pt. The electrodes and leads were single printed due to the surface density of this layer is not as important as within other elements. The firing process for electrodes and leads was cofire. The electrodes and leads thickness after firing are 10 and $8 \mu \mathrm{m}$ respectively.

For the sensor ink there was no any commercial product available. Therefore it was necessary to fabricate such ink. The fabrication process for the sensor ink is explained in detail in the next section.

\section{2 - Sensor Material}

To determine the material that would be a good candidate for the sensor ink it was necessary to focus in the work mechanism for the sensor. It was known that after the depletion region was stable, an equilibrium concentration of both anion and cation vacancies will occur within the sensor. It was also known that at high temperature the halogen gas will decompose and react with the sensor material disturbing the equilibrium reached. Therefore, to find a sensor material candidate it was necessary to know the halogen gases behavior.

Halogens are the best-defined family of chemical elements. Chemically they closely resemble one another; they are nonmetallic and form monovalent negative ions. They also exhibit an almost perfect gradation of physical properties. Halogens correspond to the chemically active elements found in group VIIa of the periodic table: Fluorine (F), 
Chlorine (Cl), bromine (Br), iodine (I), and Astatine (At). Focus for this work was on F a pale yellow gas, the least dense and chemically the most active, and $\mathrm{Cl}$, a yellow-green gas, more dense and less reactive than F. Therefore, if the halogen gas will generate anions the sensor material has to generate cations to create a reaction that will disturb the sensor equilibrium. It was concluded that elements from the first and second column in the periodic table would be considered. The selected elements were potassium (K), Lithium (Li), Sodium (Na), and Calcium (Ca). It was also known from previous works that silicates will be the ideal material for the sensor and therefore it was decided to fabricate the following silicate inks as sensor material:

- Potasium Silicate $\left(\mathrm{K}_{2} \mathrm{SiO}_{3}\right)$

- Lithium silicate $\left(\mathrm{Li}_{2} \mathrm{SiO}_{3}\right)$

- Sodium Silicate $\left(\mathrm{Na}_{2} \mathrm{SiO}_{3}\right)$

- Calcium Silicate $\left(\mathrm{CaSiO}_{3}\right)$

The materials selected are not commercial inks and therefore it was necesary to fabricate them. After several attempts to fabricate the silicate inks at the facilities at FIU the inks were fabricated in the facilities of Heraeus Company at Conshohocken, PA. Details on the fabrication are presented in the next section.

\subsection{1 - Sensor Ink Fabrication}

The raw material for an ink fabrication is the powder. Important factors for the powder selection include the specific composition, particle size, and degree of aggregation [50, 51]. Because particle size is difficult to specify and to agree on with a supplier, if the size is higher than the recommended $(\phi \leq 10 \mu \mathrm{m})$, it is necessary to reduce it. Therefore, the first stage includes the mixing, elimination of aggregates and reduction of the particle 
size. The most commonly used method of initial mixing is wet ball milling. A ball-mill is a barrel (usually a ceramic material) that rotates on its axis and is partially filled with a grinding medium in the form of sphere, cylinders or rods. The grinding medium is in such quantity that the rotation of the mill causes it to cascade, rather like the breaking of a wave on the shore, so that both a shearing and a crushing action is applied to any material lying between the milling elements. For efficient action the real volume of material to be milled should be about a third of that of the milling media. The volume of liquid must be sufficient to form a freely flowing cream, usually between 100 and $200 \%$ of the volume of the powder. Through the mixing the aggregates tend to eliminate and the particle size reduce to the required size. The particle size can be measure using a microscope, SEM, Finest of Grand Gauge (FOG), or a Particle Size Distribution Analyzer. The maximum diameter of the particle can be calculated by Equation 5 .

$$
d_{\max }=\sqrt{\frac{18 \cdot U_{r} \mu}{\rho \cdot r \cdot \omega}}
$$

Where:

\section{Equation 5. Maximum diameter for the particle}

$d_{\max }: \quad$ maximum diameter for the particle

$U_{r}: \quad$ Radial velocity

$\mu$ : $\quad$ Diameter of the media

$\rho$ : Density difference between particle and fluid

$\omega$ : Angular velocity of the particle

The critical speed can be calculated by Equation 6 . 
Where:

$$
N_{C}=\frac{423}{\sqrt{D-d}}
$$

\section{Equation 6. Critical Speed}

$N_{C}: \quad$ Critical Speed

$D: \quad$ Internal diameter of the mill

$d: \quad$ Diameter of the media

The mixing time depends on the original particle size and the ball mill speed. At different time intervals, small samples are taken from the jar in order to measure the particle size. After the required particle size is obtained, the media and liquid are remove from the jar and the powder is place in an extractor to dry through the evaporation of the liquid used during the milling. It is important to inspect periodically the jar and the media to avoid contamination conditions.

After the powder is dry it is necessary to add the vehicle, wetting agents, and solvents in order to fabricate the ink. The selection of the additives as well as the quantity depends on the powder characteristics. It is recommended to use a minimum of $70 \%$ solid powder and $30 \%$ total for the additives. To determine the particular percentage of additives it is necessary to mix a small sample of powder and additives using a shaker to obtain a good mix. After the shaker is necessary to use a three roll milling in order to obtain a good distribution and complete adhesion of the ink elements, during this process it is necessary to define how many passes and the pressure to be used.

After the three roll milling process, it is necessary to measure the viscosity, which shows if the ink can be screen printed. Once an acceptable viscosity value is reached (below 350 kcps), it is necessary to measure the viscosity for several days due to the viscosity can 
change with time. After the viscosity value is stable, it is necessary to do screen printing and drying to verify in the microscope if the printing is uniform on the substrate. The last factor to be considered for the ink is the appearance, which can be changed with additives. The desired quantity of ink can be fabricated after verifying the percentage of additives, milling parameters, viscosity, and printing uniformity.

For the four silicate inks fabricated, the particle size distribution was measure using a Horiba - Distribution Analyzer LA-910 equipment. Because of the particle size of the four silicate powders it was necessary to reduce it using wet milling. The equipment used for this purpose was a two ball milling (US - Stoneware) with a ceramic yard, the liquid was Isopropyl alcohol (IPA), and cylindrical media. Figure 8 shows the comparison for the size particle distribution before and after the two ball milling.
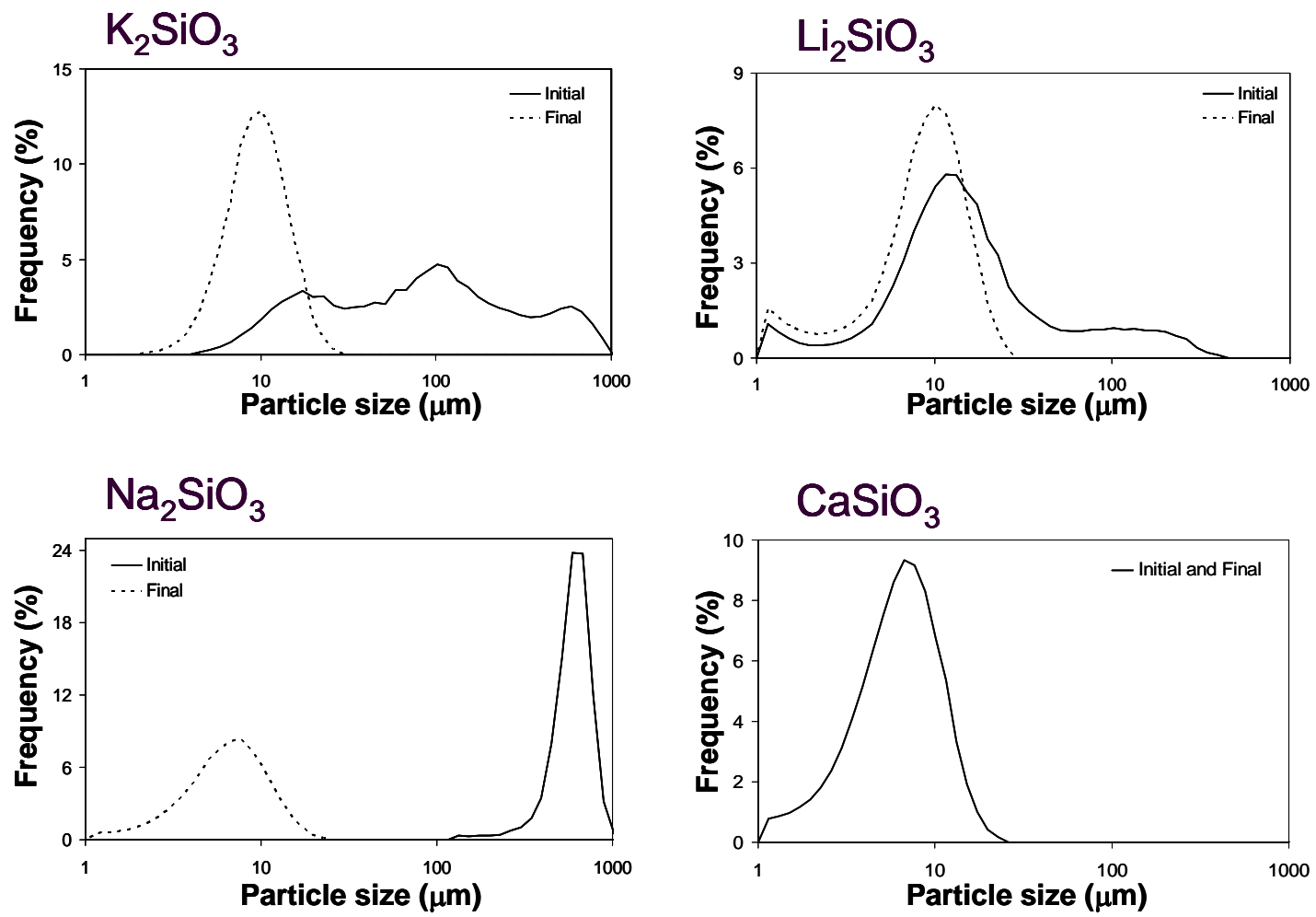

Figure 8. Particle Size Distribution - Powder Silicates 
The shaker used to mix was a SPEX 8000 Mixer/Mill. The vehicle used contains mainly: Butyl Dyglyme, Butyl Carbitol, Acetate Texanol. Different solvents and wetting agents were also added. The three roll mill was ceramic due to the four silicates where easily contaminated. For the four silicates two passes at medium pressure and three passes at thigh pressure were used. The viscosity for every ink is presented in Table 3. It is important to notice that for every ink different materials as well as percentages for vehicle, solvents and wetting agents were added.

Table 3. Final Viscosity

\begin{tabular}{|c|c|}
\hline Ink & Viscosity (kcps) \\
\hline \hline $\mathrm{Li}_{2} \mathrm{SiO}_{3}$ & 314 \\
\hline $\mathrm{Na}_{2} \mathrm{SiO}_{3}$ & 346 \\
\hline $\mathrm{K}_{2} \mathrm{SiO}_{3}$ & 335 \\
\hline $\mathrm{CaSiO}_{3}$ & 298 \\
\hline
\end{tabular}

\section{3 - Heater Design}

The heater is a key element in the sensor performance. Therefore, both sensor and heater have to be in close proximity. The heater was designed and fabricated on the substrate on the opposite side of the sensor to transfer the heat from the heater to substrate and finally to the sensor. The requirements for the micro heater includes stability, performance in temperature cycles, excellent thermal uniformity over the sensitive area, high thermal impedance to the ambient to insure low-power consumption and small chip dimensions. The design process starts with the artwork for the heater which includes four parts: heater, sensing heater, heater leads, and sensing heater leads. The heater itself has four 
passes in a serpentine shape. It is a thick film resistor with squared edges that are wider than the lines and chamfered at the corners, this is due to prevent the occurrence of current crowding and resultant thermal hot spots during operation. The ends of the heater are bigger than the passes to facilitate the leads attachment. Inside the heater there is a smaller heater that corresponds to a sensing heater used to measure the resistance to determine the heater temperature. The sensing heater has four passes too. The design is slightly different than the heater in order to bond the leads for both heaters. Finally, the leads are parallel and large contact pads attached to both heaters in one side and to bond wires for power supply and acquisition system at the other side, this side is bigger to facilitate the hand wires attachment. The heater leads are used to apply voltage and the sensing heater leads are used to measure the heater resistance. Figure 9 shows the design for the heater and the sensing heater to the left, follow by the leads and the combined design to the right.

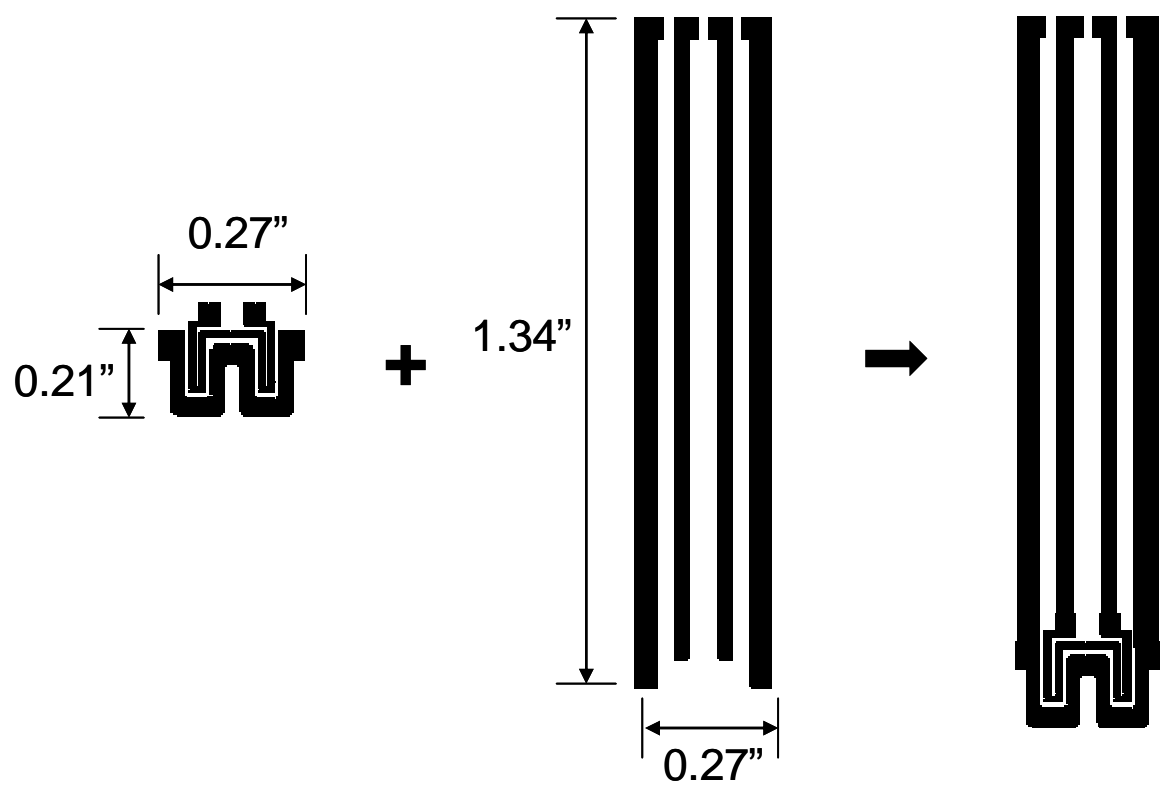

Figure 9. Original Heater Design 
For the inks selection it was know that the heater ink should contain Pt due to its stability at high temperature. The selected ink for the heater was Heraeus C4081, which contains Pt, Ag, and Pd. The leads ink has to be a conductive material and Heraeus C4740 which contains $\mathrm{Ag}$ and $1 \% \mathrm{Pt}$ was selected as leads ink. This design presented different problems such as high power consumption $(1.5 \mathrm{~W})$, low working temperature $\left(500^{\circ} \mathrm{C}\right)$, low stability and short life. After the analysis of different factors and several attempts it was concluded that three major modifications will be done on the heater: change of the ink, modification of the design and size reduction.

The ink change was due after concluded that the TCR for the heater ink was not linear relative to temperature over a wide range of temperature resulting in low stability and inaccurate values for the resistance and the heater temperature. The TCR was experimentally determined using an oven, thermocouples and a multimeter. A thermocouple was used to measure a more accurate value for the heater temperature than using the registered oven temperature. The heater was place on the oven with wires attached the multimeter to measure the resistance and to the thermocouple. A plot for Resistance vs Temperature was done and a non linear behavior was observed. It was concluded that this was due because the ink contained additional elements to Pt. Therefore, the ink was changed to Heraeus CL11-5100 that is pure Pt. For the new ink the plot for Resistance vs. Temperature was done using the same procedure and it was found that TCR for pure Pt ink is linear. The calculated TCR is approximately 2300 $\mathrm{ppm} /{ }^{\circ} \mathrm{C}$. Figure 10 corresponds to the plot for Resistance vs. Temperature for pure Pt ink. 


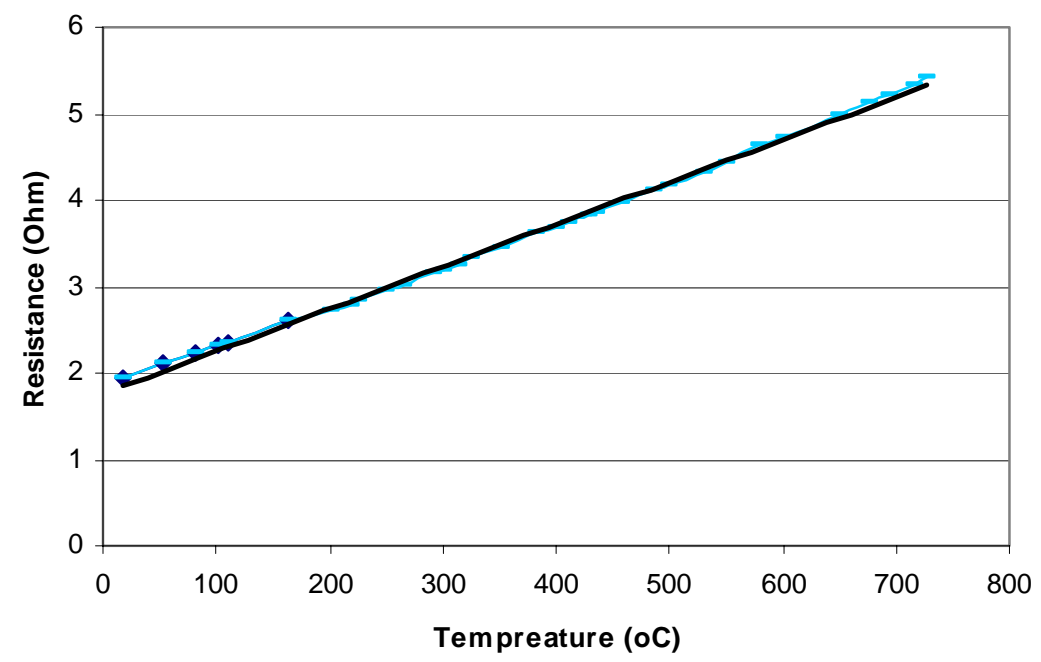

Figure 10. TCR - Pure Pt

In relation with the heater ink it was also concluded that double printing of Pt ink as well as a post fired process produces higher uniformity than single printing as well as a more dense film that could withstand instant on-off without burnout (Figure 11). The leads are single printing due to the surface density of this layer is not as important as it is within the heater. Thickness after firing for the heater and the leads are $10 \mu \mathrm{m}$ and $8 \mu \mathrm{m}$ respectively.

The final changes for the heater correspond to the modification of the design which is the elimination of the sensing heater and the heater size reduction. The sensing heater was eliminated because the heater temperature will be calculated using the TCR and $\delta$, in addition, the sensing heater was complicating the sensor fabrication due to the short space for alignment with the leads. The size reduction was done in order to reduce heating losses. The final heater and sensor design is presented in Figure 12. 

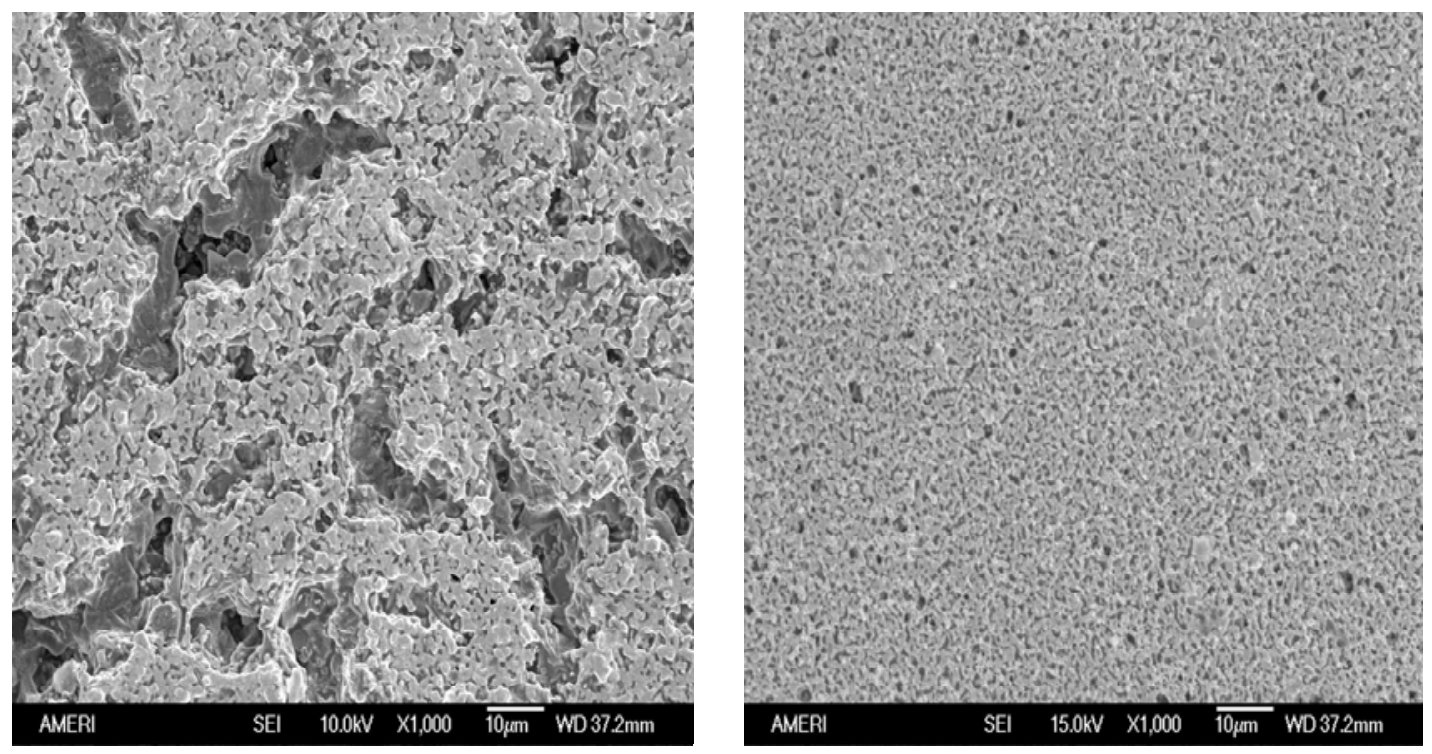

Figure 11. Heater Fired Structure: Single Printing (left) - Double Printing (right)
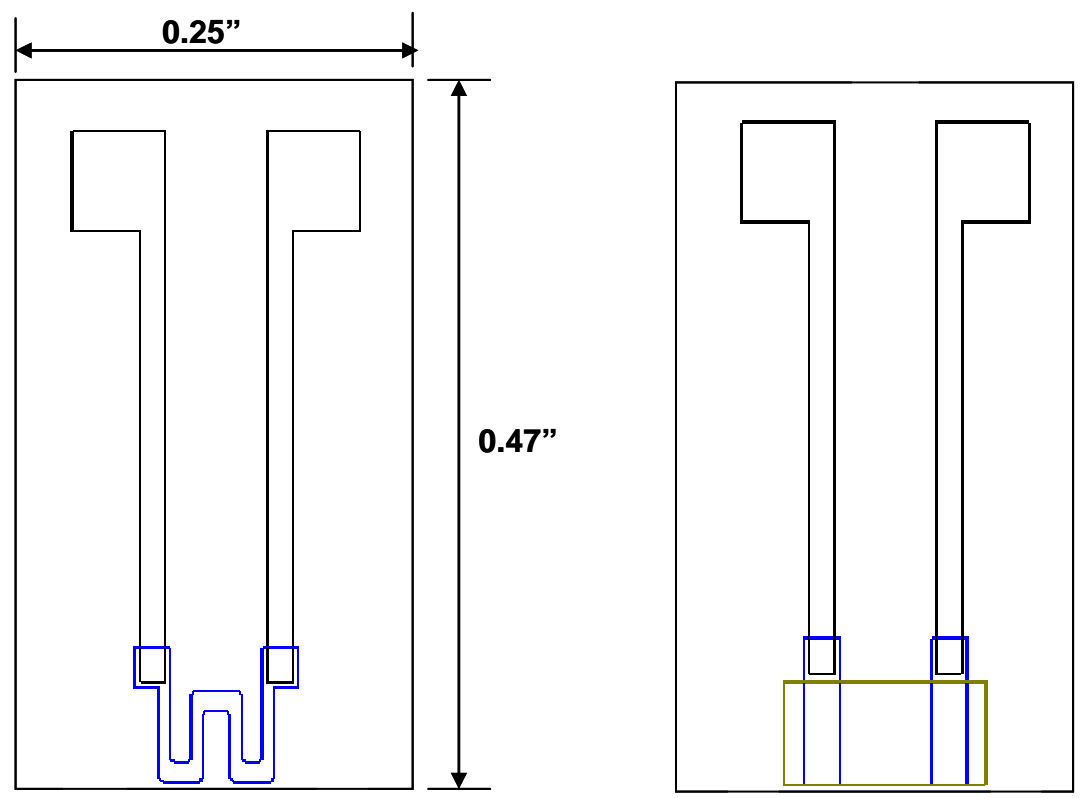

Figure 12. Final Heater (left) and Sensor (right) Design 


\section{CHAPTER 4 - EXPERIMENTAL RESULTS AND ANALYSIS}

For the experimental results the sensor inks fabricated: $\mathrm{Li}_{2} \mathrm{SiO}_{3}, \mathrm{Na}_{2} \mathrm{SiO}_{3}, \mathrm{~K}_{2} \mathrm{SiO}_{3}$, and $\mathrm{CaSiO}_{3}$ as well as several combinations between them were tested to determine their response to the gas. After the response was established the most appropriate ink or combination of inks to detect halogen gas was selected. Additionally, the experimental results includes the evaluation of different factors of the sensor performance including the

effect of the distance between the electrodes, firing temperature, operating temperature, bias voltage, gas flow, sensor size, and sensor life. The testing was done using the tube furnace experimental setup and a final test including the heater. The analysis for the sensor includes a modeling of the sensor as a resistor; thermodynamical calculations for the materials through a vacancy analysis and a reactivity analysis between the materials and the gas using Gibbs free energy. In addition, various mathematical fits were made to the experimental data to interpret the sensor response.

\section{1 - Sensor Behavior Description}

During the test of the sensor a graph of current versus time was obtained. A typical sensor behavior showing a sensor tested for first time as well as multiple tests are presented in Figure 13 and Figure 14 respectively. The first test was divided in four parts: the first part on the graph shows the formation of the depletion region in which there is not gas present. The second and third part corresponds to the sensor response to the gas. During the four part the gas stops running but remains inside the chamber. 


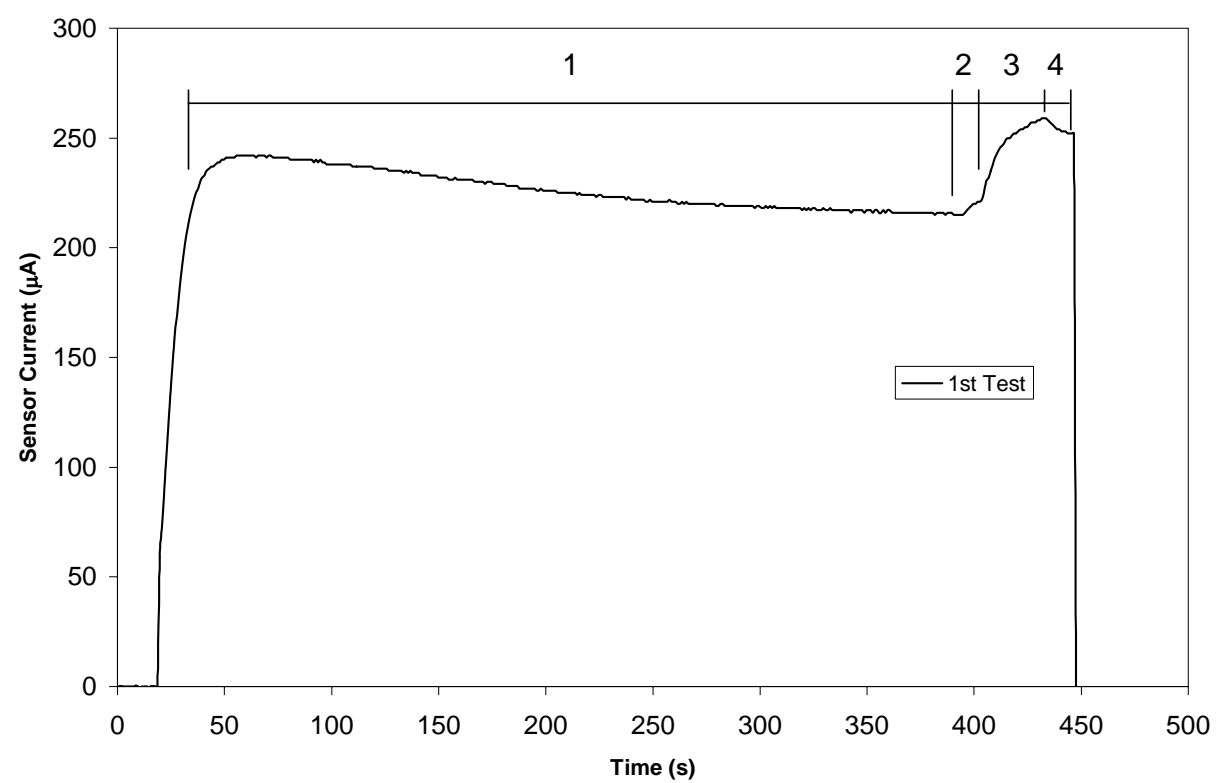

Figure 13. Sensor Behavior: First time test

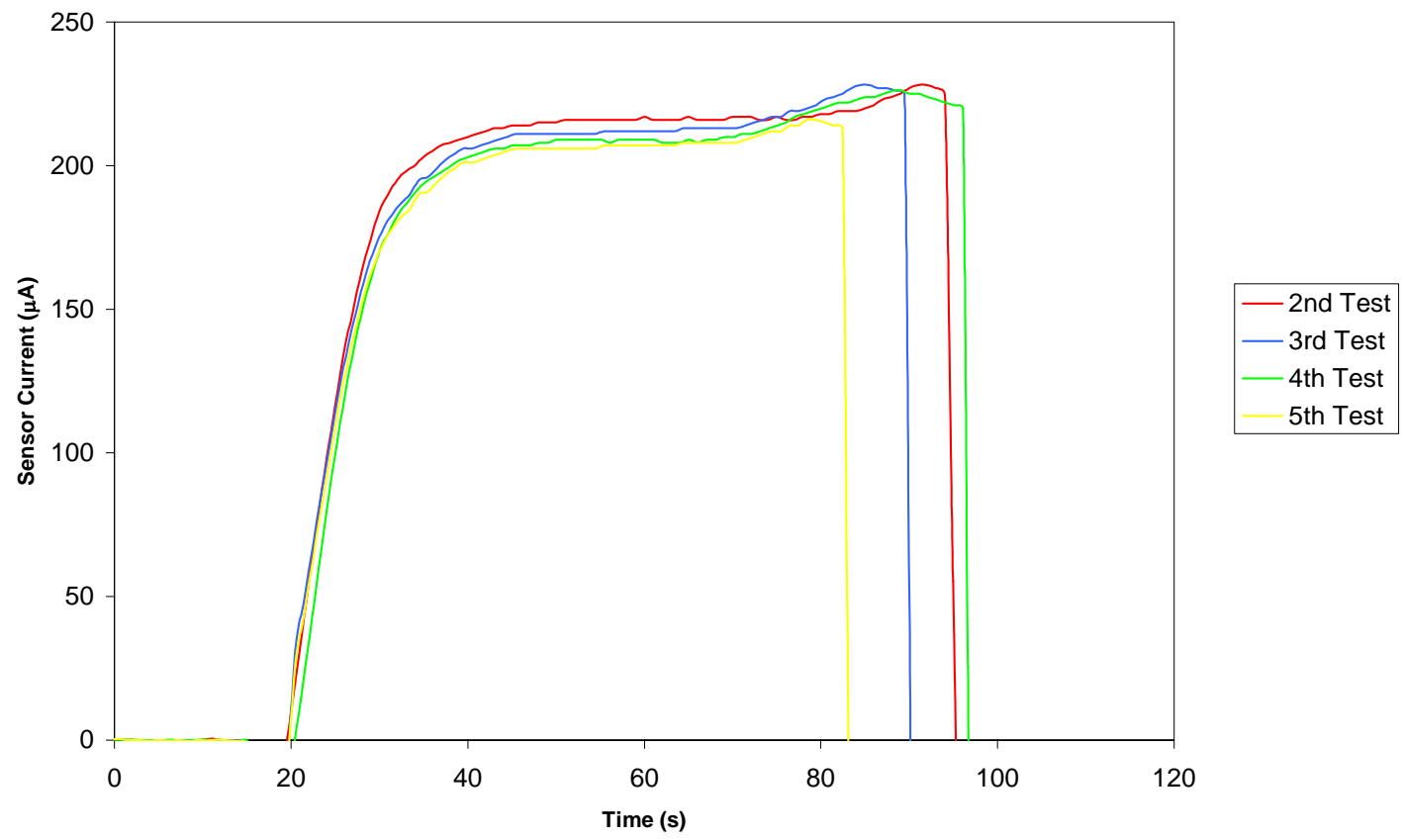

Figure 14. Sensor Behavior: Multiple tests

Figure 13 was divided in four parts. The first part corresponds to the formation of the depletion region, in which there is an arrangement of positive and negative charges until they are in equilibrium generating the current stabilization which means small current 
changes or no changes at all. The depletion region is obtained applying bias voltage and high temperature simultaneously. Comparing Figure 13 and Figure 14 it is observed the long time that a sensor tested for first time takes in achieving the stable current. Mobility of ions produce the changes in current, after the positive and negative charges are balance there is no more migration of ions and therefore the current is stable which is why during multiple testing the time to reach the stable current reduces approximately 10 times due to the positive and negative charges are already balanced. Additionally, the initial peak in current disappears during multiple testing of the sensor. The peak in current is due to inherent defects, impurities, and organics within the sensor which are burned out during the first testing and disappear during multiple testing.

The second and third part of Figure 13 corresponds to the sensor response to the gas. The second part occurs during approximately $8 \mathrm{~s}$, in which the sensor response has a linear trend and the third part that has an exponential shape. Both parts of the sensor response are in agreement with the diffusion mechanisms expected. Once the gas is in contact within the sensor the first mechanism corresponds to surface diffusion followed by bulk diffusion within the sensor. Finally, during the four part in Figure 13 the gas stops running but remains into the chamber. It is observed that the current returns to zero when the bias voltage is turned off. The stable current for the sensor before it is expose to the gas as well as the sensor response to the gas including surface and bulk diffusion were analyzed.

\section{2 - Sensor Analysis before Gas}

In order to analyze the sensor behavior before the gas is present the sensor inks fabricated ( $\mathrm{Li}_{2} \mathrm{SiO}_{3}, \mathrm{Na}_{2} \mathrm{SiO}_{3}, \mathrm{~K}_{2} \mathrm{SiO}_{3}$, and $\mathrm{CaSiO}_{3}$ ) were tested individually to determine the stable 
current and the time to reach stabilization. A modeling of the sensor as a resistor was done to calculate the current and compare with the experimental results.

The parameters used for testing were:

1. Sensor material:
a. $100 \% \mathrm{~K}_{2} \mathrm{SiO}_{3}$
b. $100 \% \mathrm{Li}_{2} \mathrm{SiO}_{3}$
c. $100 \% \mathrm{Na}_{2} \mathrm{SiO}_{3}$
d. $100 \% \mathrm{CaSiO}_{3}$

2. Sensor size: $1.98 \times 1.17 \times 0.30 \mathrm{~mm}$

3. Firing temperature: $875^{\circ} \mathrm{C}$

4. Operating temperature: $690^{\circ} \mathrm{C}$

5. Bias voltage: $3 \mathrm{~V}$

6. Electrodes size: $0.86 \times 2.43 \times 0.01 \mathrm{~mm}$

Every sensor was tested 5 times and the results for stable current and the time to reach stabilization are presented in Table 4. The values for the stable current correspond to the average for the five tests, however for the time to reach stabilization is the average without including the first test due to the long time for the depletion region formation during the first test as explained in the previous section.

Table 4. Results for Pure Materials before Gas

\begin{tabular}{|c|c|c|}
\hline $\begin{array}{c}\text { Sensor } \\
\text { Material }\end{array}$ & $\begin{array}{c}\text { Stable } \\
\text { Current }(\mu \mathrm{A})\end{array}$ & $\begin{array}{c}\text { Time for } \\
\text { Stabilization (s) }\end{array}$ \\
\hline \hline $100 \% \mathrm{~K}_{2} \mathrm{SiO}_{3}$ & 250 & 37 \\
\hline $100 \% \mathrm{Na}_{2} \mathrm{SiO}_{3}$ & 255 & 25 \\
\hline $100 \% \mathrm{CaSiO}_{3}$ & 258 & 35 \\
\hline $100 \% \mathrm{Li}_{2} \mathrm{SiO}_{3}$ & 206 & 31 \\
\hline
\end{tabular}


The material with the highest stable current or baseline corresponds to $\mathrm{CaSiO}_{3}$ follow by $\mathrm{Na}_{2} \mathrm{SiO}_{3}, \mathrm{~K}_{2} \mathrm{SiO}_{3}$ and finally $\mathrm{Li}_{2} \mathrm{SiO}_{3}$. These results were compared with values calculated through a modeling of the sensor like a resistor. The model with the equivalent resistant as well as a cross sectional view of the sensor, electrodes and substrate is presented in Figure 15.

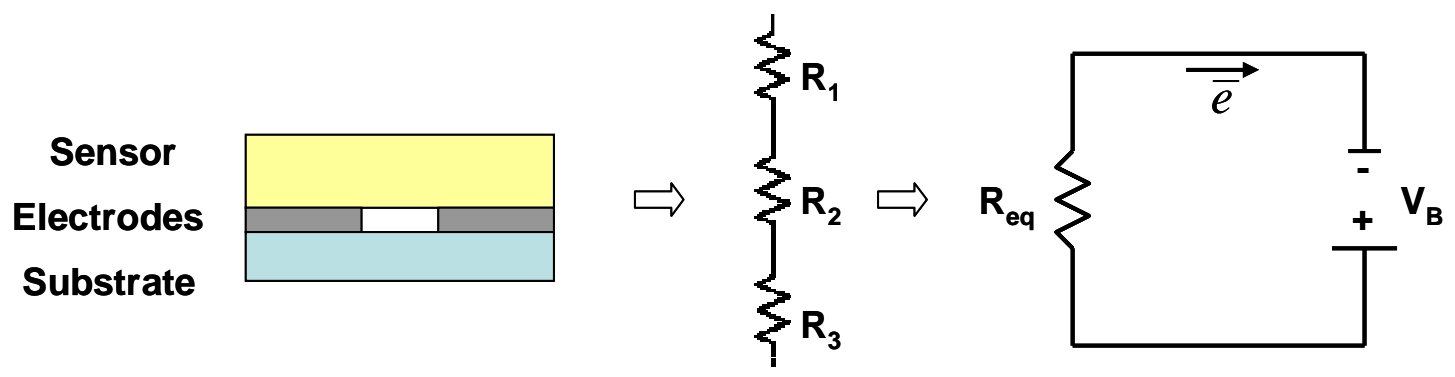

Figure 15. Sensor Modeling as a Resistor

Therefore the equivalent resistance is calculated adding $R_{1}+R_{2}+R_{3}$ that correspond to the resistance for the sensor, electrodes and substrate respectively. The resistance for every component is calculated using Equation 7.

$$
R=\frac{\rho \cdot L}{A}
$$

\section{Equation 7. Electrical Resistance}

Where:

R: $\quad$ Resistance

$\rho: \quad$ Resistivity

L: $\quad$ Length

A: $\quad$ Cross sectional area

Once the equivalent resistant for the sensor, electrodes and substrate is known and the voltage applied is defined, the current through the sensor can be calculated using Ohms 
Law. The experimental and calculated results for stable current are presented in Figure 16. The data used for the calculations is presented in appendix 2 (Table 21).

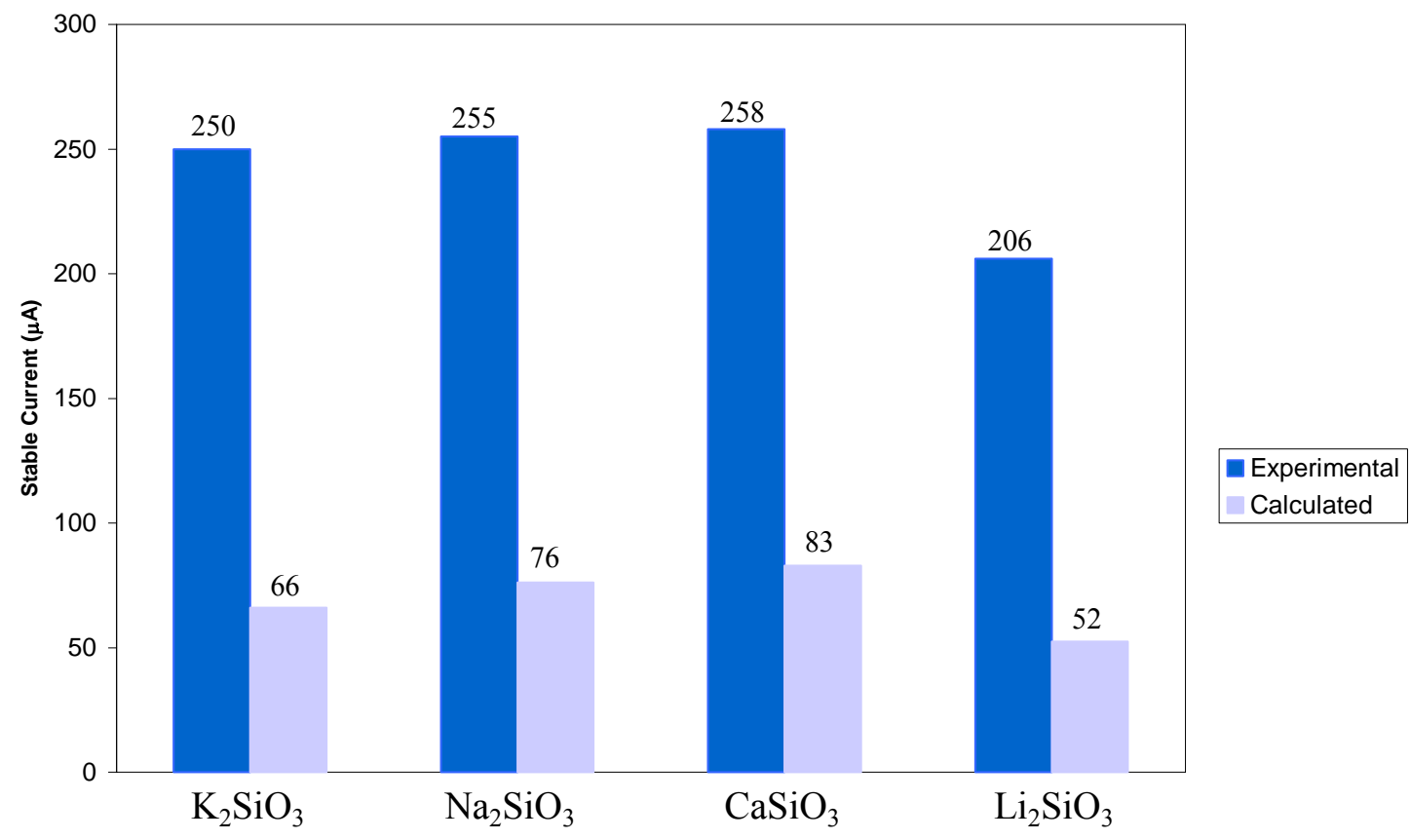

Figure 16. Experimental and Calculated Stable Current

The calculated results have the same trend that the experimental values for the stable current showing that the material with the highest stable current corresponds to $\mathrm{CaSiO}_{3}$ follow by $\mathrm{Na}_{2} \mathrm{SiO}_{3}, \mathrm{~K}_{2} \mathrm{SiO}_{3}$ and finally $\mathrm{Li}_{2} \mathrm{SiO}_{3}$. The calculated results are lower than the experimental due to the literature values for resistivity were found at $300^{\circ} \mathrm{C}[54,55$, and 56] and the experiments were done at $690^{\circ} \mathrm{C}$. The sensor with $100 \% \mathrm{Na}_{2} \mathrm{SiO}_{3}$ showed high instability in its results and stop responding during the second test in most of the cases.

\section{3 - Sensor Analysis with Gas}

The reactivity between the sensor material and the gas as well as the time for the sensor to respond to the gas were experimentally determined and compared with calculations 
using Gibbs free energy values. The surface diffusion was described with a linear trend and its slope was validated with the number of cations for every the sensor. Finally, the bulk diffusion results are presented and compared with a vacancy analysis.

\subsection{1 - Gibbs Free Energy Analysis}

The Gibbs free energy is one of the most important thermodynamic functions for the characterization of a system. It is a state function defined in terms of enthalpy, entropy, and temperature. It is expressed in terms of energy per mol $(\mathrm{KJ} / \mathrm{mol})$ and it is defined as a measure of the tendency of a chemical change to occur spontaneously. It is not a measure of the rate at which the reaction occurs $[57,58]$. Gibbs free energy can be calculated using Equation 8.

$$
\Delta G=\Delta H-T \Delta S
$$

Where:

\section{Equation 8. Gibbs Free Energy}

$\Delta G: \quad$ Gibbs free energy

$\Delta S_{f}: \quad$ Entropy of formation

$\Delta H_{f:} \quad$ Enthalpy of formation

T: $\quad$ Absolute temperature

The reactivity is the susceptibility of a substance to undergoing a chemical reaction or change. Gibbs free energy determines when a reaction is feasible. Natural process occurs spontaneously (exergonic process) if the associated change in $G$ for the system is negative $(\Delta G<0)$. Likewise, a system reaches equilibrium when the associated change in $G$ for the system is zero ( $\Delta G=$ zero), and no spontaneous process (endergonic) will occur if the change in $\mathrm{G}$ is positive $(\Delta G>0)$. For any reaction: 


$$
A+B \rightarrow C+D
$$

Where $\mathrm{A}$ and $\mathrm{B}$ correspond to the products and $\mathrm{C}$ and $\mathrm{D}$ to the reactants. Gibbs free energy for a reaction is expressed by Equation 9.

$$
\Delta G=\sum G_{P R O D U C T S}-\sum G_{R E A C T A N T S}
$$

\section{Equation 9. Gibbs Free Energy for a Reaction}

In order to calculate $\Delta G$ for the reaction between the silicates and the halogen gas it is necessary to define the reactions between them. After the depletion region is formed and the sensor is in equilibrium of positive and negative charges. The halogen gas is put in contact with the sensor and because of the high temperature the gas will dissociate separating the $\mathrm{F}$ atoms which will react with the sensor material. In order to write the general reaction $\mathrm{M}$ will represent the cation $(+)$ from the sensor material $(\mathrm{K}, \mathrm{Li}, \mathrm{Na}$ or $\mathrm{Ca}$ ) and $\mathrm{F}$ is the anion (-) from the halogen gas. Due to its higher thermodynamic free energy of reaction $\mathrm{F}$ will react with $\mathrm{M}$ creating a vacancy in the sensor material. This can be seen schematically in Figure 17.

\section{SENSOR}
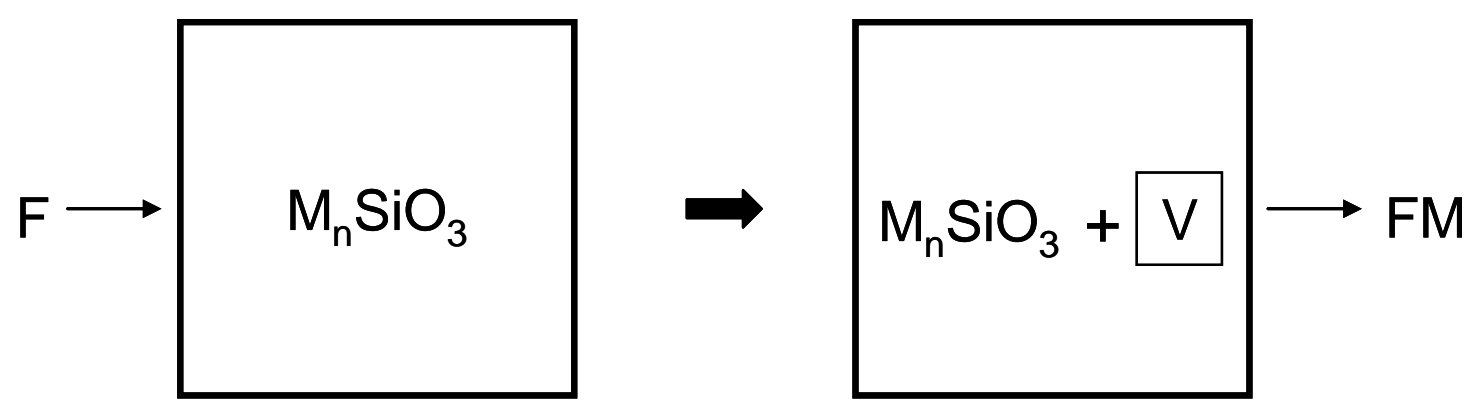

Figure 17. Reaction between $M$ - X

The subscrip $\mathrm{n}$ is 2 for $\mathrm{K}, \mathrm{Li}$, and $\mathrm{Na}$ and 1 for $\mathrm{Ca}$. The general reaction will be: 


$$
\mathrm{F}+\mathrm{M}_{n} \mathrm{SiO}_{3} \rightarrow \mathrm{FM}+\mathrm{M}_{n} \mathrm{SiO}_{3}+V_{M}^{\prime}
$$

For the vacancy notation the subscript means the type of site occupied and the superscript means the excess charge associated with the site. In this case there is the removal of a cation from a cation site to produce a cation vacancy leaving excess negative charge (') associated with the surrounding anions. The sensor material is no longer balance and therefore it is necessary to create an oxygen vacancy to maintain the balance:

$$
O_{O}^{F} \rightarrow \frac{1}{2} O_{2(g)}+V_{O^{*}}+2 e^{\prime}
$$

The reactant is oxygen where the anion (superscript) is going to leave an oxygen site (subscript). In the products there is the oxygen and the oxygen vacancy which will generate the electrons to produce the current that will be the measure of the gas presence. In order to find the most reactive sensor material, the Gibbs free energy was calculated using the reaction between the sensor materials and $\mathrm{F}$. The reaction between $\mathrm{F}$ and $\mathrm{K}$ has two reactants: atomic $\mathrm{F}$ in gas state $(\mathrm{g})$ and $\mathrm{K}$ in solid state (s). The product is $\mathrm{FK}$ in gas state (g). Similarly for the other silicates:

$$
\begin{gathered}
F_{(g)}+K_{(s)} \rightarrow F K_{(g)} \\
F_{(g)}+L i_{(s)} \rightarrow F L i_{(g)} \\
F_{(g)}+N a_{(s)} \rightarrow F N a_{(g)} \\
F_{(g)}+C a_{(s)} \rightarrow F C a_{(g)}
\end{gathered}
$$


The results for the Gibbs free energy calculations between the sensor material and F are presented in Table 5. The data used for the calculations is presented in appendix 2 (Table 22).

Table 5. Reactivity analysis between sensor and gas

\begin{tabular}{|c|c|}
\hline Elements & $\Delta \mathbf{G ~ ( K J / m o l )}$ \\
\hline \hline $\mathrm{F}-\mathrm{K}$ & -410 \\
\hline $\mathrm{F}-\mathrm{Li}$ & -432 \\
\hline $\mathrm{F}-\mathrm{Na}$ & -377 \\
\hline $\mathrm{F}-\mathrm{Ca}$ & -380 \\
\hline
\end{tabular}

All reactions have negative values for Gibbs free energy meaning that the sensor materials will react spontaneously with the gas which is in agreement with the fact that all sensor materials tested respond to the gas presence. Additionally, Gibbs free energy values show that the first material that reacts with the gas is $\mathrm{Li}_{2} \mathrm{SiO}_{3}$ follow by $\mathrm{K}_{2} \mathrm{SiO}_{3}$, $\mathrm{CaSiO}_{3}$, and finally $\mathrm{Na}_{2} \mathrm{SiO}_{3}$ which is also in agreement with the measure time that the sensor takes to response to the gas: $0.7 \mathrm{~s}, 1.0 \mathrm{~s}, 1.2 \mathrm{~s}$ and $1.3 \mathrm{~s}$ for $\mathrm{Li}_{2} \mathrm{SiO}_{3}, \mathrm{~K}_{2} \mathrm{SiO}_{3}$, $\mathrm{CaSiO}_{3}, \mathrm{Na}_{2} \mathrm{SiO}_{3}$ respectively.

\subsection{2 - Surface Diffusion Analysis}

As it was explained in the previous section fluorine atoms will react with $\mathrm{K}, \mathrm{Li}, \mathrm{Na}$ or $\mathrm{Ca}$ cations within the sensor. Therefore, once the sensor reaches its stable current and the gas runs into the chamber the first reaction between the gas and the sensor occurs with the cations at the sensor surface. This corresponds to the surface diffusion which is observed in the sensor response as a linear trend that stays for approximately 8 seconds. The correlation for the surface diffusion is as follows:

$$
\text { For } \quad 0 \leq t \leq 8: \quad I(t)=I_{S}+s \cdot t
$$


Where:

$\mathrm{I}(\mathrm{t})$ : Current as function of time

IS: $\quad$ Stable current

s: $\quad$ Slope

t: $\quad$ Time that the gas is in contact within the sensor.

An essential factor in this equation is the slope due to the stable current is constant for every sensor and the time that the gas is in contact within the sensor is a predefined value. In order to compare the surface diffusion in the different sensor materials the slope for the sensor response to the gas was determined. The sensor inks fabricated $\left(\mathrm{Li}_{2} \mathrm{SiO}_{3}\right.$, $\mathrm{Na}_{2} \mathrm{SiO}_{3}, \mathrm{~K}_{2} \mathrm{SiO}_{3}$, and $\mathrm{CaSiO}_{3}$ ) were tested individually using the same parameters in section 4.2 Sensor analysis before gas. The gas used during testing is R-134a at 10,000 ppm and the gas flow is $0.5 \mathrm{SCFH}$. The results for the slope during the surface diffusion for every sensor material are presented in Table 6 .

Table 6. Sensor Response to Gas - Surface Diffusion

\begin{tabular}{|c|c|}
\hline $\begin{array}{c}\text { Sensor } \\
\text { Material }\end{array}$ & $\begin{array}{c}\text { Surface Diffusion } \\
\text { Slope }(\mu \mathrm{A} / \mathbf{s})\end{array}$ \\
\hline \hline $100 \% \mathrm{~K}_{2} \mathrm{SiO}_{3}$ & 0.5 \\
\hline $100 \% \mathrm{Na}_{2} \mathrm{SiO}_{3}$ & 1.3 \\
\hline $100 \% \mathrm{CaSiO}_{3}$ & 0.7 \\
\hline $100 \% \mathrm{Li}_{2} \mathrm{SiO}_{3}$ & 1.6 \\
\hline
\end{tabular}

It is observed that the silicate with the highest slope for the response to the gas is $\mathrm{Li}_{2} \mathrm{SiO}_{3}$, follow by $\mathrm{Na}_{2} \mathrm{SiO}_{3}, \mathrm{CaSiO}_{3}$ and finally $\mathrm{K}_{2} \mathrm{SiO}_{3}$. Once again, due to the fluorine atoms will react with potassium, sodium, lithium or calcium atoms due to the higher thermodynamic free energy of reaction. Therefore, knowing the number of atoms that will react there 
should be a direct relation between them and slope for the current response. The number of atoms can be calculated using Equation 10.

$$
N=\frac{m \cdot N_{A}}{m_{a}}
$$

Where:

\section{Equation 10. Number of Atoms}

$\begin{array}{cl}N: & \text { Number of atoms } \\ m: & \text { Mass } \\ N_{A}: & \text { Avogadro's number } \\ m_{a}: & \text { Atomic mass }\end{array}$

The atomic mass, volume and density are known quantities. The mass can be obtained multiplying volume by density. The results are presented in Table 7. The data used for the calculations is presented in appendix 2 (Table 23).

Table 7. Number of Atoms

\begin{tabular}{|c|c|}
\hline Element & Number of Atoms \\
\hline \hline $\mathrm{K}$ & $3.05 \mathrm{E}+18$ \\
\hline $\mathrm{Li}$ & $1.07 \mathrm{E}+19$ \\
\hline $\mathrm{Na}$ & $5.86 \mathrm{E}+18$ \\
\hline $\mathrm{Ca}$ & $3.24 \mathrm{E}+18$ \\
\hline
\end{tabular}

As it was expected there is a direct relation between the number of cations within the sensor and the slope for the sensor response. The number of atoms at the surface depends at the bulk number of atoms showing that the silicate with highest number of atoms has the highest slope for the sensor response.

\subsection{3 - Bulk Diffusion Analysis}

Imperfections in the arrangement of atoms in space occur as point defects, line defects, or surface defects. The two primary classes of point defects are interstitials and vacancies. 
An interstitial defect occurs when an atom occupies a position in the crystal other than a normal lattice. A vacancy defect exists in a crystal where a normal lattice site is unoccupied. Interstitial defects correspond to Frenkel defects and vacancy defects to Schottky defects [51, and 52]. Therefore, the sensor material is analyzed using Schottky defects that consists of a vacant cations site and a vacant anion site which correspond to the bulk diffusion process within the sensor that occurs during the sensor response after the linear diffusion process. The bulk diffusion process is observed in the sensor response as an exponential trend which starts after approximately 8 seconds that the gas is in contact within the sensor. The correlation for the bulk diffusion is as follows:

$$
\text { For } \quad t>8: \quad I(t)=I_{O} \cdot \exp (i \cdot t)
$$

Where:

$I(t)$ Current as function of time

$\mathrm{I}_{\mathrm{O}}: \quad$ Current at $\mathrm{t}=8 \mathrm{~s}$

i: $\quad$ Increase factor

$\mathrm{t}$ : Time that the gas is in contact within the sensor.

In this equation the increase factor is an essential value due to $I_{O}$ can be calculated with the equation for the surface diffusion and $t$ is a predefined value. In order to compare the bulk diffusion in the different sensor materials the increase factor for the sensor response to the gas was determined. The testing process is a continuation of the testing in the previous section. The results for the increase factor during the bulk diffusion for every sensor material are presented in Table 8. 
Table 8. Sensor Response to Gas - Bulk Diffusion

\begin{tabular}{|c|c|}
\hline $\begin{array}{c}\text { Sensor } \\
\text { Material }\end{array}$ & $\begin{array}{c}\text { Increase } \\
\text { Factor (1/s) }\end{array}$ \\
\hline \hline $100 \% \mathrm{~K}_{2} \mathrm{SiO}_{3}$ & $6.50 \mathrm{E}-03$ \\
\hline $100 \% \mathrm{Na}_{2} \mathrm{SiO}_{3}$ & $7.50 \mathrm{E}-03$ \\
\hline $100 \% \mathrm{CaSiO}_{3}$ & $5.50 \mathrm{E}-03$ \\
\hline $100 \% \mathrm{Li}_{2} \mathrm{SiO}_{3}$ & $9.00 \mathrm{E}-03$ \\
\hline
\end{tabular}

It is observed that the silicate with the highest factor for the response to the gas during the bulk diffusion is $\mathrm{Li}_{2} \mathrm{SiO}_{3}$ followed by $\mathrm{Na}_{2} \mathrm{SiO}_{3}, \mathrm{~K}_{2} \mathrm{SiO}_{3}$ and $\mathrm{CaSiO}_{3}$. Due to the diffusion process corresponds to a vacancy defects the number of vacancy was calculated to compare the results obtained.

\subsection{4 - Vacancy Analysis}

Once the atom leaves its lattice site to fill a nearby vacancy creating new vacancies at the original lattice site and the diffusion process continues there is a countercurrent flow of atoms and vacancies. The concentration of vacancies can be calculated using Equation 11.

$$
n_{v}=n \cdot \exp \left(-\frac{Q_{v}}{R T}\right)
$$

Where:

\section{Equation 11. Concentration of Vacant Sites}

$n_{v}: \quad$ Number of vacancies per volume unit

$n$ : Number of atoms per volume unit

$Q_{v}: \quad$ Energy required to produce one mole of vacancies

R: $\quad$ Gas constant

T: Absolute temperature 
The number of atoms was previously calculated and presented in Table 7. The results for the sensor tested at $690^{\circ} \mathrm{C}$ are presented in Table 9. The data used for the calculations is presented in appendix 2 (Table 24).

Table 9. Vacancies within the sensor

\begin{tabular}{|c|c|}
\hline Silicate & $\mathbf{n}_{\mathbf{v}}($ vacancies/cm \\
& ) \\
\hline \hline $100 \% \mathrm{~K}_{2} \mathrm{SiO}_{3}$ & $2.28 \mathrm{E}+18$ \\
\hline $100 \% \mathrm{Li}_{2} \mathrm{SiO}_{3}$ & $7.38 \mathrm{E}+18$ \\
\hline $100 \% \mathrm{Na}_{2} \mathrm{SiO}_{3}$ & $4.24 \mathrm{E}+18$ \\
\hline $100 \% \mathrm{CaSiO}_{3}$ & $1.11 \mathrm{E}+18$ \\
\hline
\end{tabular}

As it was expected the material with highest number of vacancies allows faster movement of atoms within the sensor resulting in a higher increase for the sensor response. The results show that the sensor material with highest vacancies number which will lead to a higher response corresponds to $\mathrm{Li}_{2} \mathrm{SiO}_{3}$ followed by $\mathrm{Na}_{2} \mathrm{SiO}_{3}, \mathrm{~K}_{2} \mathrm{SiO}_{3}$ and $\mathrm{CaSiO}_{3}$ which are in agreement with the increase factors during the bulk diffusion calculated for every sensor material.

All sensor material tested respond to the gas presence. $\mathrm{Li}_{2} \mathrm{SiO}_{3}$ corresponds to the sensor with highest values for Gibbs free energy, number of atoms, as well as vacancies number; however, it has the lowest stable current leading to a low current value as response to the gas. $\mathrm{Na}_{2} \mathrm{SiO}_{3}$ has the highest stable current value but unfortunately it has a short life and stops responding after the second or third testing and that is the reason that is not being considered in the selection. Therefore, considering the stable current and the surface diffusion results the material selected corresponds to $\mathrm{CaSiO}_{3}$. The time for the current stabilization as well as the time for the sensor respond to the gas were not considered due to the values are similar for all sensors tested. SEM pictures for the silicates after testing are presented in Figure 18. 

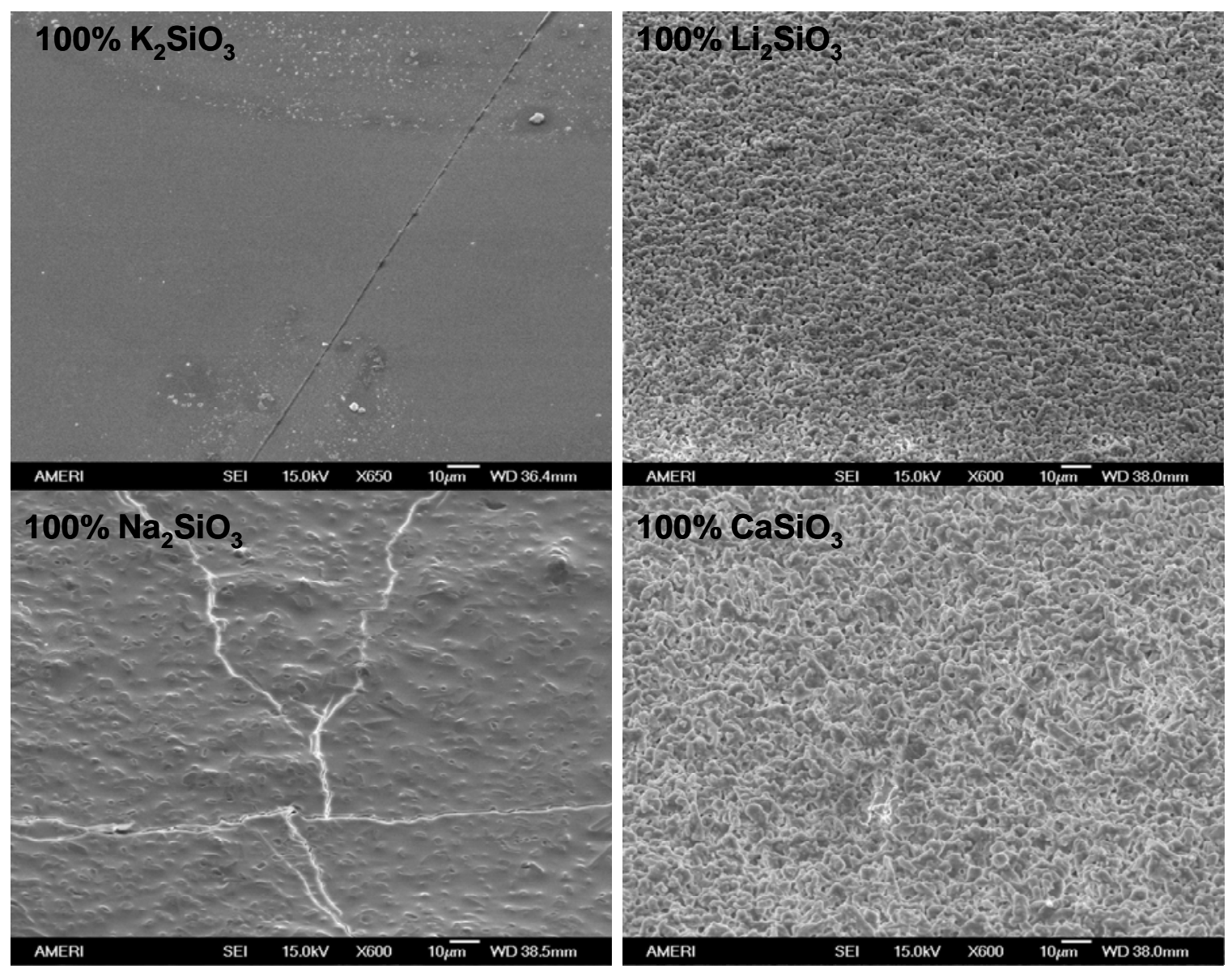

Figure 18. SEM Pictures for sensors after testing (Pure Materials)

It is observed that all materials have a homogeneous surface. $\mathrm{Li}_{2} \mathrm{SiO}_{3}$ and $\mathrm{CaSiO}_{3}$ show porosity and have similar surfaces. $\mathrm{K}_{2} \mathrm{SiO}_{3}$ and $\mathrm{Na}_{2} \mathrm{SiO}_{3}$ do not show porosity. $\mathrm{K}_{2} \mathrm{SiO}_{3}$ has smoother surface compared with the other silicates. Contrary, $\mathrm{Na}_{2} \mathrm{SiO}_{3}$ shows cavities within the sensor and cracks which are in agreement with the failure of this sensor.

\section{4 - Sensor Material Combinations}

Once the sensor response for the pure silicates was determined, combinations between the silicates that show better behavior, in general maintaining or increasing the stable current as well as the slope for the sensor response were selected from different phase 
diagrams and tested. Additionally, different percentages between $\mathrm{K}_{2} \mathrm{SiO}_{3}$ and $\mathrm{Li}_{2} \mathrm{SiO}_{3}$ as well the addition of $\mathrm{Al}_{2} \mathrm{O}_{3}$ were also tested.

\subsection{1 - Combinations from phase diagrams}

In order to determine combinations between the silicates to detect the gas, three phase diagrams were used: KF-LiF- $\mathrm{K}_{2} \mathrm{SiO}_{3}-\mathrm{Li}_{2} \mathrm{SiO}_{3}$ (Figure 19), $\mathrm{LiF}-\mathrm{CaF}_{2}-\mathrm{Li}_{2} \mathrm{SiO}_{3}-\mathrm{CaSiO}_{3}$ (Figure 20), and $\mathrm{LiF}-\mathrm{NaF}-\mathrm{Li}_{2} \mathrm{SiO}_{3}-\mathrm{Na}_{2} \mathrm{SiO}_{3}$ (Figure 21). The combinations were selected through the eutectic points in the diagrams.

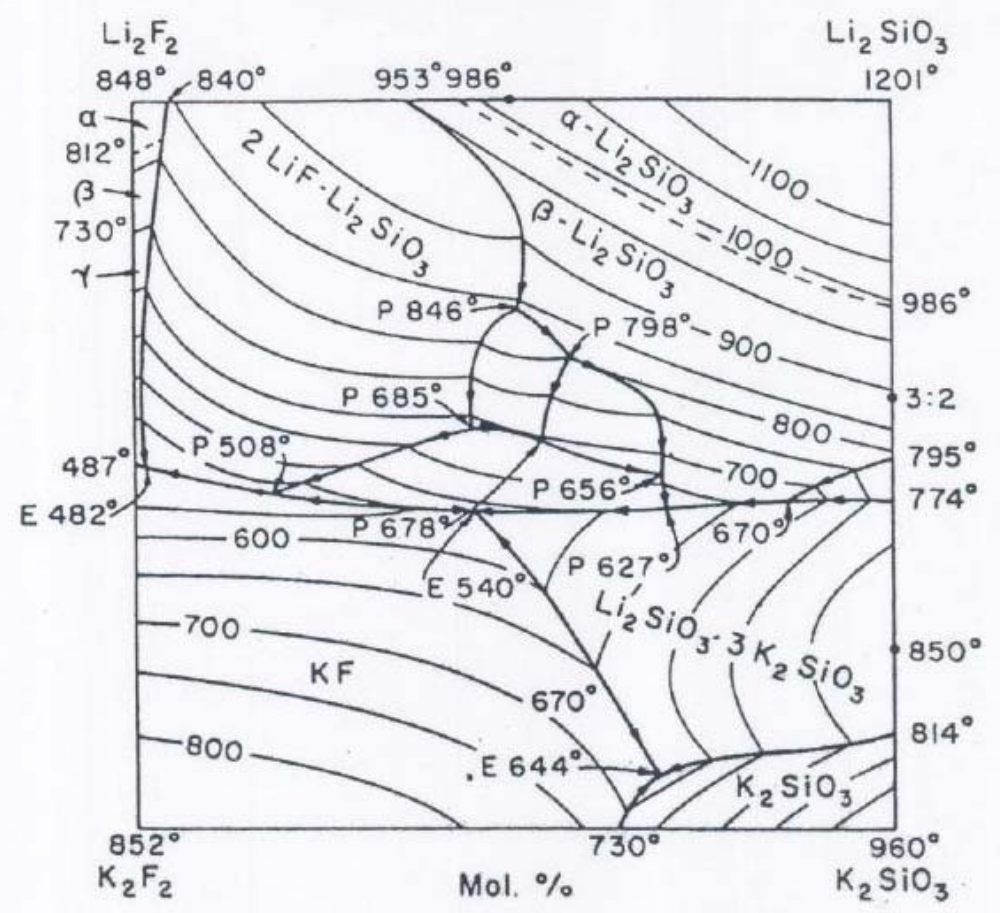

Figure 19. $\mathrm{KF}-\mathrm{LiF}-\mathrm{K}_{2} \mathrm{SiO}_{3}-\mathrm{Li}_{2} \mathrm{SiO}_{3}$ System 


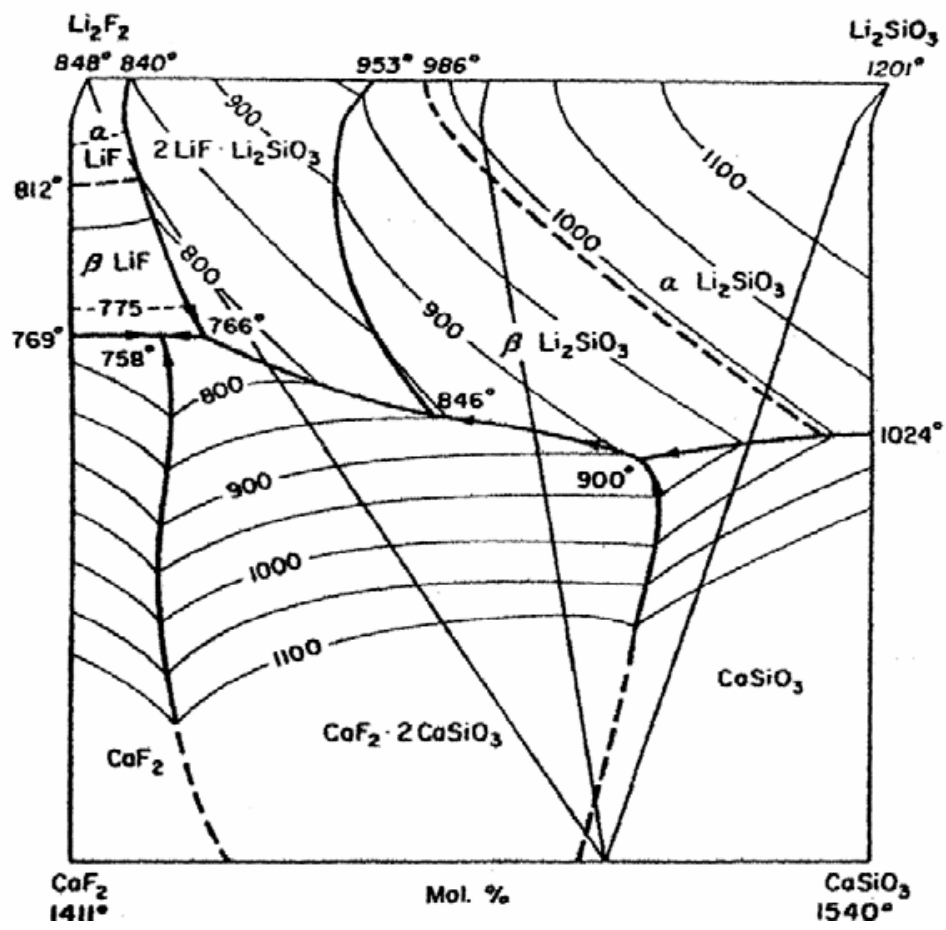

Figure 20. $\mathrm{LiF}-\mathrm{CaF}-\mathrm{Li}_{2} \mathrm{SiO}_{3}-\mathrm{CaSiO}_{3}$ System

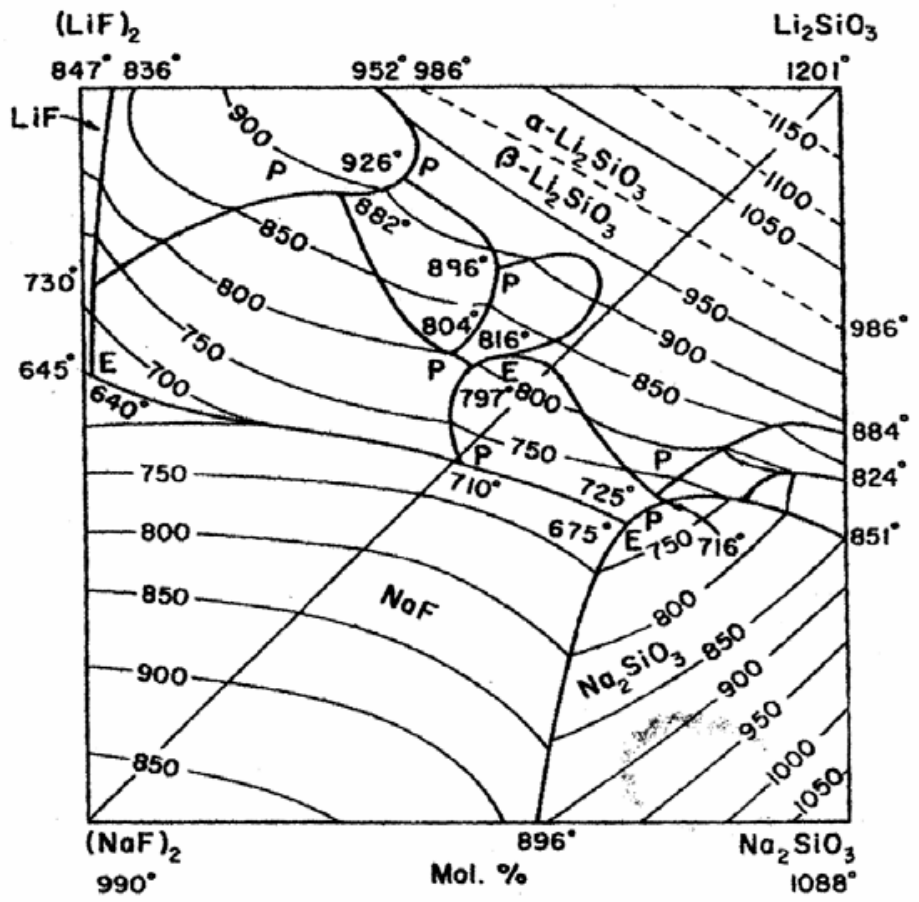

Figure 21. LiF-NaF-Li $\mathrm{SiO}_{3}-\mathrm{Na}_{2} \mathrm{SiO}_{3}$ System 
The combination selected using the eutectic points in the phase diagrams are:

1. $56 \% \mathrm{~K}_{2} \mathrm{SiO}_{3}+44 \% \mathrm{Li}_{2} \mathrm{SiO}_{3}$

2. $51.5 \% \mathrm{CaSiO}_{3}+48.5 \% \mathrm{Li}_{2} \mathrm{SiO}_{3}$

3. $58.6 \% \mathrm{Na}_{2} \mathrm{SiO}_{3}+41.4 \% \mathrm{Li}_{2} \mathrm{SiO}_{3}$

4. $68 \% \mathrm{Li}_{2} \mathrm{SiO}_{3}+32 \% \mathrm{CaSiO}_{3}$

5. $65 \% \mathrm{Li}_{2} \mathrm{SiO}_{3}+35 \% \mathrm{Na}_{2} \mathrm{SiO}_{3}$

6. $62.5 \% \mathrm{Li}_{2} \mathrm{SiO}_{3}+37.5 \% \mathrm{Na}_{2} \mathrm{SiO}_{3}$

The parameters used for testing are: sensor size $(1.98 \times 1.17 \times 0.3 \mathrm{~mm})$; operating temperature $\left(690^{\circ} \mathrm{C}\right)$; bias voltage $(3 \mathrm{~V})$; gas flow $(0.5 \mathrm{scfh})$. The results for stable current, the time to reach stabilization (before the gas is present) and the slope for the sensor response to the gas are presented in Table 10.

Table 10. Results for Combinations from Phase Diagram

\begin{tabular}{|c|c|c|c|}
\hline $\begin{array}{c}\text { Sensor } \\
\text { Material }\end{array}$ & $\begin{array}{c}\text { Stable } \\
\text { Current }(\mu \mathrm{A})\end{array}$ & $\begin{array}{c}\text { Time for } \\
\text { Stabilization }(\mathbf{s})\end{array}$ & $\begin{array}{c}\text { Surface Diffusion } \\
\text { Slope }(\mu \mathrm{A} / \mathbf{s})\end{array}$ \\
\hline \hline $56 \% \mathrm{~K}_{2} \mathrm{SiO}_{3}+44 \% \mathrm{Li}_{2} \mathrm{SiO}_{3}$ & 279 & 31 & 0.85 \\
\hline $51.5 \% \mathrm{CaSiO}_{3}+48.5 \% \mathrm{Li}_{2} \mathrm{SiO}_{3}$ & 280 & 34 & 0.90 \\
\hline $58.6 \% \mathrm{Na}_{2} \mathrm{SiO}_{3}+41.4 \% \mathrm{Li}_{2} \mathrm{SiO}_{3}$ & 305 & 25 & 0.92 \\
\hline $68 \% \mathrm{Li}_{2} \mathrm{SiO}_{3}+32 \% \mathrm{CaSiO}_{3}$ & 265 & 40 & 0.86 \\
\hline $65 \% \mathrm{Li}_{2} \mathrm{SiO}_{3}+35 \% \mathrm{Na}_{2} \mathrm{SiO}_{3}$ & 256 & 36 & 0.76 \\
\hline $62.5 \% \mathrm{Li}_{2} \mathrm{SiO}_{3}+37.5 \% \mathrm{Na}_{2} \mathrm{SiO}_{3}$ & 275 & 32 & 0.78 \\
\hline
\end{tabular}

The results obtained for the sensor combinations show significant differences comparing them with the pure materials. The combination with more than $50 \%$ is $\mathrm{Na}_{2} \mathrm{SiO}_{3}$ has the highest stable current as well as the slope for the surface diffusion but this combination has short life and stop responding after the second or third test. Combinations containing less than $50 \% \mathrm{Na}_{2} \mathrm{SiO}_{3}$ keep responding during all tests realized. Comparing the other combinations, the $51.5 \% \mathrm{Ca}_{2} \mathrm{SiO}_{3}+48.5 \% \mathrm{Li}_{2} \mathrm{SiO}_{3}$ show higher stable current as well as slope for the sensor response and consequently it shows better response than the other 
combinations as well as the sensor with $100 \% \mathrm{Ca}_{2} \mathrm{SiO}_{3}$. SEM pictures for the sensors after testing are presented in Figure 22

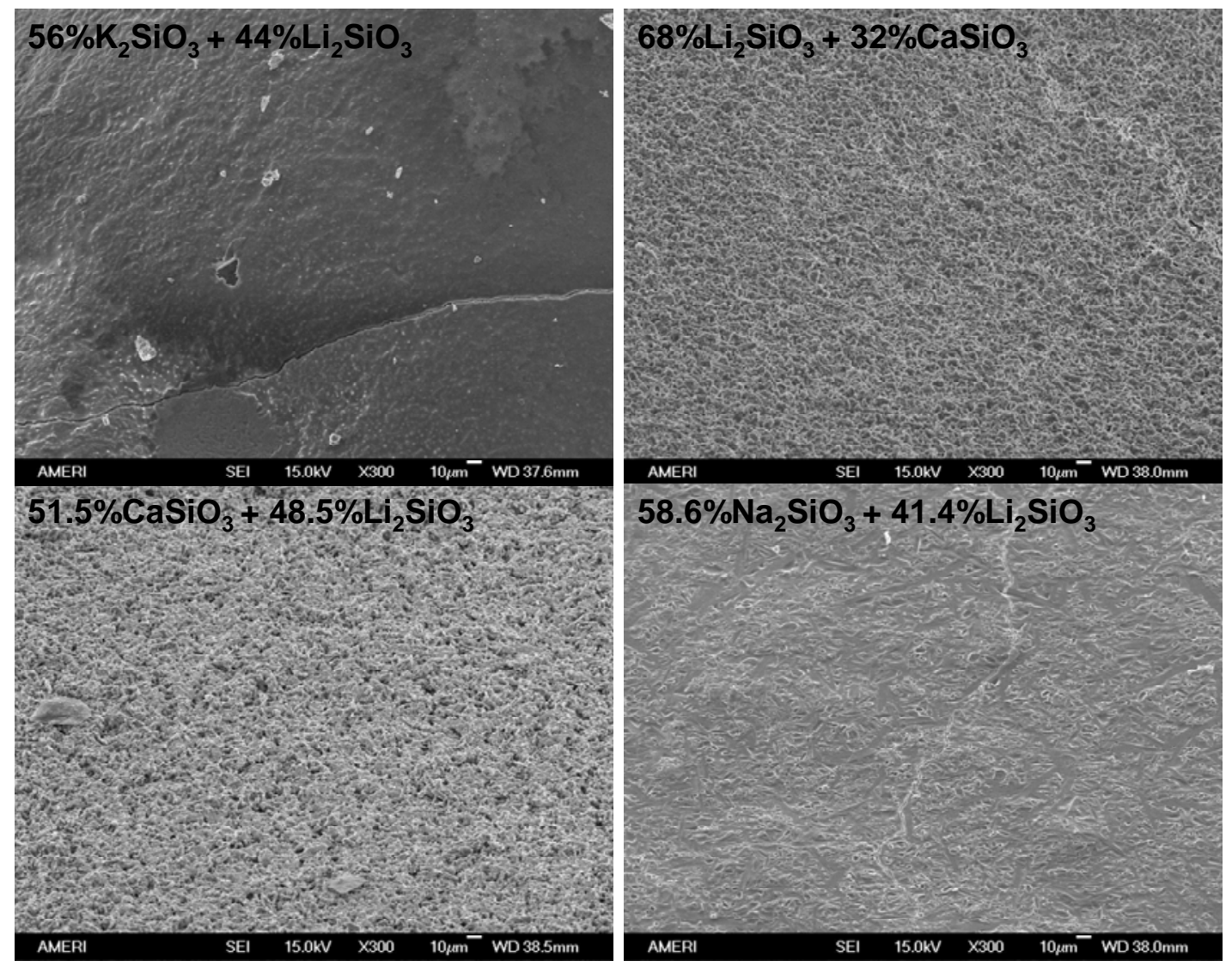

Figure 22. SEM Pictures for sensors after testing (Phase Diagram Combinations)

The surfaces for the combinations are similar to the surfaces for the pure materials showing a homogeneous surface for the sensors. $\mathrm{CaSiO}_{3}$ and $\mathrm{Li}_{2} \mathrm{SiO}_{3}$ show higher porosity. Cracks are presented in the sample containing $\mathrm{K}_{2} \mathrm{SiO}_{3}$ which was expected due to the operating temperature is higher than the eutectic point corresponding to this combination. All combinations were tested at the same temperature in order to compare the results. The results for the testing of this combination at the temperature from the eutectic point in the phase diagram will be presented in the section 4.6 Operating Temperature Effect. 


\subsection{2 - Additional Combinations}

Based on previous works [6, and 29] different percentages $\mathrm{K}_{2} \mathrm{SiO}_{3}$ and $\mathrm{Li}_{2} \mathrm{SiO}_{3}$ as well the addition of $\mathrm{Al}_{2} \mathrm{O}_{3}$ were tested to determine if there was a significant impact on the sensor behavior. The selected combinations are:

1. $90 \% \mathrm{~K}_{2} \mathrm{SiO}_{3}+10 \% \mathrm{Li}_{2} \mathrm{SiO}_{3}$

2. $80 \% \mathrm{~K}_{2} \mathrm{SiO}_{3}+20 \% \mathrm{Li}_{2} \mathrm{SiO}_{3}$

3. $70 \% \mathrm{~K}_{2} \mathrm{SiO}_{3}+30 \% \mathrm{Li}_{2} \mathrm{SiO}_{3}$

4. $60 \% \mathrm{~K}_{2} \mathrm{SiO}_{3}+40 \% \mathrm{Li}_{2} \mathrm{SiO}_{3}$

5. $50 \% \mathrm{~K}_{2} \mathrm{SiO}_{3}+50 \% \mathrm{Li}_{2} \mathrm{SiO}_{3}$

6. $70 \% \mathrm{~K}_{2} \mathrm{SiO}_{3}+10 \% \mathrm{Li}_{2} \mathrm{SiO}_{3}+20 \% \mathrm{Al}_{2} \mathrm{O}_{3}$

7. $60 \% \mathrm{~K}_{2} \mathrm{SiO}_{3}+20 \% \mathrm{Li}_{2} \mathrm{SiO}_{3}+20 \% \mathrm{Al}_{2} \mathrm{O}_{3}$

8. $50 \% \mathrm{~K}_{2} \mathrm{SiO}_{3}+30 \% \mathrm{Li}_{2} \mathrm{SiO}_{3}+20 \% \mathrm{Al}_{2} \mathrm{O}_{3}$

9. $80 \% \mathrm{~K}_{2} \mathrm{SiO}_{3}+20 \% \mathrm{Al}_{2} \mathrm{O}_{3}$

10. $80 \%\left[90 \% \mathrm{~K}_{2} \mathrm{SiO}_{3}+10 \% \mathrm{Li}_{2} \mathrm{SiO}_{3}\right]+20 \% \mathrm{Al}_{2} \mathrm{O}_{3}$

The parameters used for testing are: Sensor size $(1.98 \times 1.17 \times 0.30 \mathrm{~mm})$; firing temperature $\left(864^{\circ} \mathrm{C}\right)$; operating temperature $\left(690^{\circ} \mathrm{C}\right)$; bias voltage $(3 \mathrm{~V})$; gas flow $(0.5$ scfh). The results for stable current, the time to reach stabilization and the slope for the sensor response to the gas are presented in Table 11.

There is not significant difference for the slope in the sensor response for all samples tested but there is some difference in the values for the stable current. The combinations without $\mathrm{Al}_{2} \mathrm{O}_{3}$ have higher stable currents, than the samples with $\mathrm{Al}_{2} \mathrm{O}_{3}$. For the combinations between $\mathrm{K}_{2} \mathrm{SiO}_{3}$ and $\mathrm{Li}_{2} \mathrm{SiO}_{3}$, the combination selected from the phase diagram $\left(56 \% \mathrm{~K}_{2} \mathrm{SiO}_{3}+44 \% \mathrm{Li}_{2} \mathrm{SiO}_{3}\right)$ has higher stable current than the additional 
combinations tested. SEM pictures after testing are presented in Figure 23. Two samples without alumina (upper part) and two samples with alumina (bottom part).

Table 11. Results for Additional Combinations

\begin{tabular}{|c|c|c|c|}
\hline $\begin{array}{c}\text { Sensor } \\
\text { Material }\end{array}$ & $\begin{array}{c}\text { Stable } \\
\text { Current }(\mu \mathrm{A})\end{array}$ & $\begin{array}{c}\text { Time for } \\
\text { Stabilization }(\mathbf{s})\end{array}$ & $\begin{array}{c}\text { Surface Diffusion } \\
\text { Slope }(\mu \mathrm{A} / \mathbf{s})\end{array}$ \\
\hline \hline $90 \% \mathrm{~K}_{2} \mathrm{SiO}_{3}+10 \% \mathrm{Li}_{2} \mathrm{SiO}_{3}$ & 252 & 38 & 0.88 \\
\hline $80 \% \mathrm{~K}_{2} \mathrm{SiO}_{3}+20 \% \mathrm{Li}_{2} \mathrm{SiO}_{3}$ & 277 & 40 & 0.89 \\
\hline $70 \% \mathrm{~K}_{2} \mathrm{SiO}_{3}+30 \% \mathrm{Li}_{2} \mathrm{SiO}_{3}$ & 261 & 29 & 0.88 \\
\hline $60 \% \mathrm{~K}_{2} \mathrm{SiO}_{3}+40 \% \mathrm{Li}_{2} \mathrm{SiO}_{3}$ & 276 & 35 & 0.86 \\
\hline $50 \% \mathrm{~K}_{2} \mathrm{SiO}_{3}+50 \% \mathrm{Li}_{2} \mathrm{SiO}_{3}$ & 259 & 30 & 0.83 \\
\hline $70 \% \mathrm{~K}_{2} \mathrm{SiO}_{3}+10 \% \mathrm{Li}_{2} \mathrm{SiO}_{3}+20 \% \mathrm{Al}_{2} \mathrm{O}_{3}$ & 242 & 31 & 0.84 \\
\hline $60 \% \mathrm{~K}_{2} \mathrm{SiO}_{3}+20 \% \mathrm{Li}_{2} \mathrm{SiO}_{3}+20 \% \mathrm{Al}_{2} \mathrm{O}_{3}$ & 220 & 29 & 0.86 \\
\hline $50 \% \mathrm{~K}_{2} \mathrm{SiO}_{3}+30 \% \mathrm{Li}_{2} \mathrm{SiO}_{3}+20 \% \mathrm{Al}_{2} \mathrm{O}_{3}$ & 223 & 36 & 0.82 \\
\hline $80 \% \mathrm{~K}_{2} \mathrm{SiO}_{3}+20 \% \mathrm{Al}_{2} \mathrm{O}_{3}$ & 228 & 30 & 0.87 \\
\hline $80 \%\left(90 \% \mathrm{~K}_{2} \mathrm{SiO}_{3}+10 \% \mathrm{Li}_{2} \mathrm{SiO}_{3}\right)+20 \% \mathrm{Al}_{2} \mathrm{O}_{3}$ & 222 & 29 & 0.84 \\
\hline
\end{tabular}
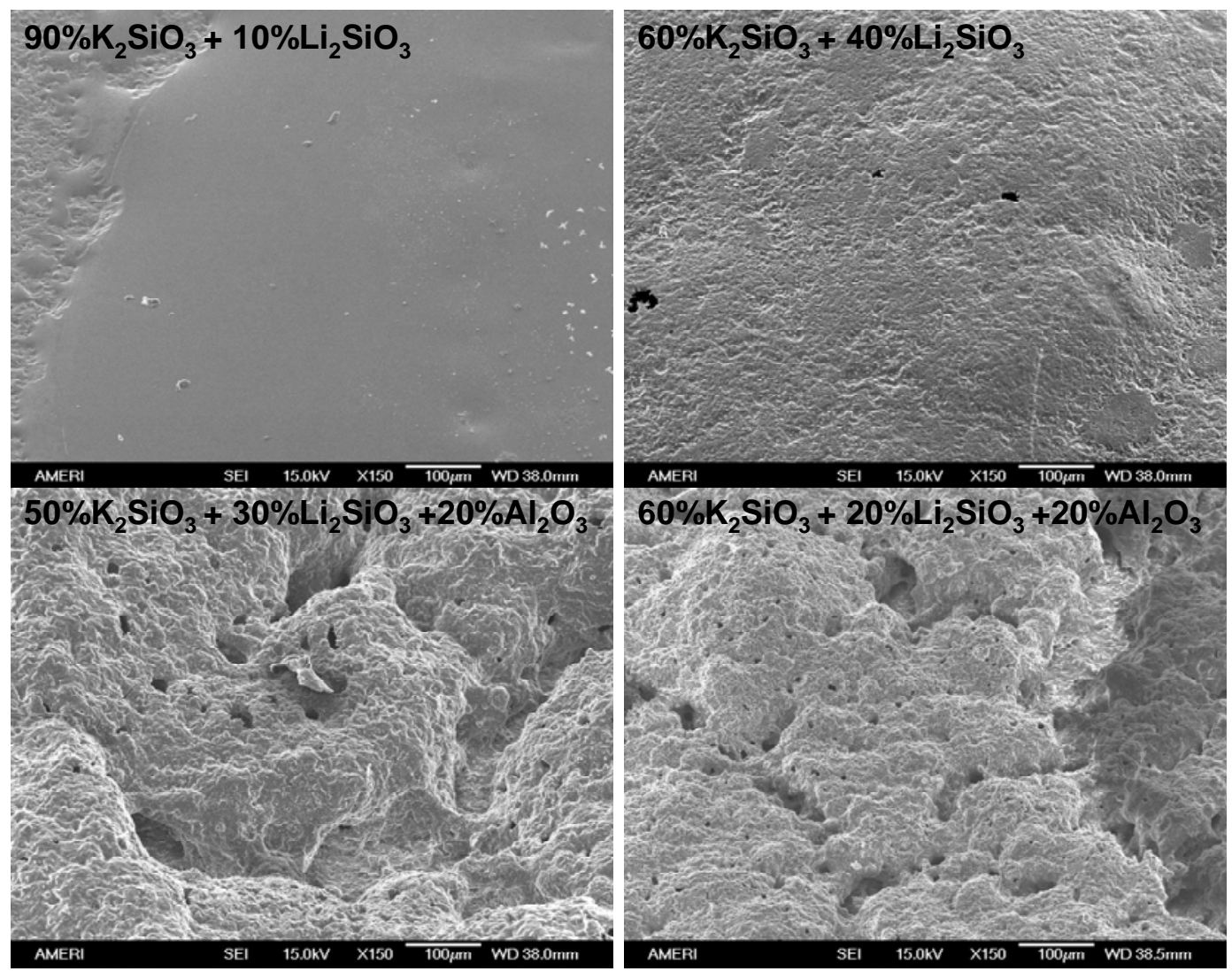

Figure 23. SEM Pictures for sensors after testing (Additional Combinations) 
Samples with $\mathrm{Al}_{2} \mathrm{O}_{3}$ show higher porosity than samples without $\mathrm{Al}_{2} \mathrm{O}_{3}$. It is also observed than when the $\mathrm{K}_{2} \mathrm{SiO}_{3}$ content increases the surface of the sensor is smoother.

\section{5 - Sensor Size Effect}

The sensor design is a rectangular element with an area of $1.17 \times 1.98 \mathrm{~mm}$. In order to test the effect of the sensor size three thicknesses were evaluated: $0.30,0.15$ and 0.01 $\mathrm{mm}$. The sensors were classified based on its thickness as follows: large, medium, and small sensor. The volume is $0.7 \mathrm{~mm}^{3}, 0.3 \mathrm{~mm}^{3}$, and $0.02 \mathrm{~mm}^{3}$ for the big and small sensor respectively. The parameters used for testing are: Firing temperature $\left(864^{\circ} \mathrm{C}\right)$; operating temperature $\left(690^{\circ} \mathrm{C}\right)$; bias voltage $(3 \mathrm{~V})$; gas flow $(0.5 \mathrm{scfh})$. The results for the sensor with $100 \% \mathrm{Ca}_{2} \mathrm{SiO}_{3}$ including the stable current, the time to reach stabilization and the slope for the sensor response to the gas are presented in Table 12.

Table 12. Sensor Size Results

\begin{tabular}{|c|c|c|c|}
\hline $\begin{array}{c}\text { Sensor } \\
\text { Size }\end{array}$ & $\begin{array}{c}\text { Stable } \\
\text { Current }(\mu \mathrm{A})\end{array}$ & $\begin{array}{c}\text { Time for } \\
\text { Stabilization }(\mathbf{s})\end{array}$ & $\begin{array}{c}\text { Sensor Response } \\
\text { Slope }(\mu \mathrm{A} / \mathbf{s})\end{array}$ \\
\hline \hline Small & 180 & 32 & 0.48 \\
\hline Medium & 215 & 34 & 0.62 \\
\hline Large & 258 & 35 & 0.70 \\
\hline
\end{tabular}

It is observed a direct relation between the sensor size and the sensor behavior: when the sensor size increases the values for the stable current, the time for stabilization as well as the slope for the sensor response increases. The results for the effect of the size on the sensor behavior agree with the expected results due to if the sensor volume increases the number of atoms as well as the vacancies increases and therefore the slope for the sensor response should increase as well as the time for stabilization of the sensor. The same modeling of the sensor as a resistor explained in section 4.2 Sensor Analysis Before Gas was used to calculate the stable current with different thickness. From Equation 7, it is 
observed that if the thickness increases the resistance reduces increasing the value for the current. The current was calculated for three thickness and the results are presented in Figure 24 .

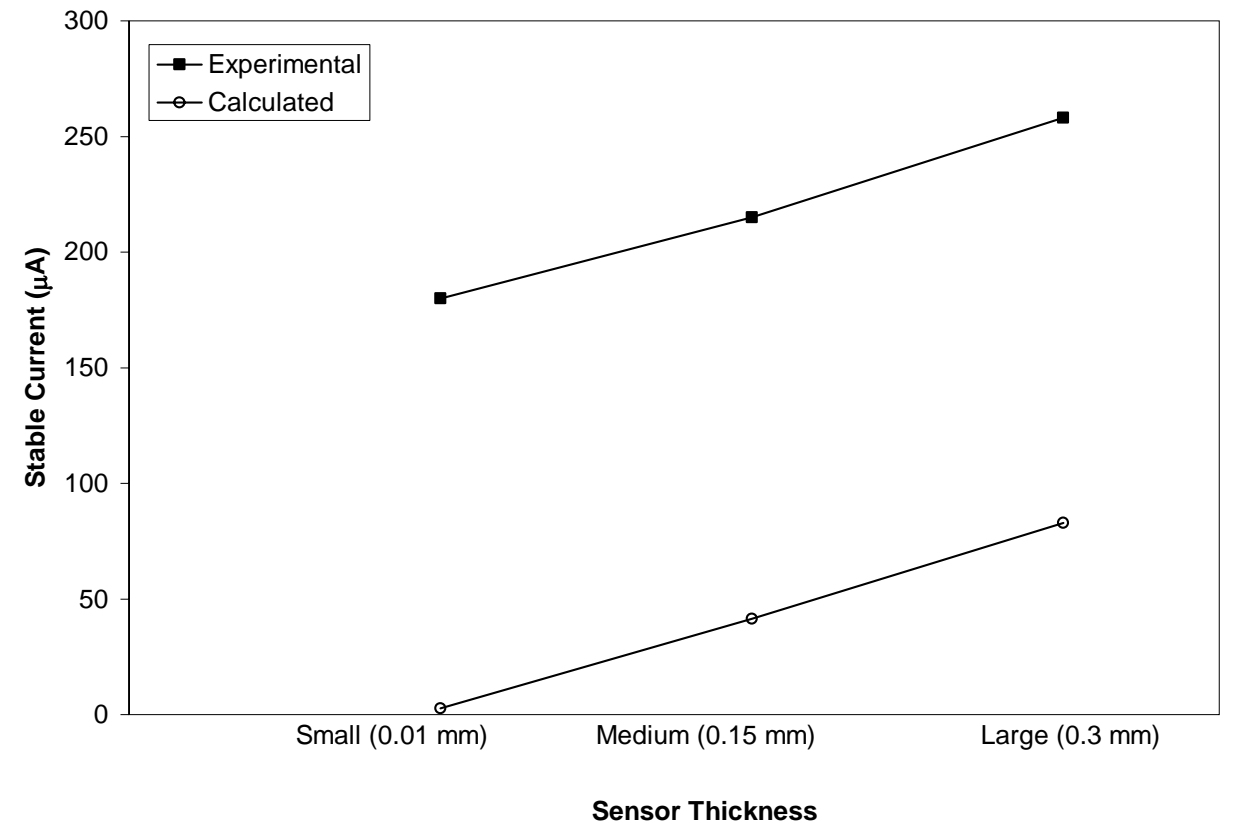

Figure 24. Sensor Size Effect

An agreement between the calculated and the experimental results is observed. The calculated results are lower than the experimental due to the literature values for resistivity were found at $300^{\circ} \mathrm{C}$ and the experiments were done at $690^{\circ} \mathrm{C}$. Additionally, large sensor (LS) and small sensor (SS) for some combinations from the phase diagram were tested. The results are presented in Table 13.

Table 13. Sensor Size - Results for Combinations

\begin{tabular}{|c|c|c|c|}
\hline $\begin{array}{c}\text { Sensor } \\
\text { Material }\end{array}$ & $\begin{array}{c}\text { Stable } \\
\text { Current }(\mu \mathrm{A}) \text { LS/SS }\end{array}$ & $\begin{array}{c}\text { Time for } \\
\text { Stabilization }(\mathbf{s}) \text { LS/SS }\end{array}$ & $\begin{array}{c}\text { Surface Diffusion } \\
\text { Slope }(\mu \mathrm{A} / \mathrm{s}) \text { LS/SS }\end{array}$ \\
\hline \hline $56 \% \mathrm{~K}_{2} \mathrm{SiO}_{3}+44 \% \mathrm{Li}_{2} \mathrm{SiO}_{3}$ & $279 / 235$ & $31 / 31$ & $0.85 / 0.58$ \\
\hline $51.5 \% \mathrm{CaSiO}_{3}+48.5 \% \mathrm{Li}_{2} \mathrm{SiO}_{3}$ & $278 / 249$ & $34 / 33$ & $0.90 / 0.84$ \\
\hline $58.6 \% \mathrm{Na}_{2} \mathrm{SiO}_{3}+41.4 \% \mathrm{Li}_{2} \mathrm{SiO}_{3}$ & $305 / 280$ & $25 / 23$ & $0.92 / 0.89$ \\
\hline $68 \% \mathrm{Li}_{2} \mathrm{SiO}_{3}+32 \% \mathrm{CaSiO}_{3}$ & $265 / 245$ & $40 / 40$ & $0.86 / 0.82$ \\
\hline
\end{tabular}


The results are in agreement with the results for the pure materials showing the direct relation between the sensor size and the stable current, the time for stabilization as well as the sensor response to the gas.

\section{6 - Operating Temperature Effect}

A critical factor in the sensor response is the operating temperature. Due to the sensor works through a diffusion mechanism in which the vacancies are the key, it is known that the process is temperature dependant. Therefore, if the temperature increases it is expected an increase in response. However, since the sensor is a portable device and the heater is the source for the temperature, for practical purposes, the operating temperature should be as low as possible to reduce the power applied to the heater. In order to determine the effect of the operating temperature on the sensor response six samples were compared. Large and small sensors with the same sensor composition were used. The ideal temperature to assure the maximum number of vacancies should be $90 \%$ of the melting temperature. Since most of the sensors that temperature is higher than the autoignition temperature, the highest operating temperature was selected below the autoignition temperature for the gas and the lowest operating temperature was obtained directly from the $\mathrm{KF}-\mathrm{LiF}-\mathrm{K}_{2} \mathrm{SiO}_{3}-\mathrm{Li}_{2} \mathrm{SiO}_{3}$ phase diagram. The three operating temperatures are: $690^{\circ} \mathrm{C}, 600^{\circ} \mathrm{C}$, and $540^{\circ} \mathrm{C}$. The parameters used for testing are: Sensor material $\left(56 \% \mathrm{~K}_{2} \mathrm{SiO}_{3}+44 \% \mathrm{Li}_{2} \mathrm{SiO}_{3}\right)$; sensor size $(1.98 \times 1.17 \times 0.30$ and $0.01 \mathrm{~mm})$; firing temperature $\left(864^{\circ} \mathrm{C}\right)$; bias voltage $(3 \mathrm{~V})$; gas flow $(0.5 \mathrm{scfh})$. The results for stable current, the time to reach stabilization and the slope for the sensor response to the gas are presented in Table 14. 
Table 14. Operating Temperature Results

\begin{tabular}{|c|c|c|c|}
\hline $\begin{array}{c}\text { Operating } \\
\left.\text { Temperature }^{(}{ }^{\circ} \mathbf{C}\right)\end{array}$ & $\begin{array}{c}\text { Stable } \\
\text { Current }(\mu \mathrm{A}) \text { LS/SS }\end{array}$ & $\begin{array}{c}\text { Time for } \\
\text { Stabilization }(\mathbf{s}) \text { LS/SS }\end{array}$ & $\begin{array}{c}\text { Surface Diffusion } \\
\text { Slope }(\mu \mathrm{A} / \mathbf{s}) \text { LS/SS }\end{array}$ \\
\hline \hline 690 & $279 / 235$ & $31 / 31$ & $0.85 / 0.58$ \\
\hline 600 & $51 / 41$ & $32 / 31$ & $0.53 / 0.41$ \\
\hline 540 & $14 / 10$ & $34 / 33$ & $0.35 / 0.22$ \\
\hline
\end{tabular}

The sensor response as well as the stable current is directly proportional to the operating temperature; if the operating temperature increases the stable current increases significantly. The average stable current for the large and small sensors are $264 \mu \mathrm{A}$, $55 \mu \mathrm{A}$, and $14 \mu \mathrm{A}$ at $690^{\circ} \mathrm{C}, 600^{\circ} \mathrm{C}$, and $540^{\circ} \mathrm{C}$ respectively. The average slopes for the large and small sensors are $0.72,0.47$, and $0.28 \mu \mathrm{A} / \mathrm{s}$ at $690^{\circ} \mathrm{C}, 600^{\circ} \mathrm{C}$, and $540^{\circ} \mathrm{C}$ respectively showing that the operating temperature has a very important effect on the sensor behavior. It was also observed that even when the sensor responds at the lowest temperature there is a noise effect on the response. The depletion region stabilization is inversely proportional to the operating temperature which is in agreement with the movement of the ions within the sensor is also a temperature dependent process. Additionally, the resistance versus the inverse of temperature was plot and is presented in Figure 25 .

It is observed a linear relation for the resistance and the inverse of the temperature showing the conductivity effect within the sensor. The relation between the large and small sensors is the same found in the evaluation of the sensor size even at different operating temperatures. SEM pictures for the $56 \% \mathrm{~K}_{2} \mathrm{SiO}_{3}+44 \% \mathrm{Li}_{2} \mathrm{SiO}_{3}$ after testing are presented in Figure 26. 


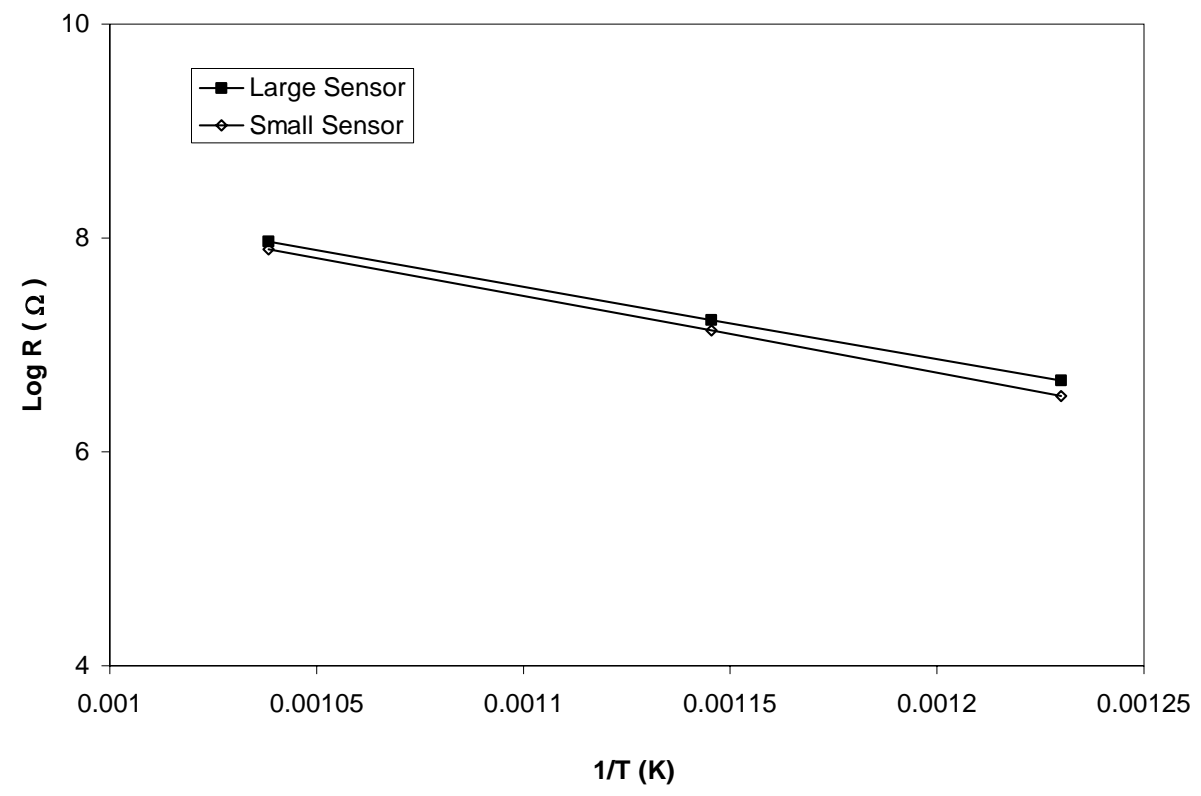

Figure 25. Operating Temperature Effect
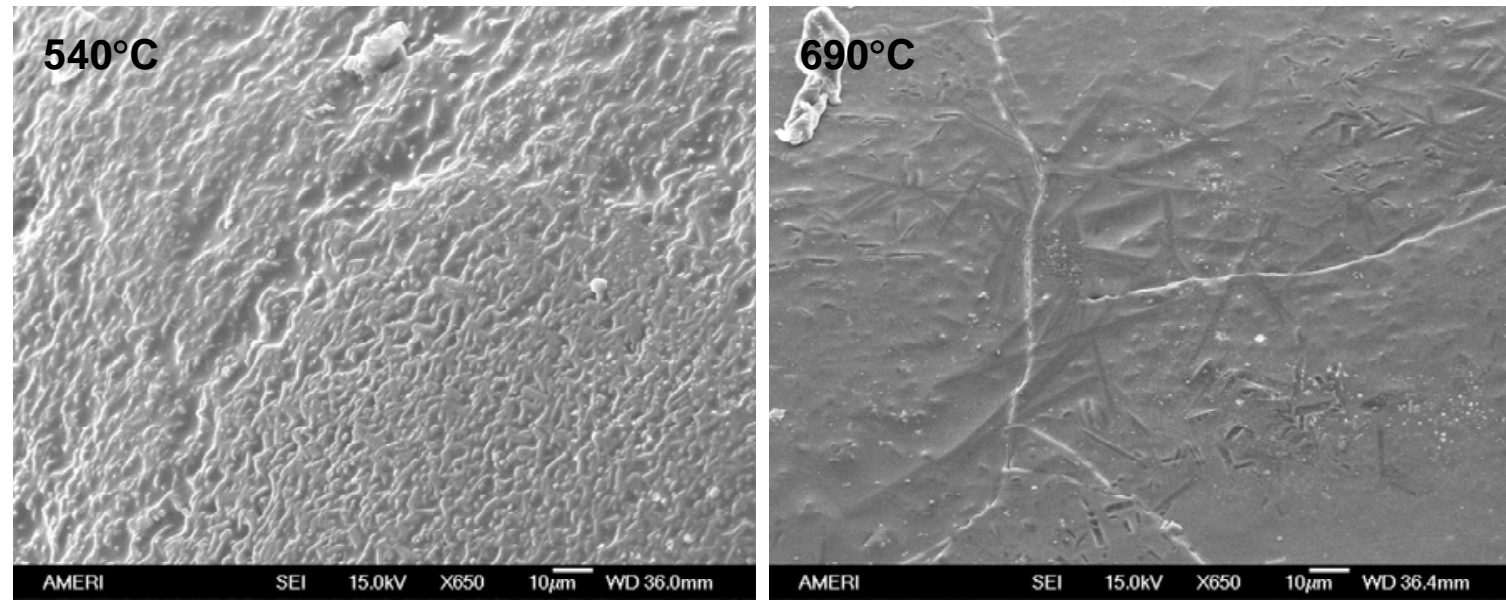

Figure 26. SEM Pictures - Operating Temperature Effect

Cracks are observed on the sample tested at $690^{\circ} \mathrm{C}$ which is in agreement with the failure of this sample during the fifth test due to burning of the sensor. That temperature exceeds the temperature from the phase diagram for the combination with $56 \% \mathrm{~K}_{2} \mathrm{SiO}_{3}+$ $44 \% \mathrm{Li}_{2} \mathrm{SiO}_{3}$. The sensor was tested at that temperature in order to compare it with the other combinations. 


\section{7 - Bias Voltage Effect}

In order to determine the effect of the bias voltage on the sensor response four small sensors with the same composition were used. Four bias voltages were selected: $5 \mathrm{~V}, 4 \mathrm{~V}$, $3 \mathrm{~V}$, and $2 \mathrm{~V}$. The parameters used for testing are: Sensor material $\left(56 \% \mathrm{~K}_{2} \mathrm{SiO}_{3}+\right.$ $\left.44 \% \mathrm{Li}_{2} \mathrm{SiO}_{3}\right)$; sensor size $(1.98 \times 1.17 \times 0.01 \mathrm{~mm})$; firing temperature $\left(864^{\circ} \mathrm{C}\right)$; operating temperature $\left(690^{\circ} \mathrm{C}\right)$; gas flow $(0.5 \mathrm{scfh})$. The results for stable current, the time to reach stabilization and the slope for the sensor response to the gas are presented in Table 15.

Table 15. Bias Voltage Results

\begin{tabular}{|c|c|c|c|}
\hline $\begin{array}{c}\text { Bias } \\
\text { Voltage }(\mathbf{V})\end{array}$ & $\begin{array}{c}\text { Stable } \\
\text { Current }(\mu \mathrm{A})\end{array}$ & $\begin{array}{c}\text { Time for } \\
\text { Stabilization }(\mathbf{s})\end{array}$ & $\begin{array}{c}\text { Surface Diffusion } \\
\text { Slope }(\mu \mathrm{A} / \mathbf{s})\end{array}$ \\
\hline \hline 5 & 372 & 32 & 0.76 \\
\hline 4 & 321 & 25 & 0.69 \\
\hline 3 & 235 & 31 & 0.58 \\
\hline 2 & 166 & 28 & 0.54 \\
\hline
\end{tabular}

It is observed that there is a direct relation between the applied bias voltage and the sensor response as well as the stable current. If the bias voltage increases the stable current increases as well as the sensor response to the gas increases. This was expected from Omh's Law for the relation between voltage and current. When the bias voltage increases $1 \mathrm{~V}$ the stable current increases $68 \mu \mathrm{A}$ approximately. There is not a linear relation for the slope in the sensor response for every voltage increase. It was also observed that when the bias voltage increases the sensor life reduces.

\section{8 - Electrodes Effect}

The electrodes designs are two straight and parallel lines. Two electrodes sizes were tested. The electrodes were classified based on their area as follows: $4.21 \mathrm{~mm}^{2}$ (Large) and $0.55 \mathrm{~mm}^{2}$ (Small). The area is for both electrodes in each design. The thickness for 
both designs is $10 \mu \mathrm{m}$. The two electrodes designs as well as the sensor area in contact within the electrodes can be seen in the upper and bottom part of Figure 27 respectively.

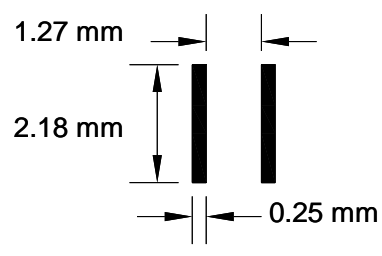

Small

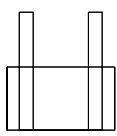

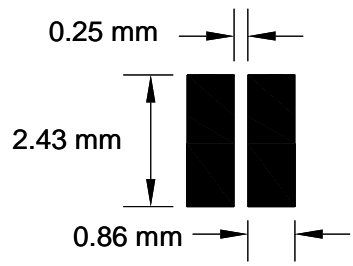

Large

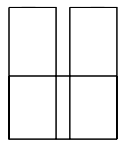

Figure 27. Electrodes (Up) - Sensor \& Electrodes (Bottom)

The parameters used for testing are: Sensor material $\left(100 \% \mathrm{CaSiO}_{3}\right.$ and $80 \%\left(90 \% \mathrm{~K}_{2} \mathrm{SiO}_{3}\right.$ $\left.\left.+10 \% \mathrm{Li}_{2} \mathrm{SiO}_{3}\right]+20 \% \mathrm{Al}_{2} \mathrm{O}_{3}\right)$; sensor size $(1.98 \times 1.17 \times 0.30 \mathrm{~mm})$; firing temperature $\left(864^{\circ} \mathrm{C}\right)$; operating temperature $\left(690^{\circ} \mathrm{C}\right)$; bias voltage $(3 \mathrm{~V})$; gas flow $(0.5 \mathrm{scfh})$. The results for stable current, the time to reach stabilization and the slope for the sensor response to the gas are presented in Table 16.

Table 16. Electrodes Size Results

\begin{tabular}{|c|c|c|c|}
\hline $\begin{array}{c}\text { Sensor } \\
\text { Material }\end{array}$ & $\begin{array}{c}\text { Stable } \\
\text { Current }(\mu \mathrm{A}) \text { LE/SE }\end{array}$ & $\begin{array}{c}\text { Time for } \\
\text { Stabilization }(\mathbf{s}) \text { LE/SE }\end{array}$ & $\begin{array}{c}\text { Sensor Response } \\
\text { Slope }(\mu \mathrm{A} / \mathrm{s}) \text { LE/SE }\end{array}$ \\
\hline \hline $100 \% \mathrm{CaSiO}_{3}$ & $258 / 247$ & $35 / 31$ & $0.70 / 0.27$ \\
\hline $80 \%\left(90 \% \mathrm{~K}_{2} \mathrm{SiO}_{3}+10 \% \mathrm{Li}_{2} \mathrm{SiO}_{3}\right)+20 \% \mathrm{Al}_{2} \mathrm{O}_{3}$ & $222 / 209$ & $33 / 29$ & $0.84 / 0.38$ \\
\hline
\end{tabular}

It is observed the direct relation between the area in contact between the electrodes and the sensor. When the size in the electrodes increases the stable current as well as the sensor response increases meanwhile the time for stabilization reduces. Using the modeling of the sensor as a resistor explained in section 4.2 Sensor Analysis Before Gas the results for the sensor with $100 \% \mathrm{CaSiO}_{3}$ were calculated and presented in Figure 28. 


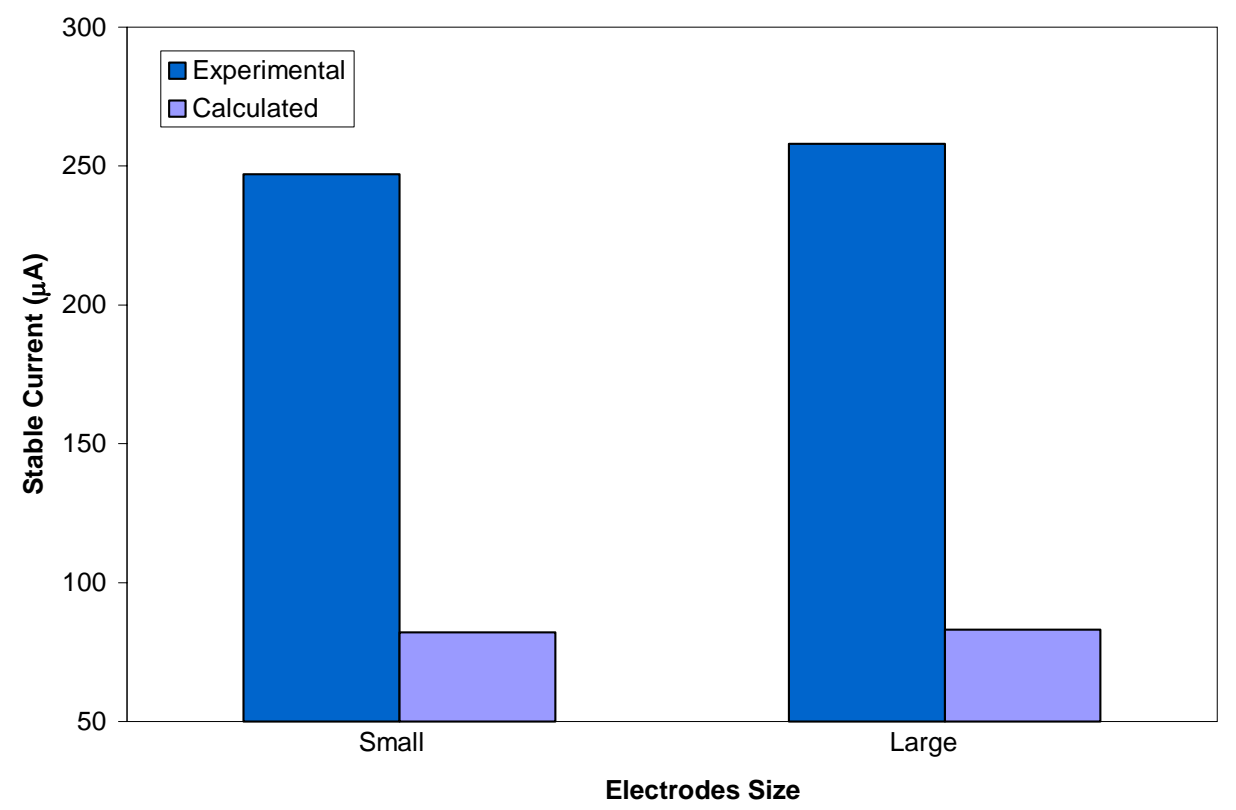

Figure 28. Electrodes Size Effect

The experimental results are in agreement with the calculations showing that the increase in separation for the electrodes has a critical impact in the sensor behavior. Therefore, reducing the distance between the electrodes as well as increasing the size of the electrodes results in an improvement for the sensor behavior increasing both the stable current and the sensor response to the gas. The calculated results are lower than the experimental due to the literature values for resistivity were found at $300^{\circ} \mathrm{C}$ and the experiments were done at $690^{\circ} \mathrm{C}$.

\section{9 - Firing Temperature Effect}

In order to determine the effect of the firing temperature on the sensor response two sensor materials were compared. Because the sensor material is not a commercial ink, there is no available information about its firing conditions. Consequently, the firing cycle used for the substrate was used for the sensor. The firing cycle for the substrate is: 
1. Increase temperature from $25^{\circ} \mathrm{C}$ to $400^{\circ} \mathrm{C}$ at a rate of $1^{\circ} \mathrm{C} / \mathrm{min}$.

2. Sustain $400^{\circ} \mathrm{C}$ for $30 \mathrm{~min}$.

3. Increase temperature from $400^{\circ} \mathrm{C}$ to $875^{\circ} \mathrm{C}$ at a rate of $10^{\circ} \mathrm{C} / \mathrm{min}$.

4. Sustain $875^{\circ} \mathrm{C}$ for $30 \mathrm{~min}$.

5. Reduce temperature from $875^{\circ} \mathrm{C}$ to $100^{\circ} \mathrm{C}$ at a rate of $10^{\circ} \mathrm{C} / \mathrm{min}$.

6. Removed substrate from the furnace after room temperature is reached.

The firing temperatures tested corresponds to the highest temperature in the cycle (steps 4-5). The firing temperatures were classified based on the melting temperature (MT) for the main component in the sensor. $\mathrm{K}_{2} \mathrm{SiO}_{3}$ is the main component in the two sensor combinations selected to evaluate the firing temperature effect. The melting temperature for $\mathrm{K}_{2} \mathrm{SiO}_{3}$ is $960^{\circ} \mathrm{C}$. The firing temperatures selected are: $864^{\circ} \mathrm{C}(90 \% \mathrm{MT})$ and $768^{\circ} \mathrm{C}$ $(80 \% \mathrm{MT})$. The parameters used for testing are: Sensor materials $\left(90 \% \mathrm{~K}_{2} \mathrm{SiO}_{3}+\right.$ $10 \% \mathrm{Li}_{2} \mathrm{SiO}_{3}$ and $\left.56 \% \mathrm{~K}_{2} \mathrm{SiO}_{3}+44 \% \mathrm{Li}_{2} \mathrm{SiO}_{3}\right)$; sensor size $(1.98 \times 1.17$ × $0.30 \mathrm{~mm})$ operating temperature $\left(690^{\circ} \mathrm{C}\right)$; bias voltage $(3 \mathrm{~V})$; gas flow $(0.5 \mathrm{scfh})$. The results for stable current, the time to reach stabilization and the slope for the sensor response to the gas are presented in Table 17.

Table 17. Firing Temperature Results

\begin{tabular}{|c|c|c|c|c|}
\hline $\begin{array}{c}\text { Firing } \\
\text { Temperature }\left({ }^{\circ} \mathbf{C}\right)\end{array}$ & $\begin{array}{c}\text { Stable } \\
\text { Current }(\mu \mathrm{A})\end{array}$ & $\begin{array}{c}\text { Time for } \\
\text { Stabilization (s) }\end{array}$ & $\begin{array}{c}\text { Sensor Response } \\
\text { Slope }(\mu \mathrm{A} / \mathbf{s})\end{array}$ & $\begin{array}{c}\text { Sensor } \\
\text { Material }\end{array}$ \\
\hline \hline $864(90 \% \mathrm{MT})$ & 279 & 31 & 0.85 & \multirow{2}{*}{$56 \% \mathrm{~K}_{2} \mathrm{SiO}_{3}+44 \% \mathrm{Li}_{2} \mathrm{SiO}_{3}$} \\
\hline $768(80 \% \mathrm{MT})$ & 240 & 34 & 0.84 & \multirow{2}{*}{$90 \% \mathrm{~K}_{2} \mathrm{SiO}_{3}+10 \% \mathrm{Li}_{2} \mathrm{SiO}_{3}$} \\
\hline $864(90 \% \mathrm{MT})$ & 252 & 38 & 0.88 & \\
\hline $768(80 \% \mathrm{MT})$ & 220 & 44 & 0.89 & \\
\hline
\end{tabular}

It is observed that there is not difference in the sensor response to the gas for both firing temperatures. However, there is a direct relation between the firing temperature and the stable current and an inverse relation between the firing temperature and the time for 
stabilization. Therefore, the optimum firing temperature is $90 \% \mathrm{MT}$ due to its highest stable current and fastest depletion region stabilization.

\subsection{0 - Gas Flow Effect}

In order to determine the effect of the gas flow on the sensor response three samples were compared. Small sensors with the same sensor composition and fired at their optimum firing temperature were used. Three gas flows were selected: $3.5 \mathrm{scfh}, 1.5 \mathrm{scfh}$, and 0.5 scfh. The parameters used for testing are: Sensor material $\left(56 \% \mathrm{~K}_{2} \mathrm{SiO}_{3}+44 \% \mathrm{Li}_{2} \mathrm{SiO}_{3}\right)$; sensor size $(1.98 \times 1.17 \times 0.01 \mathrm{~mm})$; operating temperature $\left(690^{\circ} \mathrm{C}\right)$; firing temperature $\left(864^{\circ} \mathrm{C}\right)$; bias voltage $(3 \mathrm{~V})$. The results for stable current, the time to reach stabilization and the slope for the sensor response to the gas are presented in Table 18.

Table 18. Gas Flow Results

\begin{tabular}{|c|c|c|c|}
\hline $\begin{array}{c}\text { Gas Flow } \\
(\text { scfh })\end{array}$ & $\begin{array}{c}\text { Stable } \\
\text { Current }(\mu \mathrm{A})\end{array}$ & $\begin{array}{c}\text { Time for } \\
\text { Stabilization }(\mathbf{s})\end{array}$ & $\begin{array}{c}\text { Surface Diffusion } \\
\text { Slope }(\mu \mathrm{A} / \mathbf{s})\end{array}$ \\
\hline \hline 3.5 & 234 & 31 & 0.58 \\
\hline 2.5 & 237 & 31 & 0.57 \\
\hline 0.5 & 235 & 31 & 0.58 \\
\hline
\end{tabular}

It is observed that the sensor response to the gas is independent of the gas flow showing that the sensor response depends on the sensor characteristics and previous parameters tested. For the three independent samples fabricated with the same conditions it is also observed the same results for stable current and time for stabilization showing repeatability in the sensor behavior and that the sensor can be duplicated. The small difference in stable current is due to placement of the sample on the furnace, as it was shown previously the operating temperature is a critical factor in the sensor behavior. 


\subsection{1 - Sensor response with heater}

The heater described in section 3.3 Heater Design was placed on the back of a big sensor with $56 \% \mathrm{~K}_{2} \mathrm{SiO}_{3}+44 \% \mathrm{Li}_{2} \mathrm{SiO}_{3}$ and tested. The heater reaches approximately $540^{\circ} \mathrm{C}$ applying 3.8V. The parameters used for testing are: Sensor size $(1.98 \times 1.17$ x $0.30 \mathrm{~mm})$; firing temperature $\left(864^{\circ} \mathrm{C}\right)$; bias voltage $(3 \mathrm{~V})$; gas flow $(0.5 \mathrm{scfh})$. The results comparing the sample tested with the heater and with the tube furnace including the stable current, the time to reach stabilization and the slope for the sensor response to the gas are presented in Table 19.

Table 19. Sensor \& Heater Results

\begin{tabular}{|c|c|c|c|}
\hline $\begin{array}{c}\text { Heat } \\
\text { Source }\end{array}$ & $\begin{array}{c}\text { Stable } \\
\text { Current }(\mu \mathrm{A})\end{array}$ & $\begin{array}{c}\text { Time for } \\
\text { Stabilization }(\mathbf{s})\end{array}$ & $\begin{array}{c}\text { Surface Diffusion } \\
\text { Slope }(\mu \mathrm{A} / \mathbf{s})\end{array}$ \\
\hline \hline Heater & 16 & 33 & 0.40 \\
\hline Tube Furnace & 14 & 34 & 0.35 \\
\hline
\end{tabular}

It is observed the similarity in the results for the sensor tested in the tube furnace and the sensor with the heater attached. The results for the sensor with the heater have higher stable current and slope for the response as well as shorter time for stabilization indicating that the operating temperature was higher. This is explained due to the measurement for the temperature with the heater is an approximation and not an exact value according with the results the operating temperature was higher than $540^{\circ} \mathrm{C}$. In general there is an excellent agreement of results showing that the heater placed in the back of the sensor is a good way of fabricating the sensor. Unfortunately, the sensor response at this temperature includes noise that is not desirable for the portable device.

\subsection{2 - Additional Results}

For all tests realized the gas was left running into the chamber for approximately 20 seconds, this was done due to the sensor is designed to detect gas leaks and once the 
current increases showing the presence of the gas there is not need for the sensor to keep detecting gas. However, an additional test was done leaving the gas running into the chamber for two minutes. The parameters for testing are: Sensor material: $56 \% \mathrm{~K}_{2} \mathrm{SiO}_{3}+$ $44 \% \mathrm{Li}_{2} \mathrm{SiO}_{3}$; Sensor size $(1.98 \times 1.17 \times 0.01 \mathrm{~mm})$; firing temperature $\left(864^{\circ} \mathrm{C}\right)$; bias voltage (3V) and gas flow ( $0.5 \mathrm{scfh})$. The result is presented in Figure 29.

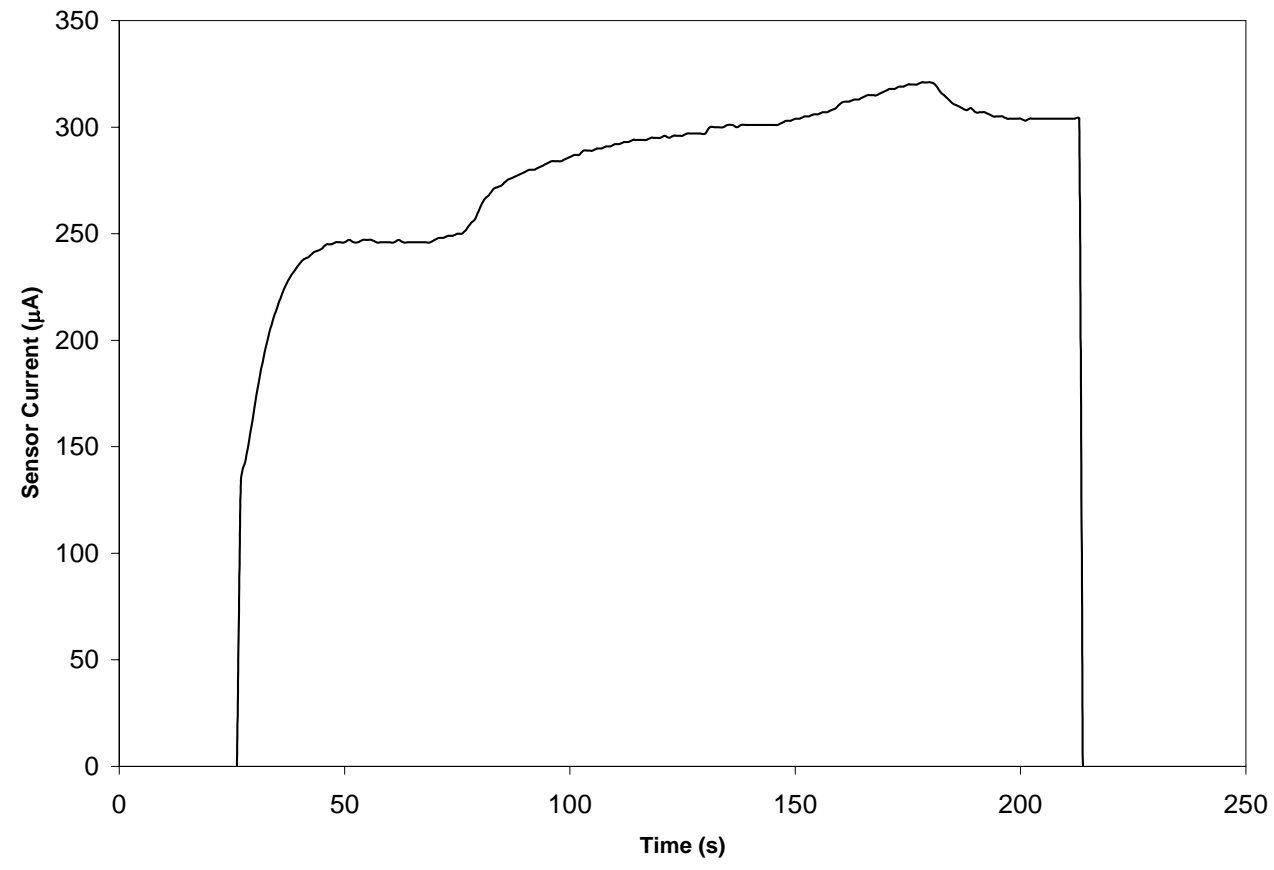

Figure 29. Sensor Response to Gas for 2 minutes

After the current is stable, there is a continue increase in current during the two minutes that the gas is running. The sensor response fits the linear and exponential trends previously presented showing the surface and bulk diffusion through the sensor. There is not a "poisoning effect" during the time that the gas is present. After the gas stops running there is a reduction in current and the current returns to zero when the bias voltage is turned off. 


\subsection{2 - Selectivity Analysis}

It was previously define selectivity as the ability of a sensor to respond selectively to a specific species while inactive to other species in the sample gas. It is the selectivity which makes a sensor specific to a chemical species of interest. One of the issues limiting the leaking gas sensors are the selectivity or cross-sensitivity. Poor selectivity toward the monitored gas or cross-sensitivity towards other gases makes a sensors output unreliable and it causes the sensor response drift with time. For the halogen gases family the main elements to test are $\mathrm{F}$ and $\mathrm{Cl}$. In order to evaluate the selectivity or ability to the sensor to respond to a specific species the Gibbs free energy analysis was repeated changing the halogen gas from $\mathrm{F}$ to $\mathrm{Cl}$. Similar reactions to the previous section were used. The results for the Gibbs free energy calculations between the sensor and $\mathrm{Cl}$ are presented in Table 20. The data used for the calculations is presented in appendix 2 (Table 26).

Table 20. Selectivity Analysis: Sensor - Cl

\begin{tabular}{|c|c|}
\hline Elements & $\Delta \mathbf{G}$ (KJ/mol) \\
\hline \hline $\mathrm{Cl}-\mathrm{K}$ & -344.91 \\
\hline $\mathrm{Cl}-\mathrm{Li}$ & -334.97 \\
\hline $\mathrm{Cl}-\mathrm{Na}$ & -315.37 \\
\hline $\mathrm{Cl}-\mathrm{Ca}$ & -259.34 \\
\hline
\end{tabular}

All reactions have negative values for $\mathrm{G}$, which means the reactions are spontaneous, and in a similar manner than with $\mathrm{F}$ there will be reaction between the sensor and $\mathrm{Cl}$. Except for $\mathrm{Cl}-\mathrm{Ca}$ the values for Gibbs free energy do not have significant difference. The comparison for the results between the sensor material and the two halogen gases can be seen in Figure 30. 


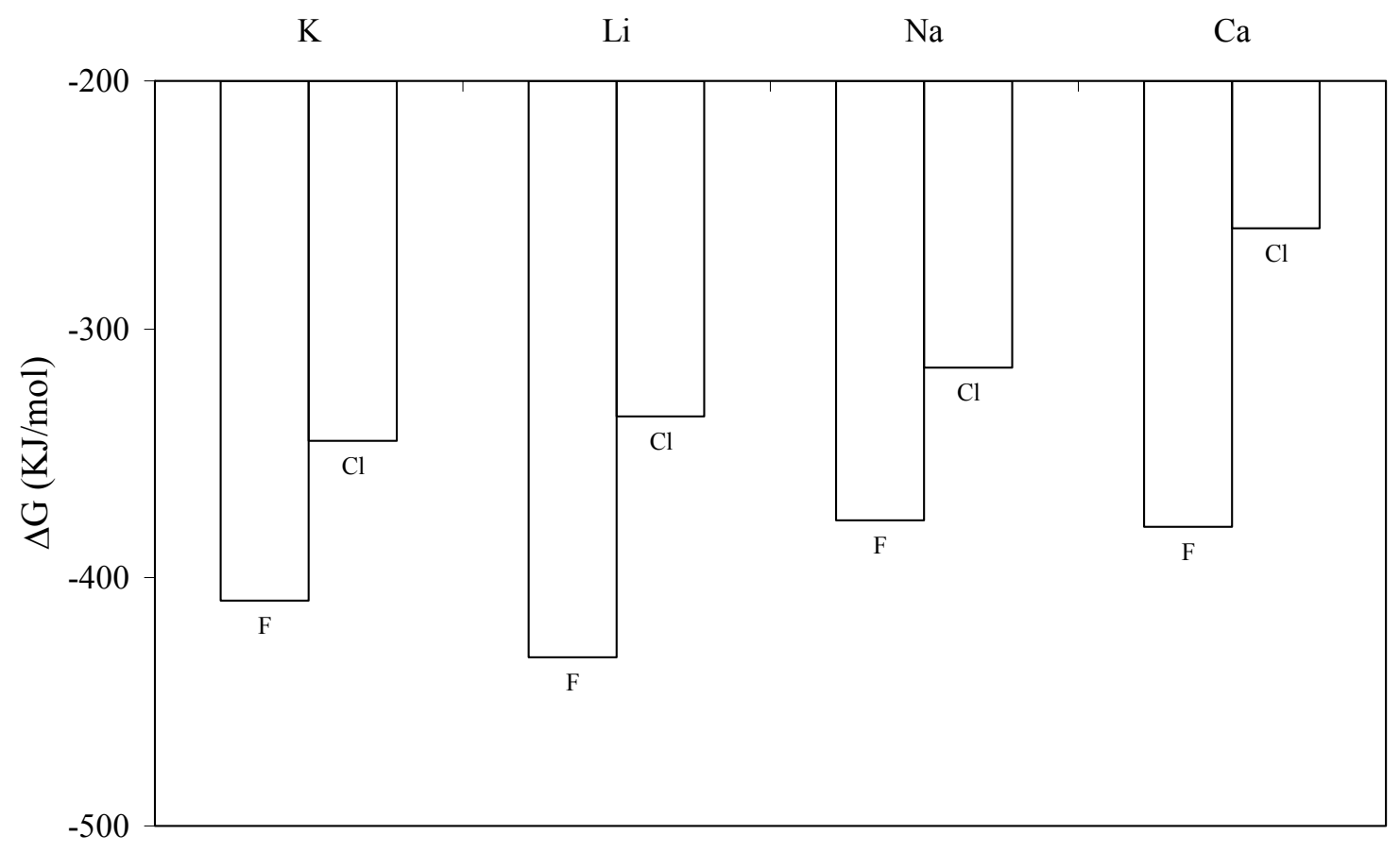

Figure 30. Gibbs free energy analysis: Sensor and (F - Cl)

The sensor material reacts with both fluorine and chlorine due to the negative values for the Gibbs Free Energy. The four sensor materials have higher reaction with $\mathrm{F}$ than $\mathrm{Cl}$. Unfortunately; experimental results for the reaction between the sensor and $\mathrm{Cl}$ were not determined. 


\section{CHAPTER 5 - CONCLUSIONS AND RECOMMENDATIONS}

\section{1 - Conclusions}

It is concluded from this research that it is possible to fabricate a heated ceramic sensor to detect leaks of halogen gases using the techniques from microelectronics assembly including LTCC and thick film technology. Consequently, the manufacturing process for the sensor and the heater can be produced in mass for commercial applications.

After a theoretical analysis, four candidates were selected like sensor materials. Due to the materials were not commercial products it was necessary to fabricate such inks. After several attempts $\mathrm{K}_{2} \mathrm{SiO}_{3}, \mathrm{Li}_{2} \mathrm{SiO}_{3}, \mathrm{Na}_{2} \mathrm{SiO}_{3}$, and $\mathrm{CaSiO}_{3}$ inks were successfully fabricated during this research.

Development and optimization of new sensor materials were done through the testing of every sensor ink fabricated as well as different combinations between them based on their phase diagrams and previous work. All sensors were successfully tested to detect halogen gas under different factors evaluated.

From the device fabrication and manufacturing point of view, the stability and reproducibility of the fabricated devices was presented through the same results obtained from different samples that were fabricated and tested under the same conditions.

The sensor analysis was done dividing the sensor behavior into two parts: the first part is the baseline which corresponds to the stable current for the sensor after the depletion region is established and the gas is not present. The second part is the response to the halogen gas. Different parameters were tested to determine the influence on both stages.

The effect of different parameters on the sensor behavior was evaluated. The parameters include: sensor material, sensor thickness, operating temperature, bias voltage, electrodes 
size, firing temperature and gas flow. Some parameters affect both the stable current as well as the sensor response to the gas. Other parameters affect just one of them. The gas flow did not affect any of them.

The stable current was calculated through the modeling of the sensor like a resistor in series and finding the equivalent resistance for the sensor, electrodes and substrate. The calculations for the stable current were compared with the experimental results and it was found and agreement between the calculated and experimental values.

The factors affecting the baseline or stable current for the sensor before the gas is present are: sensor material, sensor thickness, operating temperature, bias voltage, electrodes size and firing temperature. If any of the factors mentioned increase the stable current increases showing a direct relationship between them.

The sensor response to the gas showed two mechanisms that are in agreement with the diffusion literature. The first is surface diffusion and the second is bulk diffusion within the sensor. The surface diffusion has a linear trend and it maintains during the first 8 seconds. After this, the bulk diffusion appears with an exponential trend.

The Gibbs free energy analysis between the sensor and the gas were done writing the chemical reactions between the sensor and the gas. The calculations show the reactivity between the sensor and the gas which is in agreement with the experimental results due to all sensors tested respond to the gas presence. Similarly, the calculated results are in agreement with the time that the sensor takes to detect the gas.

The number of cations as well as the number of vacancies within the sensor were calculated and the results were in agreement with the experimental values for the sensor response to the gas. 
The factors affecting the sensor response to the gas are: sensor material, sensor thickness, operating temperature, bias voltage, and electrodes size. If any of the factors mentioned increase the stable current increases showing a direct relationship between them.

The evaluation of the sensor with the micro heater was done and the results obtained were in agreement with the results for the sensor tested using the tube furnace experimental set-up verifying the feasibility of fabricating a portable device to sense low levels of halogen gas.

Comparing the results for the different materials as well as the different parameters evaluated it was concluded that the sensor with the best behavior including stable current, sensor response to the gas and sensor life is the sensor with $51.5 \% \mathrm{CaSiO}_{3}+$ $48.5 \% \mathrm{Li}_{2} \mathrm{SiO}_{3}$

\section{2 - Recommendations}

Selectivity is one of the major issues limiting widespread applications and further development of sensors. An array of sensors combining sensing elements and signal processing at simultaneous or sequential acquisition of more than one type of signal, will resolve the problem of selectivity resulting in detection of different gases.

There is not much work done in the area of modeling and simulation of ceramic gas sensors including the fundamental chemical reactions and electron transport through the surface and bulk regions. There is a need to combine successful models developed in order to drive new research and guide experimental efforts for designing sensors with optimized properties. 


\section{LIST OF REFERENCES}

[1] Monguillo J. F., and Zierdt-Warshaw L., "Encyclopedia of Environmental Science", Orix Press, Phoenix, AR, pp.180-185, 2000.

[2] Alexander D., and Fairbridge R., "Clorofluorocarbons, The Chapman \& Hall Encyclopedia of Environmental Science", Kluwer Academic, Boston, MA, pp.78-80, 1999.

[3] Environmental Protection Agency, "Replace your CFC Air Conditioning Chiller", Global Programs Division (6205J) and Climate Protection Partnerships Division (6202J), pp. 1-12, 2002.

[4] Fialho P. S., and Nieto A., "Prediction of the Vapor Pressure of Environmentally Acceptable Halocarbons", International Journal of Thermophysics, V. 21, N. 2, pp. 385$392,2000$.

[5] Dieterle F., Belge G., et al, "Quantification of the Refrigerants R22 and R134a in Mixtures by means of Different Polymers and Reflectometric Interference Spectroscopy", Journal of Analytical and Bioanalytical Chemistry, V. 374, N. 5, pp. 858-867, 2002.

[6] Lee, Tony, et al, "Miniature Gas Sensor", United States Patent Number 5,284,569, February 81994.

[7] Zhang Y., and Yan G. "Detection of Gas Pipe Wall Thickness Based on Elecgtromagnetic Flux Leakage", Russian Journal of non Destructive Testing, V. 43, N. 2, pp. 123-132, 2007.

[8] Guth U., Zosel J., "Electrochemical Solid Electrolyte Gas Sensors - Hydrocarbon and $\mathrm{NO}_{\mathrm{x}}$ Analysis in Exhaust Gases", Ionics Journal, pp. 366-377, 2006.

[9] Sheikh A., "Ceramic Sensors for Industrial Applications", NSF Center for Industrial Sensor and Measurements, pp. 1-9, 2004.

[10] Kalinina M. V., Moshnikov V. A., et al, "Temperature Dependence of the Resistivity for Metal-Oxide Semiconductors Based on Tin Dioxide", Journal of Glass Physics and Chemistry, V. 29, N. 4, pp. 422-427, 2004.

[11] ASM International "The Materials Information V4 Engineering Materials Handbook: Ceramics and Glasses”, 1991.

[12] Kita J., "Laser Forming of LTCC Ceramics for Hot-Plate Gas Sensors", International Microelectronics and Packaging Society JMEP, V. 2, N. 1, ${ }^{\text {st }}$ Qtr, pp.14-18, 2005. 
[13] Kita J., Dziedzic A., et al, "Surface Temperature Distribution Analysis in Sensors With Buried Heater Made in LTCC Technology", Proc. $13^{\text {th }}$ European Microelectronic and Packaging Conference, pp. 123-128, 2001.

[14] Gangqiang W., Barlow F., et al, "Cold Processing of Green State LTCC with a $\mathrm{CO}_{2}$ Laser", Journal of Applied Physics A: Materials Science \& Processing, V. 84, N. 3, IMAPS , pp. 267-270, 2005.

[15] Koiwai K., Kawamura Y., et al, "Low Temperature Co-Fired Ceramics MultiLayer Substrate Utilized with Ink-Jet Printed Silver Layers", Proceeding International Microelectronics and Packaging Society, IMAPS, pp. 823-833, 2005.

[16] Ewsuk K. G., DiAntonio C.B., et al, "Materials and Process Control Technology for LTCC Microelectronics Packaging", Proceeding Ceramics Interconnected Technology Conference, IMAPS, pp. 1-6, 2004.

[17] Peterson K., Patel K., et al, "Novel Microsystem Applications With New Techniques in Low Temperature Cofired Ceramics", International Journal of Applied Ceramic Tec hnology 2 [5] pp. 345-363, 2005.

[18] Qu W., Green R., et al, "Development of Multifunctional Sensors in Thick Film and Thin Film Technology", Meas Science Technology, V. 11, pp. 1111-1118, 2000.

[19] Hrovat M., Belavic D., et al, "Temperature Sensors Made by Combinations of some standard thick film materials", Journal of Materials Science Letter, V. 19, pp. 651$655,2000$.

[20] Pisarkiewicz T., Sutor A., et al, "Microsensor based on Low Temperature Cofired Ceramics and Gas Sensitive Thin Film", Thin Solid Films 436, pp. 84-89, 2003.

[21] Moos R. Rettig F., et al, "Temperature Independent Resistive Oxygen Exhaust Gas Sensor for Lean Burn Engines in Thick Film Technology", Sensors and Actuators B 93, pp. 43-50, 2003.

[22] Sahner K., Moos R., et al, "Hydrocarbon Sensing with Thick and Thin Film ptype Conducting Perovskite Materials" Sensors and Actuators B 108, pp. 102-112, 2005.

[23] Palaniappan A., Su X., et al, "Functionalized Mesoporous Silica Films for Gas Sensing Applications, Journal of Electroceramics, V. 16, N. 4, pp 503-505, 2006.

[24] Mo Y., Okawa Y., et al, "Micro-Machined Gas Sensor Array Based on Metal film Micro Heater", Sensors and Actuators B 79, pp. 175-181, 2001.

[25] Rettig F., "Ceramic Meso Hot-Plates for Gas Sensors", Elsevier, Sensors and Actuators B, V. 103, pp. 91-97, 2004. 
[26] Moilanen V., Kemppainen A., et at, "Multiplex Read-Out Electronics Implemented on LTCC Substrate for PbS Array', Journal of Measurement Science and Technology, V. 15, pp. 2188-2192, 2004.

[27] Gong C., Xia S., et al, "Electric Field Sensors Based on MEMS Technology", Journal of Electronics, V. 22, N. 4, pp. 443-448, 2005.

[28] Simon I., Barsan N., et al, "Micromachined Metal Oxide Gas Sensors: Opportunities to Improve Sensor Performance", Sensors and Actuators B-Chemical, V. 73, pp. 1-26, 2001.

[29] Lopez R., "Development of a Sensor for the Selective Detection of Halogen Containing Gases", Master Thesis, Mechanical and Materials Engineering Department, Florida International University, 2001.

[30] Narayana S., "Development of Low-Power High Temperature Micro Heater Based on CMEMS Technology", Master Thesis, Mechanical and Materials Engineering Department, Florida International University, 2005.

[31] Zhu B., Sheng C., et al, "Laser Sintering $\mathrm{ZnO}$ Thick Film for Gas Sensor Application", Journal of Materials Science, V. 42, N.18, pp. 5416-5420, 2007.

[32] Gulyaev A. M., Slepneva M. A., et al, "Atmosphere Analyzer Based on an Array of Resitor Gas Sensors", Journal of Measurement Techniques, V. 49, N. 2, pp. 187-191, 2006.

[33] Zheng H., Toft O., "Integrated Oxygen Sensors Based on Mg-doped $\mathrm{Sr} \mathrm{TiO}_{3}$ Fabricated by Screen Printing", Sensors and Actuators B 65, pp. 299-301, 2000.

[34] Schwebel T., "A New Type of Gas Sensor Based on Thermionic Charge Emission", Sensors and Actuators B68, pp. 157-161, 2000.

[35] Malinovskaya T. D., Aparnev A. I., et al, "Carbon Monoxide Semiconductor Sensors Based on $\mathrm{SnO}_{2}-\mathrm{Bi}_{2} \mathrm{O}_{3}$ ”, Russian Journal of Applied Chemistry, V. 74, N. 11, pp. 1864-1867, 2001.

[36] Skutin E. D., Budanova E. M., et al, "Improving the Selectivity of Semiconductor Gas Sensors Using the Pulse Adsoption Mode", Journal of Analytical Chemistry, V. 59, N. 12, pp.1142-1145, 2005.

[37] Gongora-Rubio M., Espinoza-Vallejo P., et al, "Overview of Low Temperature co-fired Cermics Tape Technology for Meso-system Technology", Sensors and Actuators A, V. 89, pp. 222-241, 2001. 
[38] Astié S., Gué A., Scheid E., Guillemet J., "Design of a Low Power $\mathrm{SnO}_{2}$ Gas Sensor Integrated on Silicon Oxynitride Membrane", Sensors and Actuators B 67, pp. 84$88,2000$.

[39] Astié S., Gué A., Scheid E., et al, "Optimization of an Integrated $\mathrm{SnO}_{2}$ Gas Sensor Using a FEM Simulator”, Sensors and Actuators B 69, pp. 205-211, 1998.

[40] Fung S. K., Than Z., et al, "Thermal Analysis and Design of a Micro-Hot Plate for Integrated Gas Sensor Applications", Sensors and Actuators A, V. 54, pp. 482-487, 1996.

[41] Kita J., Retting F., Moos R. "Hot plate Gas Sensors - Are Ceramics Better", International Journal of Applied Ceramic Technology 2 [5], pp. 383-389, 2005.

[42] Kita J., Dziedzic A., et al, "Properties of Laser Cut LTCC Heaters", Microelectronics Reliability 40, pp. 1005-1010, 1999.

[43] Adluru H., Zampino M., et al, "Embedded Heat Exchanger in LTCC substrate", Proceeding Ceramics Interconnected Technology Conference, IMAPS, pp. 205-210, 2003.

[44] Jones W. K., Liu Y., et al, "Micro Heat Pipes in Low Temperature Cofire Ceramic LTCC Substrates", IEEE Trans actions on Compact Packaging Technology, V. 26 - N. 1, pp. 110-115, 2003.

[45] Peterson K., Patel K., Novel Microsystem applications with new techniques in LTCC, Sandia National Laboratories, 2005.

[46] Lee, Tony, et al, "Gas Sensor", United States Patent Number 5,104,513, April 14 1992.

[47] Jones W. K., Y Liu, et at, "Chemical, Structural and Mechanical Properties of the LTCC tapes", Proceeding International Microelectronics and Packaging Society, IMAPS, pp. 469-473, 2000.

[48] Sergent J. E. and Harper C. "Hybrid Microelectronics Handbook", McGraw Hill, 1995.

[49] Lau J., at al "Electronic Packaging: Design, Materials, Process and Reliability", McGraw Hill, 1998.

[50] ASM International: The Materials Information Society - Engineering Materials Handbook: "Ceramics and Glasses", V. 4, 1991. 
[51] Harper C. A., "Handbook of Ceramics, Glasses, and Diamonds", McGraw-Hill, 2001.

[52] Smyth D. M., "The Deffect Chemistry of Metal Oxides", Oxford University Press, 2000.

[53] Moulson A. J., Herbert J. M., "Electroceramics: Materials, Properties, Applications", $2^{\text {nd }}$ ed., Wiley, 2003.

[54] Samoteikin V. V., and Gladushko O. A., "Specifics of Electrical Conduction in Alkali-Silicate Glasses", Journal of Glass and Ceramics, V. 59, N. 1-2, pp. 8-10, 2002.

[55] Nakayama S., Asahi T., et al "Electrical Properties of $\left(\mathrm{K}_{2} \mathrm{O}\right)_{35.7}\left(\mathrm{RE}_{2} \mathrm{O}_{3}\right)_{7.2}\left(\mathrm{SiO}_{2}\right)_{57.1}(\mathrm{RE}=\mathrm{Sm}, \mathrm{Gd}$, Dy, Ho, Y, ER, Yb) Glasses", Journal of the Ceramic Society of Japan, V. 112, N. 4, pp. 238-241, 2004.

[56] Magnus K., Andreas H., "Nonlinear Ionic Conductivity of Lithium Silicate Glass Studied Via Molecular Dynamics Simulations", Journal of Chemical Physics, V. 124, N. 21, pp. 21403-214703-7, 2006.

[57] DeHoff R. T., Materials Science and Engineering Series: "Thermodynamics in Materials Science", McGraw Hill, 1993.

[58] Babushkin V. I., at al, "Thermodynamics of Silicates”, Springer, 1985. 
APPENDIX 1. EXPERIMENTAL SET-UP PICTURES

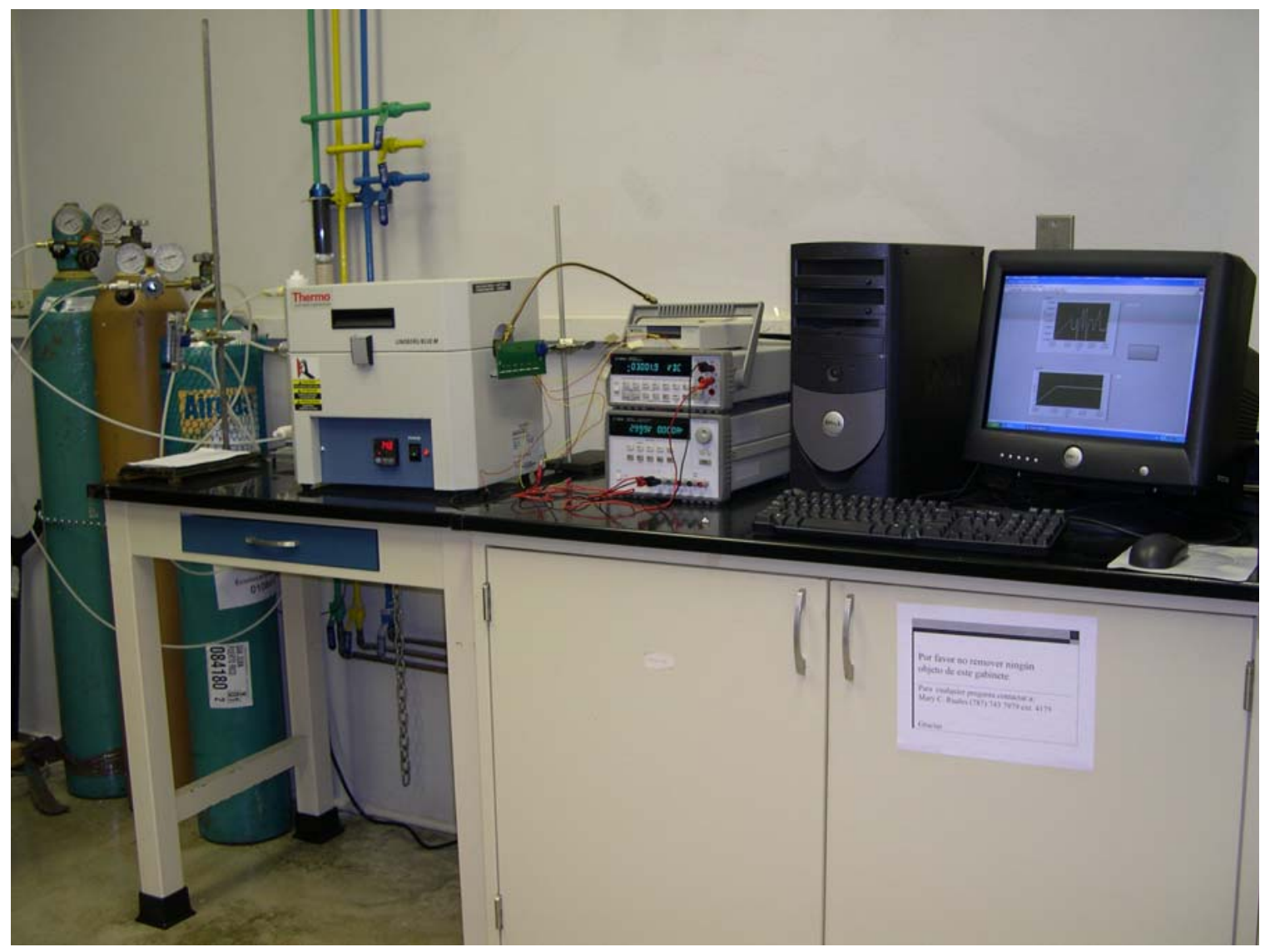

Figure 31. Experimental Set-Up 
APPENDIX 2. ADDITIONAL DATA

\begin{tabular}{|c|c|c|c|c|c|}
\hline $\begin{array}{c}\text { Resistivity } \\
\Omega \mathbf{m}\end{array}$ & $\begin{array}{c}\text { Length } \\
\mathbf{m}\end{array}$ & $\begin{array}{c}\text { Width } \\
\mathbf{m}\end{array}$ & $\begin{array}{c}\text { Thickness } \\
\mathbf{m}\end{array}$ & $\begin{array}{c}\text { Resistance } \\
\Omega\end{array}$ & $\begin{array}{c}\text { Sensor } \\
\text { Material }\end{array}$ \\
\hline \hline $2.31 \mathrm{E}+01$ & $1.17 \mathrm{E}-03$ & $1.98 \mathrm{E}-03$ & $3.00 \mathrm{E}-04$ & $4.54 \mathrm{E}+04$ & $100 \% \mathrm{~K}_{2} \mathrm{SiO}_{3}$ \\
\hline $2.01 \mathrm{E}+01$ & $1.17 \mathrm{E}-03$ & $1.98 \mathrm{E}-03$ & $3.00 \mathrm{E}-04$ & $3.95 \mathrm{E}+04$ & $100 \% \mathrm{Na}_{2} \mathrm{SiO}_{3}$ \\
\hline $1.84 \mathrm{E}+01$ & $1.17 \mathrm{E}-03$ & $1.98 \mathrm{E}-03$ & $3.00 \mathrm{E}-04$ & $3.62 \mathrm{E}+04$ & $100 \% \mathrm{CaSiO}_{3}$ \\
\hline $2.91 \mathrm{E}+01$ & $1.17 \mathrm{E}-03$ & $1.98 \mathrm{E}-03$ & $3.00 \mathrm{E}-04$ & $5.72 \mathrm{E}+04$ & $100 \% \mathrm{Li}_{2} \mathrm{SiO}_{3}$ \\
\hline $2.04 \mathrm{E}-07$ & $2.43 \mathrm{E}-03$ & $1.73 \mathrm{E}-03$ & $1.00 \mathrm{E}-05$ & $2.87 \mathrm{E}-02$ & Electrodes \\
\hline $2.85 \mathrm{E}-06$ & $1.56 \mathrm{E}-01$ & $1.02 \mathrm{E}-02$ & $2.70 \mathrm{E}-04$ & $1.62 \mathrm{E}-01$ & Substrate \\
\hline
\end{tabular}

Table 21. Data for stable current

\begin{tabular}{|c|c|c|}
\hline Element & $\Delta \mathbf{H}_{\mathbf{f}}(\mathbf{K J} / \mathbf{m o l})$ & $\Delta \mathbf{S}_{\mathbf{f}}(\mathbf{K J} / \mathbf{m o l K})$ \\
\hline \hline $\mathrm{F}$ & 79.39 & 0.15878 \\
\hline $\mathrm{K}$ & 0.00 & 0.06463 \\
\hline $\mathrm{FK}$ & -326.77 & 0.22660 \\
\hline $\mathrm{Li}$ & 0.00 & 0.02909 \\
\hline $\mathrm{FLi}$ & -340.79 & 0.20021 \\
\hline $\mathrm{Na}$ & 0.00 & 0.05146 \\
\hline $\mathrm{FNa}$ & -290.45 & 0.21759 \\
\hline $\mathrm{Ca}$ & 0.00 & 0.04159 \\
\hline $\mathrm{FCa}$ & -271.96 & 0.22965 \\
\hline
\end{tabular}

Table 22. Data for reactivity analysis between sensor and gas (fluorine)

\begin{tabular}{|c|c|c|c|c|}
\hline Element & $\begin{array}{c}\text { Density } \\
\mathbf{( g / \mathbf { c m } ^ { 3 } )}\end{array}$ & $\begin{array}{c}\text { Mass } \\
\mathbf{( g )}\end{array}$ & $\begin{array}{c}\text { Atomic mass } \\
\mathbf{( g / m o l})\end{array}$ & $\begin{array}{c}\text { Number } \\
\text { of Atoms }\end{array}$ \\
\hline \hline $\mathrm{K}$ & 0.86 & $1.98 \mathrm{E}-04$ & 39.09 & $3.05 \mathrm{E}+18$ \\
\hline $\mathrm{Li}$ & 0.53 & $1.24 \mathrm{E}-04$ & 6.94 & $1.07 \mathrm{E}+19$ \\
\hline $\mathrm{Na}$ & 0.97 & $2.24 \mathrm{E}-04$ & 22.99 & $5.86 \mathrm{E}+18$ \\
\hline $\mathrm{Ca}$ & 1.55 & $2.15 \mathrm{E}-04$ & 40.08 & $3.24 \mathrm{E}+18$ \\
\hline
\end{tabular}

Table 23. Data for number of atoms 


\begin{tabular}{|c|c|c|c|}
\hline Silicate & $\mathbf{Q}_{\mathbf{v}}(\mathbf{K J} / \mathbf{m o l})$ & Atoms $/ \mathbf{~ c m}^{3}$ & $\mathbf{n}_{\mathbf{v}}\left(\right.$ vacancies $\left./ \mathbf{~ c m}^{3}\right)$ \\
\hline \hline $100 \% \mathrm{~K}_{2} \mathrm{SiO}_{3}$ & 2.32 & $3.05 \mathrm{E}+18$ & $2.28 \mathrm{E}+18$ \\
\hline $100 \% \mathrm{Li}_{2} \mathrm{SiO}_{3}$ & 3.00 & $1.07 \mathrm{E}+19$ & $7.38 \mathrm{E}+18$ \\
\hline $100 \% \mathrm{Na}_{2} \mathrm{SiO}_{3}$ & 2.59 & $5.86 \mathrm{E}+18$ & $4.24 \mathrm{E}+18$ \\
\hline $100 \% \mathrm{CaSiO}_{3}$ & 8.54 & $3.24 \mathrm{E}+18$ & $1.11 \mathrm{E}+18$ \\
\hline
\end{tabular}

Table 24. Data for concentration of vacancies

\begin{tabular}{|c|c|c|}
\hline Element & $\Delta \mathbf{H}_{\mathbf{f}}(\mathbf{K J} / \mathbf{m o l})$ & $\Delta \mathbf{S}_{\mathbf{f}}(\mathbf{K J} / \mathbf{m o l K})$ \\
\hline \hline $\mathrm{Cl}$ & 121.3 & 0.16519 \\
\hline $\mathrm{K}$ & 0.00 & 0.06463 \\
\hline $\mathrm{ClK}$ & -214.68 & 0.23909 \\
\hline $\mathrm{Li}$ & 0.00 & 0.02909 \\
\hline $\mathrm{ClLi}$ & -195.72 & 0.21292 \\
\hline $\mathrm{Na}$ & 0.00 & 0.05146 \\
\hline $\mathrm{ClNa}$ & -181.42 & 0.22979 \\
\hline $\mathrm{Ca}$ & 0.00 & 0.04159 \\
\hline $\mathrm{ClCa}$ & -104.6 & 0.2415 \\
\hline
\end{tabular}

Table 25. Data for reactivity analysis between sensor and gas (chlorine) 
VITA

MARY CRISTINA RUALES ORTEGA

November 27, 1975

1999

$2000-2001$

$2000-2001$

$2001-2003$

$2003-2007$

$2003-2005$

$2005-2007$
Pasto, Narino, Colombia

B.S., Mechanical Engineering

University of Valle

Cali, Valle

M.S., Mechanical Engineering

University of Puerto Rico

Mayaguez, Puerto Rico

Teaching Assistant

University of Puerto Rico

Mayaguez, Puerto Rico

Instructor

University of Turabo

Caguas, Puerto Rico

Doctoral Candidate in Mechanical Engineering

Florida International University

Miami, Florida

Teaching Assistant

Florida International University

Miami, Florida

Instructor

University of Turabo

Caguas, Puerto Rico

\section{PUBLICATIONS AND PRESENTATIONS}

Ruales M., Jones K., and Wang J., "Development of a Freon Gas Sensor Using a Low Power $700^{\circ} \mathrm{C}$ Microheater in Low Temperature Cofire Ceramics", Proceedings 38th International Symposium on Microelectronics IMAPS, 2005. 